\title{
MASTER ORO-140
}

Progress Report No. 3

covering the specific topic of

THE APPLICATION OF STATISTICAI FROCEDURES TO A STUDY OF THE FLOODING CAPACITY OF A PULSE COLUM

$$
\text { Contract iNo, AT }-(40-1)-1320
$$

Performance of Contactors for Liquid-Iiquid"Extr

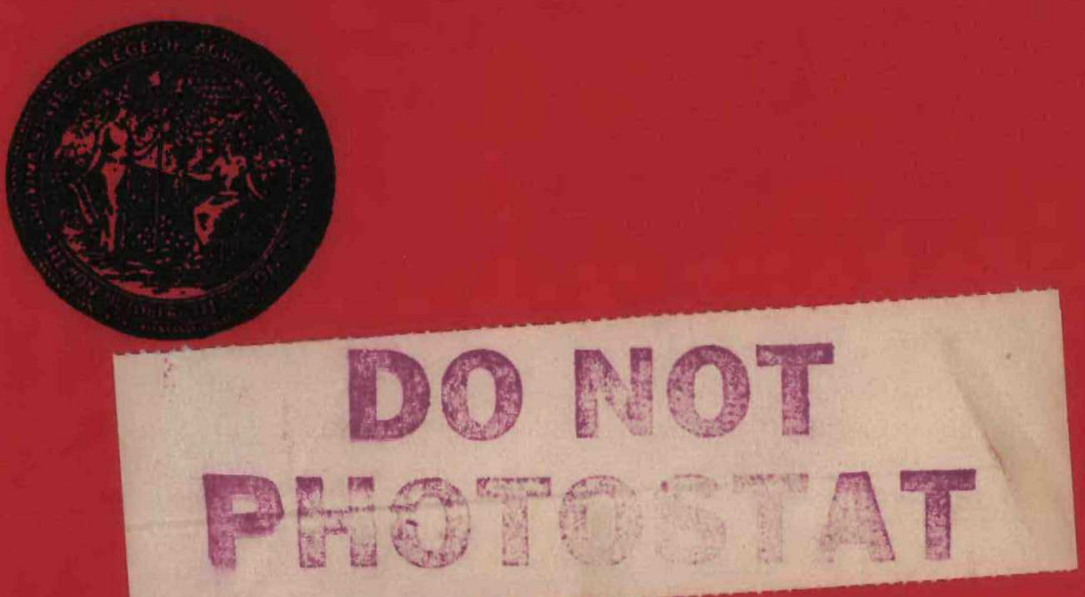

DEPARTMENT OF ENGINEERING RESERRCH NORTH CAROLINA STATE COLLEGE

RALEIGH, NORTH CAROLINA

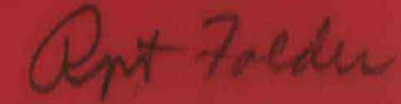




\section{DISCLAIMER}

Portions of this document may be illegible in electronic image products. Images are produced from the best available original document. 


\section{"Revisal Repont in Preparation"/"

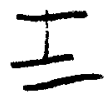 \\ PRELIMINARY \\ THE APPLICATION OF STATISTICAL FROCEDURES TO A \\ STUDY OF THE FLOODING CAPACITY OF A PULSE COLUNN}

Contract iNo, AT-(40-1) -1320

"The Performance of Contactors for Liquid-Iiquid "Extraction"

Topic Personnel

D. S, Arnold $*$

E. E. Erickson

J. K. Nelli

F. P. Pike

and

G. E. P. Box*-*

J. S. Hunter $\% *$
Submitted by:

F. Philips Pike, Project Director Professor of Chemical Engineering

DEPARTIFNT OF EIGINEERING RESEARCH NORTH CAROLINA STATE COLLEGE

R'LEIGH, NORTH CAROLINA

February \&, 1954

* Now with the National Lead Company of Ohio

$* *$ Associates from the Institute of Statistics

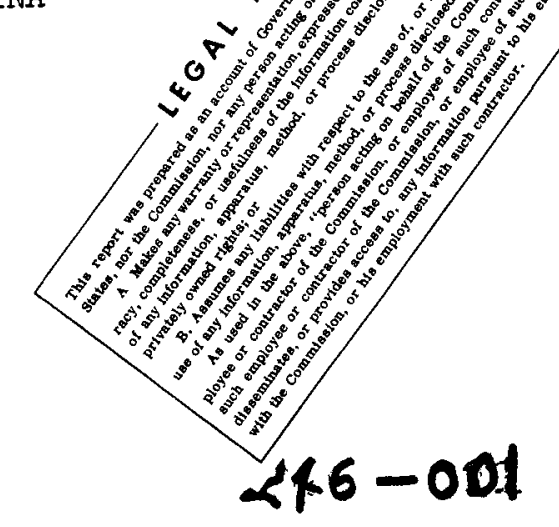




$$
\text { II }
$$

THE APPLICATION OF STATISTICAL PROCEDURES TO $\Lambda$ STUDY OF

THE FLOODING CAPACITY OF A PULSE COLUMA

I. THE BEH.VIOR OF THE SYSTEV TRICHLOROENHLENE-WATER

F. Philips Pike, Joseph R. Nelli and Eugene E。 Erickson with Donald S. Arnold*

Department of Engineering Research

II. STATISTIQII DESIGN AND HIIYSIS

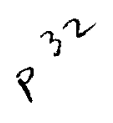

(reorge E. P. Bex ${ }^{* * *}$ and J. Stuart Hunter

Institute of Statistics

* Now with the National Lead Company of Ohio

** Visiting Professor, from Imperial Chemical Industries, Great Britain

\author{
February, 1954 \\ North Carolina State College \\ Raleigh, North Carolina
}


THE APPLICATION OF STATISTICAL PROCEDURES TO A STUDY OF THE FLOODING CAPACITY OF A PULSE COLTMN

SUMAARY

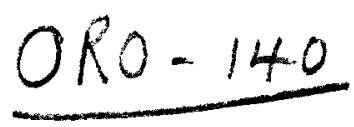

A new extension of the statistical techniques of experimental design and analysis has been applied with success to a study of the flooding capacity of a pulse column. This study serves to illustrate the manner of cooperation required between the engineer and the statistician, it attests the great economy of time and effort made possible, and it indicates the better conception and interpretation of the data as a whole which is obtainable. The experimental task was the measurement of the flooding behavior of the trichloroethylenewater system at room temperature in a pulse column unit presumed to be a typical pilot plant model. Special precautions were taken to reduce contamination and to insure precision of measurement. These precautions, while not entirely successful, did permit evidence to develop that trace contamination is a factór of great importance in pulse column flooding. This discovery, if confirmable, has major implications for pulse column work. The data obtained refer to the trichloroethylene-water system containing trace amounts of grease. The statistical analysis of the results reveals a number of details concerning pulse column flooding behavior. 
I. THE BEHAVIOR OF THE SISTEM TRICHLOROETHYLENE-WATER

Fc Phillips Pike, Joseph R. Nelli and Eugene E. Erickson with Donald S. Arnold

\section{INTRODUCTION}

The dependence of each of the various pulse column behavior patterns upon a large number of variables makes it economically desirable to employ statistical planning and analysis. Certain recently developed statistical techniques promised exceptional economy of time and effort compared to conventional procedures. It was considered desirable to demonstrate the utility and characteristics of these statistical techniques through an example. One requirement for the statistical planning is that the experimenter should know reasonably well the range of operability of the equipment. This makes an exploration of flooding capacity the logical first choice for study.

Such programs as these are of necessity cooperative efforts between two groups: one supplying the technical familiarity with the pulse column, the actual data, and their physical interpretation; the other supplying the statistical planning and treatment of the data, plus a statistical evaluation of various aspects. This study represents such a cooperative effort, wherein the specific objectives were threefold - to evaluate the application of some new statistical procedures to pulse column work, to explore fully the flooding capacity for a particular system and a typical column, and to exemplify the manner of cooperation between the engineer and the statistician. 
CONDUCT OF THE COOPERATIVE PROGRAM

The system selected for study was the trichloroethylene-water system at room temperature. The chosen pulse column unit consisted of a $1.92^{\prime \prime} i . d$. glass column containing 23 plates perforated with 1/8" holes and spaced $2.0^{\prime \prime}$ apart, together with the necessary pulsing unit and accessories. The specific experimental program was defined as the study of a single response variable, $C$, the capacity at flooding, as a function of the three most appropriate quentitative independent variables, or factors. Capacity, the response, was defined in accordance with widespread usage as $C=V_{d}+V_{c}$, the sum of the discontinuous and the continuous phase flow inputs. The chosen independent quantitative variables were the flow ratio $V_{d} / v_{c}$, the pulse frequency, F, and the pulse amplitude, A. It should be realized that, in the absence of acequate prior work, the choice of the appropriate variables is somewhat arbitrary. For instance, it can be argued that the product $F A$ is a pertinent variable in itself, and that $C$ is more properly defined as $C=V_{d}^{\frac{1}{2}}+V_{c} \frac{1}{2}$, or $C=\frac{V_{d}}{\Delta p}$ where $\Delta p$ is the difference in density, or $\mathrm{C}=\frac{\mathrm{V}_{\mathrm{d}}}{\mathrm{FA}}$, a dimensionless group.

There was a problem regarding the possible effect of any simultaneous mass transfer action on the flooding behavior. If an appreciable effect existed, it meant that the rate of mass transfer, ordinarily considered to be solely a response variable, would also at the same time be a factor variable. This uncertainty was handled by first saturating the phases with respect to each other, then recycling them in use. It was recognized that there was one quantitative independent variable that was uncontrolled, namely temperature, which varied from about 24 to $34^{\circ} \mathrm{C}$. However, temperature was recorded for each run, for possible use in latcr rork. In addition to the quantitative factors, there were qualitative independent variables of acknowledged impor- 
tance. They were controlled by selection, as follows: The plate geometry and spacing, and column and end-section geometry were fixed at values thought to be typical for the column size employed. The shape of the pulse wave, as provided by a piston pump and a good system of check valves in the lines, was essentially sinusoidal. The trichloroethylene, which did not preferentially wet either the plates or the column, was made the discontinuous phase, as is customary. The method of spacing and holding the plates was as indicated in Figure $1 \downarrow$.

The statistical analysis required that a selection be made of the functional forms in which the chosen variables were to be expressed. At stake is the ability of an assumed Taylor's Series expansion of the unknown response function to adequately fit the data, without requiring more terms than specifically listed. This particular expansion of the function is described in the second part of the paper. The basis for choice of the functional forms of the variables can also be interpreted as the desire for a certain simplicity in the shape of a space model representing the chosen response function. Often a few carefully planned exploratory runs can provide a basis for choice. In general the requirements will be best met if the variables are expressed in tbose functional forms which have a solid theoretical background. Unfortunately, such a background does not exist for this problem. However, it seemed natural to employ the logarithm of $V_{d} / V_{c}$, since related work points to its use. The choices of the logarithmic scale for $A$, the amplitude, and of arithmetic scales for $C$, the capacity, and $F$, the frequency, were intuitive and arbitrary.

It is important to realize that no amount of statistical artistry can compensate for an error in choice or in omission on the part of the experimenter. The final results will bear only that degree of validity which is 
inherent in the assumptions, no more, no less. However, the nature of the calculated results, particularly the analysis of variance, will provide valuable clues concerning the appropriateness of the choices made. This being so, it is a prime function of the statistician, after the results are in, to make those inferences which he can concerning the wisdom of the assumptions. The companion part by Box and Hunter discusses these matters. The decisions so far have been the responsibility of the experimenter. At this point the statistician guided the program with a special pattern for the experimental runs, called a statistical design. In addition, he urged a random sequence for the runs to minimize the effect of any unsuspected variable, and replication of runs to measure experimental error. The statistical design specifies the number of runs to be made and the experimental conditions for each run. Now the statistical design is a most important matter, for it serves to generate the information desired with a great economy of time and effort. The designs employed comprise a delicate balance of properties. They possess a certain symmetry which facilitates computation and act to minimize the errors in specifying the constants delineating the response. They contain more than the minimum number of runs, to permit an analysis of variance. They are so constructed as to probe rather evenly the entire field of operations, avoiding both a grouping of runs in a restricted region and a failure to explore the outer reaches.

These features carry the important implication that the delicate balance of properties is jeopardized if even one run is missing. Thus it is required that the experimenter guarantee that no limitation will arise to the attainment of the experimental data agreed upon, either because of physical limitations in the equipment or because of the inability of the system to possess the response in certain regions. While a statisticlan can often proceed with 
his calculations when an experiment or two is missing, he is most reluctant and unhappy about doing so, for the ${ }_{n}^{\text {thelid }}$ reasons, Thenefore, it became necessary to make some exploratory runs to provide an estimate of the range of operability of the equipment and the system. These preliminary runs did in fact force a revision in the plans. It would appear that this situation is a common one, and that any plans concerning a statistically patterned program should provide for exploratory runs, also repeat runs to cover accidents.

The preliminary runs indicated that the flooding behavior could both be generated and measured anywhere within the range of amplitude from $\frac{1}{4}$ to $2 \frac{1}{2}$ inches, frequency from 30 to 90 cycles per minute, and $v_{d} / v_{c}$ ratio from $1 / 3$ to 3. Further, these ranges were pertinent. For reasons of convenience to the statistician, a transformation in scale was carried out whereby each chosen function of the natural variable was expressed on a scale of standardized units. These standardized variables are featured by numbers like $0,1,1.5$ and 2, which bear a simple relationship to a unit cube, a prominent feature of the statistical designs. The conversion in scale was carried out in this manner, using the case of $V_{d} / N_{c}$ as an example. The statistical designs called for subdividing the range of $\mathrm{Ig} \mathrm{V}_{\mathrm{d}} / \mathrm{N}_{\mathrm{c}}$ into four equal increments. Inspection showed that if the lower limit of $\nabla_{d} / V_{c}$, which was $1 / 3$, was multiplied successively by the square root of 3 , by the time $V_{d} / N_{c}=3$, the upper limit, the Ig $V_{d} / N_{c}$ scale had been properly subaivided. Similarly, the relations indicated in the following Table 1 , and companion equations, vrere derived.

In actuality, two statistical designs were employed, the first one assuming only second order terms and a second one designed to estimate cubic terms in the assumed Taylor's Series. Random sequences were employed. Each run was repeated, some a number of times, in an effort to measure the experimental error. The details of these actions and their consequences are described further on. 
7.

TABLE 1

Correspondence Between Natural and Standardized Variables for the Flooding Study

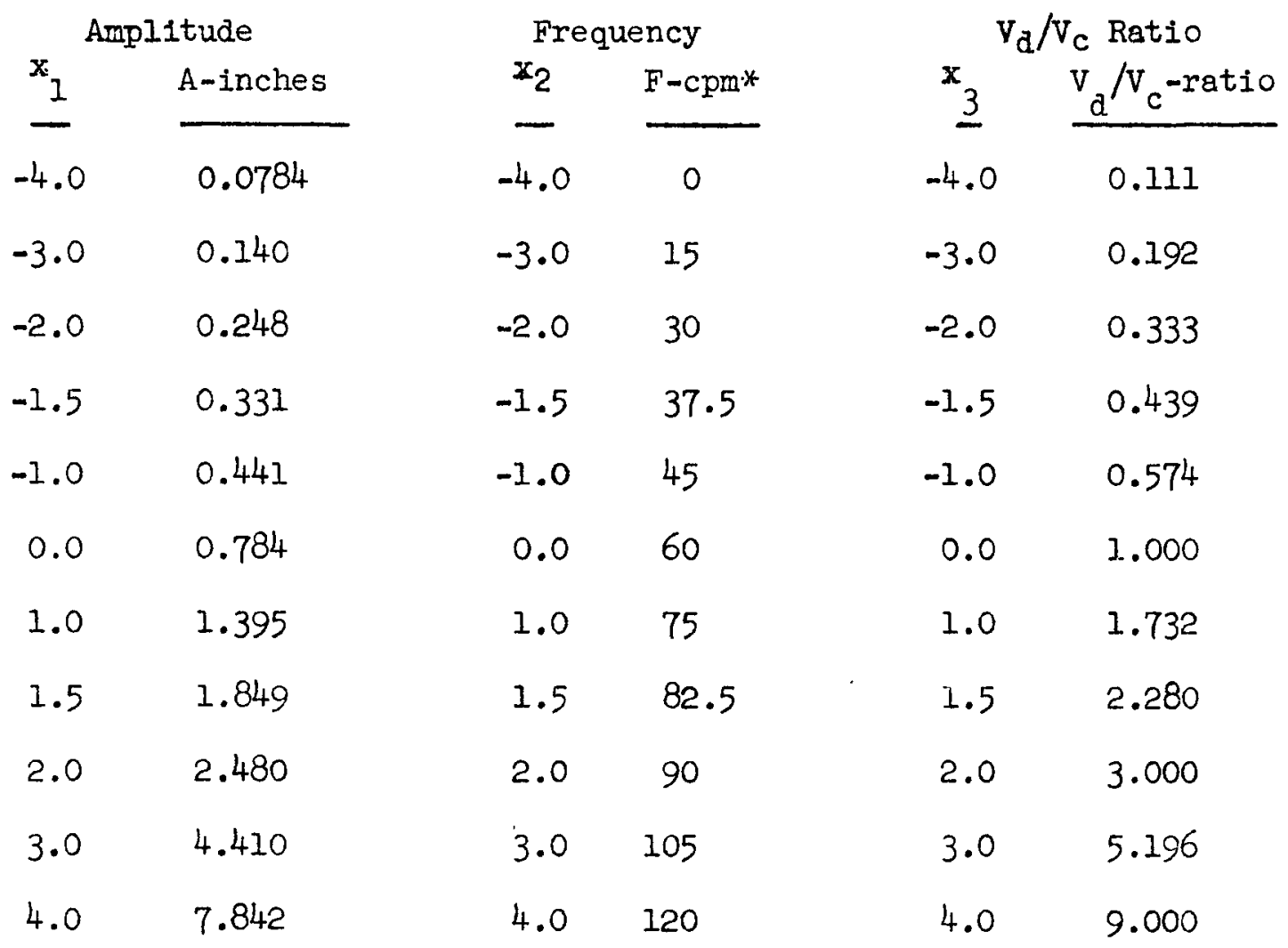

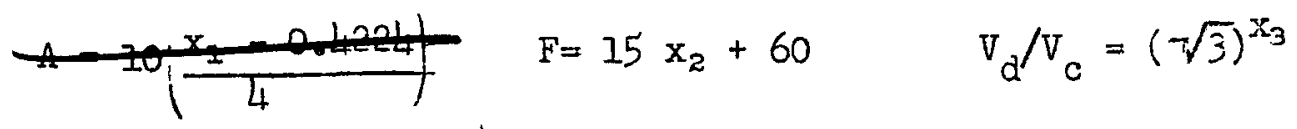

$$
A=10^{\left(\frac{x_{1}-0.4224}{4}\right)}
$$

*com $=$ cycles per minute.

$\therefore \quad 009$ 
DATA AND OBSERVATIONS

A summary of the experimental data is presented in Table 2, which includes a selected average value, corrected to $30^{\circ} \mathrm{C}$, for each design point, and also the values predicted by the final second degree equation expressing the least squares fit of the data. The 27 runs were carried out and duplicated in two random sequences of 15 and 12 runs. In addition, other repeat runs were made whenever the experimental error seemed exceptionally large. For the capacity calculation, the area was taken to be the area of the column minus the area of the plate spacers.

During the course of the experimentation, it became apparent that some unknown influence was causing large variation in the results. Some ten percent of the capacity determinations were 20 to $80 \%$ higher than supposedly duplicate runs, while the remainder of the runs agreed among themselves within better than 15\%. By studying the deviations as a function of run sequence, it was found that the excessively high capacities were suspiciously related to instances when the pumps were greased, even though only traces of grease could enter the system. Throughout the runs an emulsified precipitate of what was probably grease components collected gradually at the interface, to be drawn off at intervals. Incidentally, through this precipitation, the system had the tendency to rid itself of contamination. In subsequent work on another system, a strenuous effort was made to eliminate all grease contamination. Although not entirely successful, the grease effect was then greatly reduced, the data became much more concordant, and the precipitation of grease substance at the interface declined greatly. on the basis of these observations, the data points which are starred were discarded as being unduly influenced by grease. It must be realized, however, that the retained results apply to the trichloroethylene-water system contaminated with approximately an equilibrium amount of 
TABLE 2

Flooding Data for the Trichloroethylene-Water System at $30^{\circ} \mathrm{C}$. (with a slight grease contamination)

Experimental Capacities

Set Cubic feet per square foot Number yes hour

\begin{tabular}{|c|c|c|c|c|c|c|}
\hline Number & pe: hour & at $30^{\circ} \mathrm{C}$ & Capacity & Inches & $\mathrm{cpm}$ & $\frac{d^{2} c}{\text { Ratio }}$ \\
\hline 1 & 178,180 & 179 & 208 & 0.441 & 45 & 0.574 \\
\hline 2 & $316,349,350$ & 338 & 296 & 1.395 & 45 & 0.574 \\
\hline 3 & $263,290,286$ & 280 & 304 & 0.441 & 75 & 0.574 \\
\hline 4 & 299.301 & 300 & 261 & 1.395 & 75 & 0.574 \\
\hline 5 & $174,194, .286$ & 185 & 208 & 0.441 & 45 & 1.732 \\
\hline 6 & $353 \% 339 \%, 290,288$ & 288 & 262 & 1.395 & 45 & 1.732 \\
\hline 7 & $227,263,262$ & 251 & 262 & 0.447 & 75 & 1.732 \\
\hline 8 & $340^{*}, 304^{*}, 192,195,191$ & 193 & 186 & 1.395 & 75 & 1.732 \\
\hline 9 & $323,343,328,314,3014$ & 322 & 338 & 0.784 & 60 & 1.000 \\
\hline 10 & $129,140,132$ & 134 & 100 & 0.248 & 60 & 1.000 \\
\hline 11 & $132,101,105$ & 113 & 111 & 2.480 & 60 & 1.000 \\
\hline 12 & 208,213 & 211 & 239 & 0.784 & 30 & 1.000 \\
\hline 13 & $274,260,276$ & 270 & 258 & 0.784 & 90 & 1.000 \\
\hline 14 & $389,387,372,384$ & 380 & 339 & 0.784 & 60 & 0.333 \\
\hline 15 & $\begin{array}{l}349 \% 355 \%, 273,262 \\
264,265,281\end{array}$ & 267 & 264 & 0.784 & 60 & 3.000 \\
\hline 16 & 102,113 & 107 & 73 & 0.331 & 37.5 & 1.000 \\
\hline 17 & 215,216 & 216 & 233 & 0.331 & 82.5 & 1.000 \\
\hline 18 & 174,179 & 175 & 192 & 0.331 & 60 & 0.439 \\
\hline 19 & $182: 183$ & 182 & 173 & 0.331 & 60 & 2.280 \\
\hline 20 & $238, \cdot 250$ & 244 & 227 & 1.849 & 37.5 & 1.000 \\
\hline 21 & 77,79 & 78 & 95 & 1.849 & $82.5:$ & 1.000 \\
\hline & $0 / 1$. & & & & & \\
\hline
\end{tabular}




\section{TABIE 2}

Flooding Data for the Trichloroethylene-Water System at $30^{\circ} \mathrm{C}$. (with a slight grease contamination)

$$
\text { (Cont) ; }
$$

$$
\text { Experimental, Capacities"; }
$$

Set Cubic feet per square foot Number

\begin{tabular}{|c|c|c|c|c|}
\hline \multirow[b]{2}{*}{$\begin{array}{l}\text { AveragE } \\
\text { at } 30^{\circ} \mathrm{C} \text {. }\end{array}$} & \multirow{2}{*}{$\begin{array}{l}\text { Predicted } \\
\text { Capacity }\end{array}$} & \multicolumn{2}{|c|}{$\begin{array}{l}\text { Experimental } \\
\text { Conditions } \\
\end{array}$} & \\
\hline & & Inches & $\begin{array}{c}\mathrm{F} \\
\mathrm{cpm}\end{array}$ & $\frac{V_{d} / \sqrt{V_{c}}}{\text { Ratio }}$ \\
\hline 168 & 238 & 1.849 & 60 & 0.439 \\
\hline 130 & 144 & 1.849 & 60 & 2.280 \\
\hline 260 & 265 & 0.784 & 37.5 & 0.439 \\
\hline 243 & 255 & 0.784 & 37.5 & 2.280 \\
\hline 337 & 326 & 0.784 & 82.5 & 0.439 \\
\hline 230 & 223 & 0.784 & 82.5 & 2.280 \\
\hline
\end{tabular}
per hour

\# For each design point, the experimental capacities are listed in their time sequenoe. Thuse capacities are based upon the area of the column ninus the area of the spacers. To obtain capacities based on the area of the column, multiply by 1.016 .

\#\# The average value indicated includes a judgement on a slight temperature correction.

\#\# The predicted capacities were derived from the equation fitting the data.

* The starred values were eliminated from consideration because of assumed excessive grease contamination. 
grease. Efforts to measure the grease contamination only served to demonstrate that it was in trace amounts. It was estimated to be of the order of magnitude of 0.01 grams per liter for either phase.

The data include a considerable number of repeat runs, which were made to provide an estimate of experimental error. For the earlier runs the discrepancles were the greatest. As time progressed and attention became focused on the grease problem, the actions taken served to decrease contamination and the discrepancies became accordingly less. In Table $\hat{\imath}$, this time effect is noticeable by comparing the first 15 run sets with the second 12 run sets. Because of this changing nature of the experimental error, it was thought appropriate to merely average the set values to obtain a single response value for each run condition.

During the search for an explanation for the maverick runs, the data were examined for evidence of a temperature effect. The listed average response values include a correction for the temperature effect, which was so slight as to be of no interest here.

\section{$2: 013$}




\section{RESUITS AND DISCUSSION}

Within the range of the experiments, the best relationship fitting the data is the second degree equation listed below. The inclusion of third order terms gave no significant improvement in the fit. However, the rather large. experimental error tended to obscure the effects that third order terms might have disclosed.

$$
\begin{aligned}
C=337.9 & +2.706 x_{1}+4.779 x_{2}-18.780 x_{3}-58.069 x_{1}{ }^{2}-22.284 x_{2}^{2} \\
& -9.145 x_{3}^{2}-32.522 x_{1} x_{2}-8.327 x_{1} x_{3}-10.425 x_{2} x_{3}
\end{aligned}
$$

where $C=$ capacity in cubic feet per square foot per hour, and $x_{1}, x_{2}$ and $x_{3}$ are the amplitude, frequency and $\mathrm{V}_{\mathrm{d}} / \mathrm{v}_{\mathrm{c}}$ ratio in the standardized units described previously。

The conrersion of the above equation into terms cf $\mathrm{A}, \mathrm{F}$ and $\mathrm{V}_{\mathrm{d}} / \mathrm{V}_{\mathrm{c}}$ results in a most cumberscine relationship. To utilize tha information of the equation, it is best to convent to a: canonical form (see Part II), and calculate from it the contours in terms of $x_{1}, x_{2}$, and $x_{3}$, then convert these contours into values of $A, F$ and $V_{d} / V_{C}$ 。 Plots of these contours are a convenient manner of utilizing the information of the equatione Figure $l$ is a three dimensional presentation of the fitting equation in standardized units, constant values of the response appearing as contour surfaces. Figures 2, 3 and 4 represent cross-sections of this model, taken at constant values respectively of amplitude, frequency and flow ratio at positions which roughly bisect the model. Figures 5, 6 and 7 represent the same cross sections in conventional rather than standardized units. The solid parts of the contours represent the experimental region and what seems to be a reasonable extrapolation.

Taking these and similar drawings at their face value, some regions show little change in capacity with change in fiow ratio at constant frequency and 


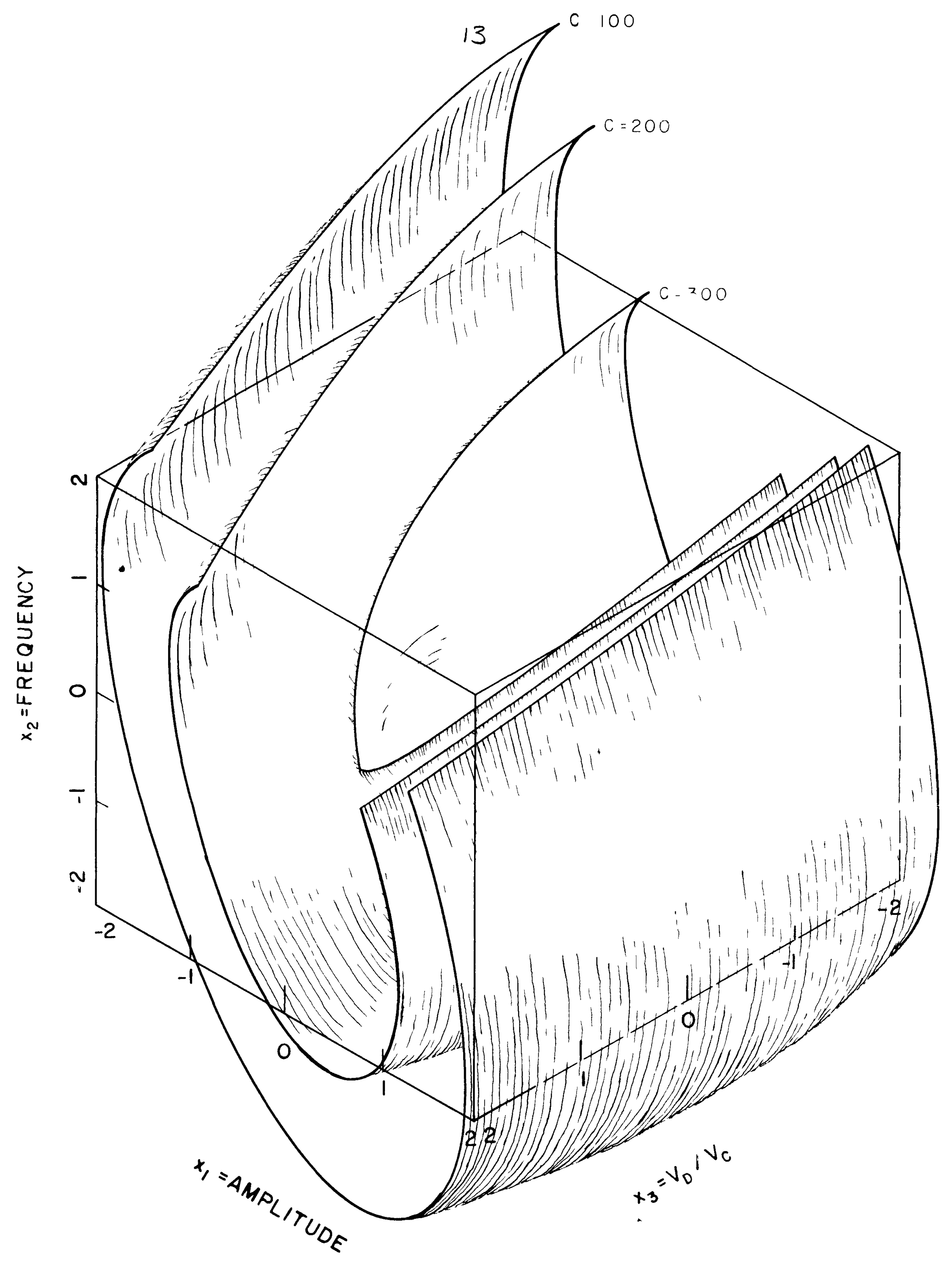

$\mid \begin{aligned} & * \\ & \vdots \\ & \vdots\end{aligned}$

FIGURE I

SPACE MODEL OF

CAPACITY CONTOURS

14 
$+$

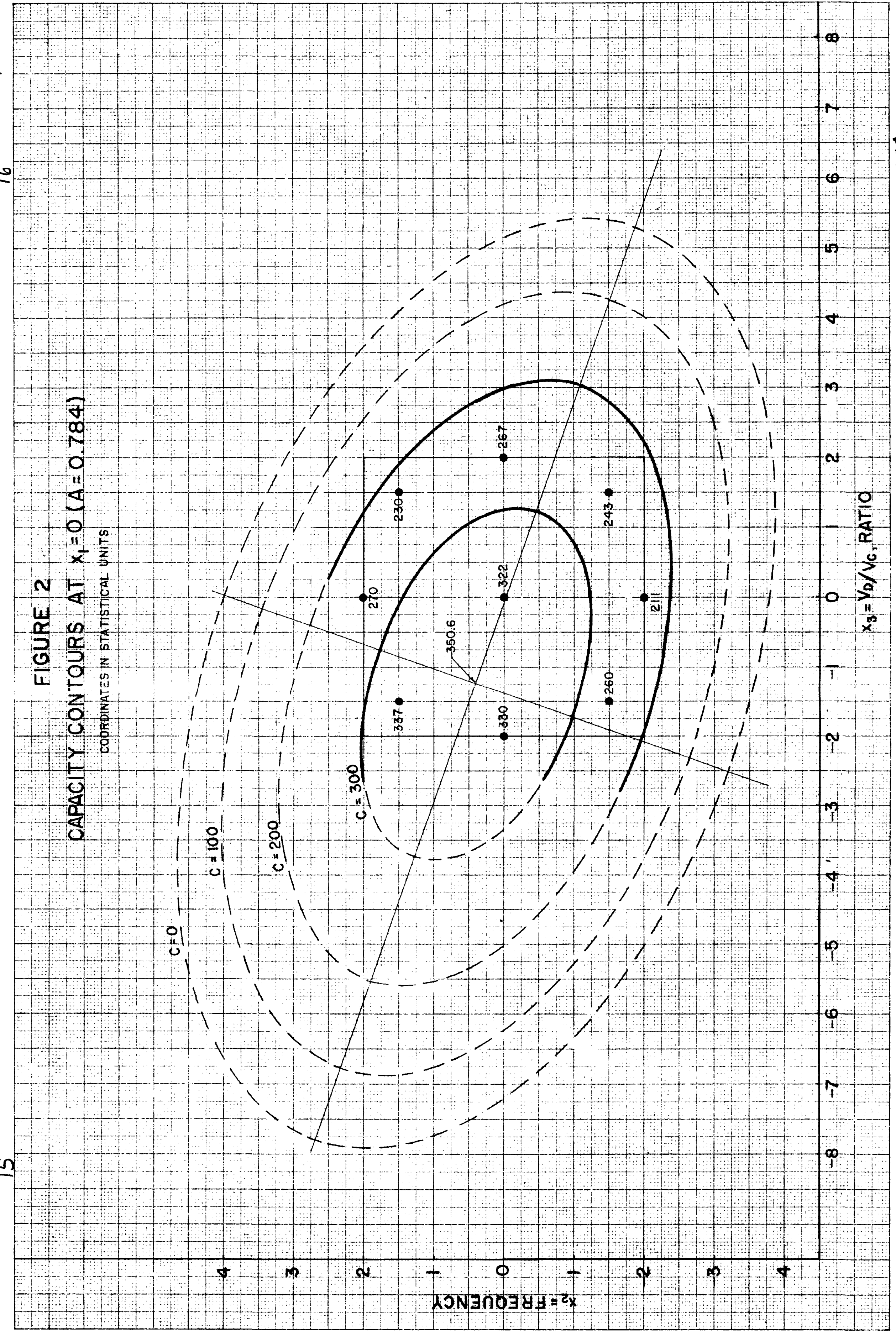




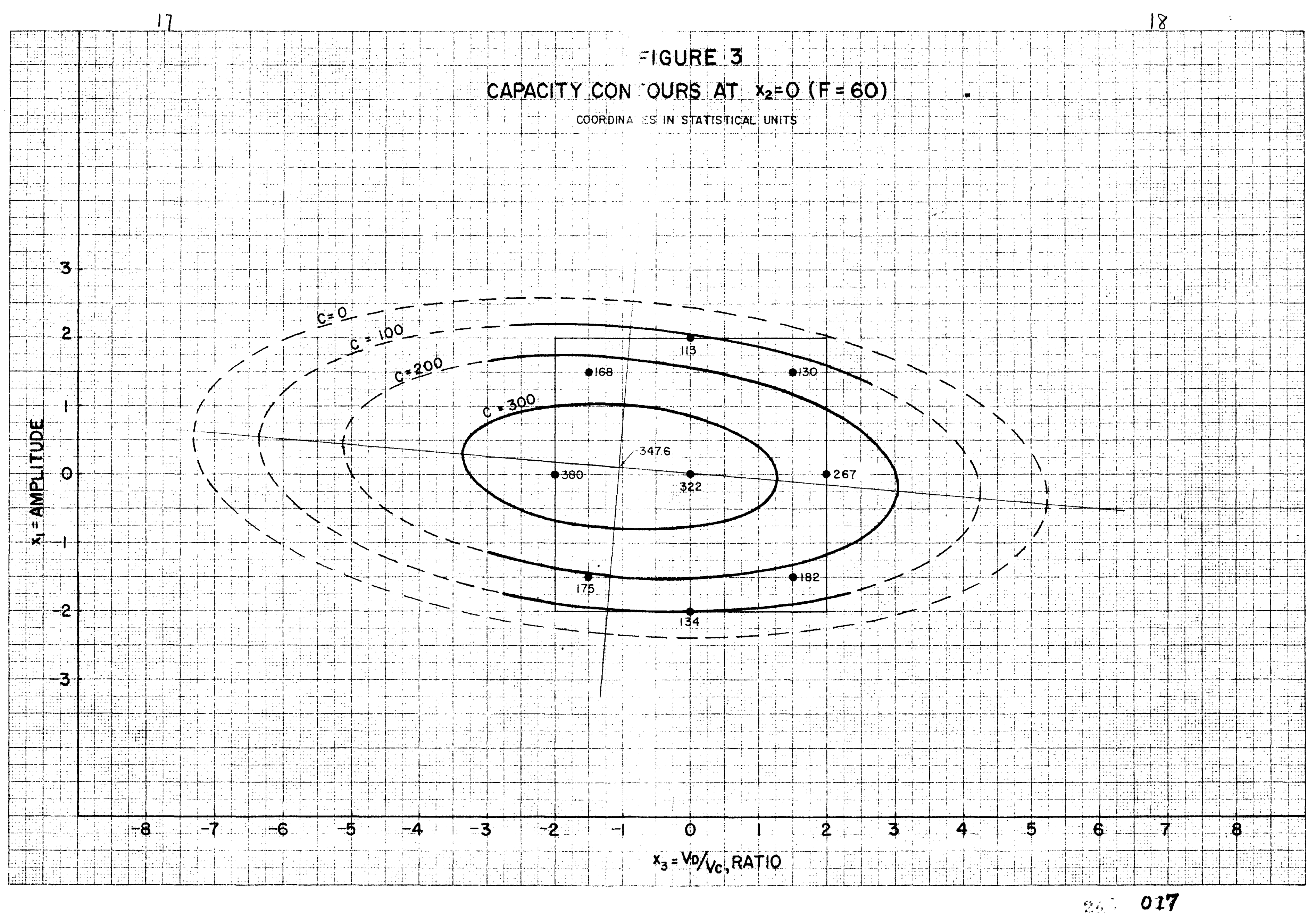


19

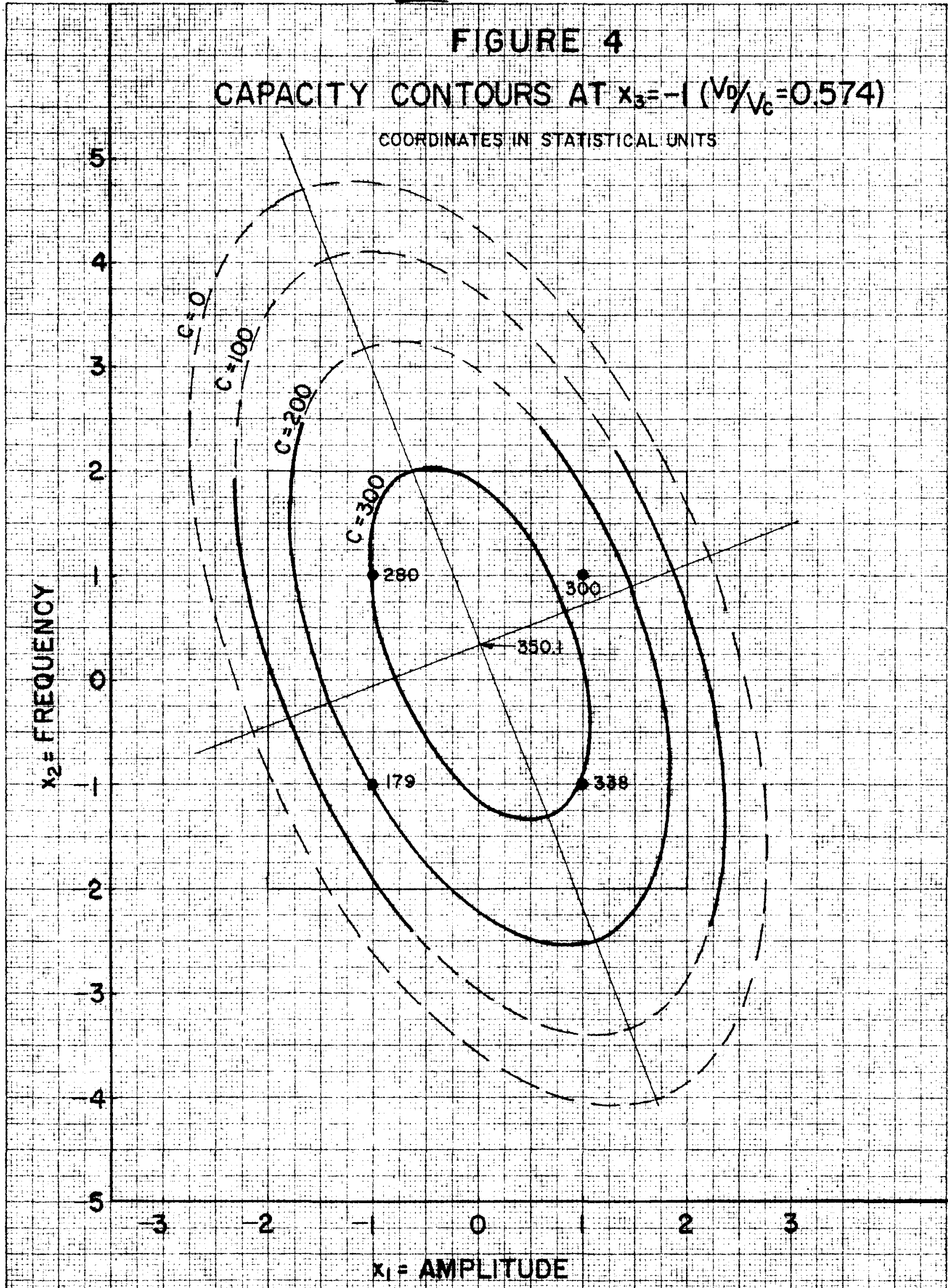




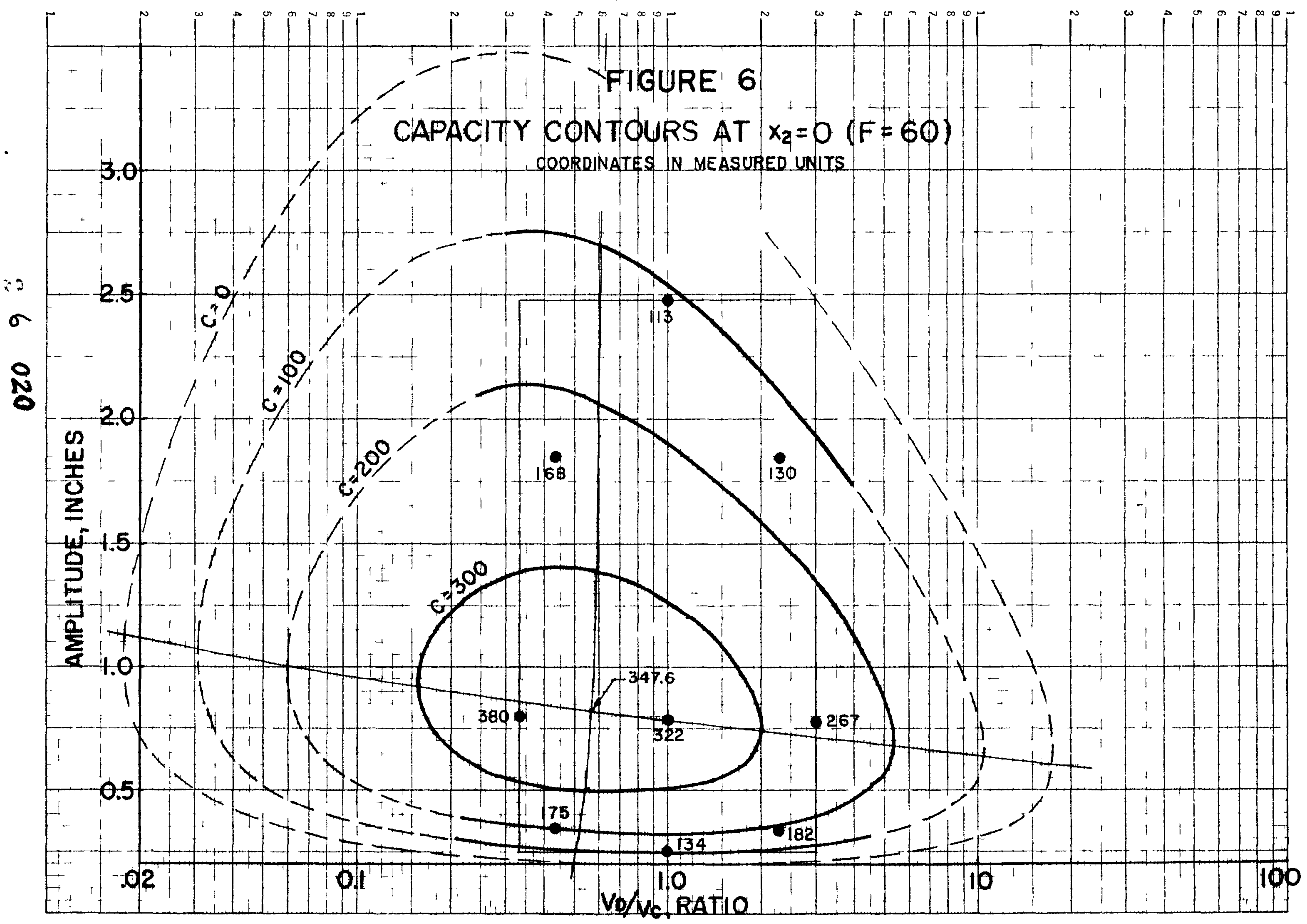




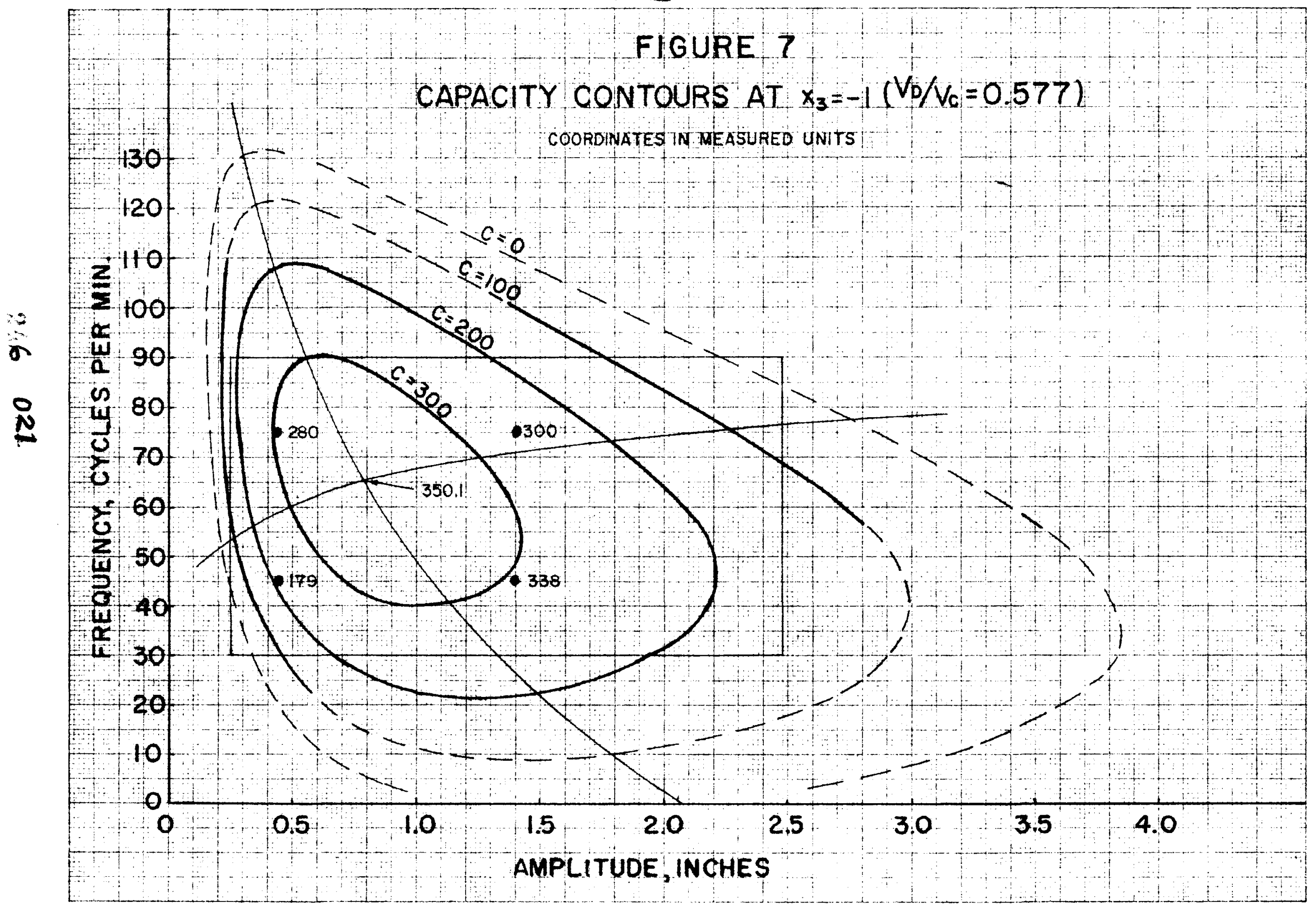




\section{3}

amplitude, while other ranges indicate a large effect. It is thus understandable why some, working in restricted regions, have concluded that capacity, as defined here, is reasonably independent of the flow ratio. Further study shows that the flow ratio $V_{d} / V_{c}$ tends to act independently of frequency and amplitude, but that frequency and amplitude tend to act in conjunction with one another. It is to be emphasized that the dashed sections of the contours represent unwarranted extrapolations of the data. However, these extrapolations do serve a useful purpose at this early stage in the study of flooding behavior. For instance, they indicate clearly that a wider range of experimental values would have been pertinent and, further, they provide a first approximation of the maximum ranges. In making inferences about the contours, it must be realized that the absence of terms of higher than second order in the assumed Taylor's Series forces the contours to be conic sections, hence either ellipses, parabolas or hyperbolas. The present evidence indicates them to be closed contours, ellipses. In this connection, note that the center of the ellipsoids of response lies within the experimental region. It would be a point of real interest to verify or disprove the indicated closure with respect to $\mathrm{V}_{\mathrm{d}} / \mathrm{V}_{\mathrm{c}}$ changes in the regionsof extreme values of $\mathrm{V}_{\mathrm{d}} / \mathrm{V}_{\mathrm{c}}$. The statistical measure of standard error was \pm 32.6 units of capacity, for the final second order equation. The inclusion of third order terms reduced the standard error only to \pm 27.6 , a reduction not considered significant. According to the statistical assumptions, the errors are considered constant throughout the entire response region. Based upon a typical capacity of about 200 , this is a relative error of about $\pm 15 \%$. In contrast, the experimental error had been expected to be less than $\pm 5 \%$. On Figure 8 is plotted the measured capacity for the 27 sets against the predicted capacity, thus giving a visual impression of the aiscrepancies involved. Also are 
24

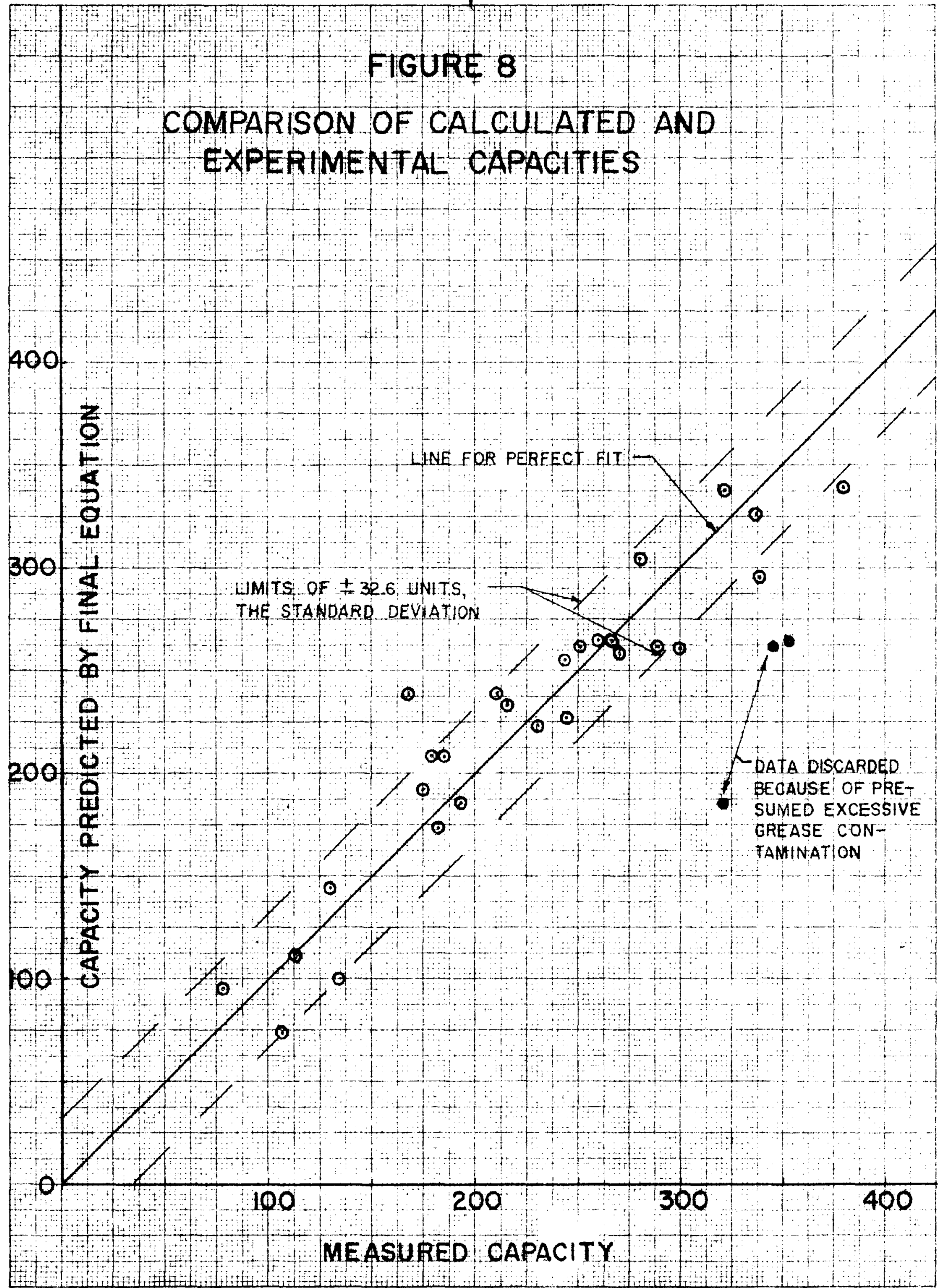

\section{FIGURE 8}

EXPERIMENTAL CAPACITIES 


\section{5}

shown three points representing the discordant data that were discarded because they were presumed to involve excessive grease contamination. In this case, the flooding eapacity tended to increase sharply upon contamination with traces of grease constituents. It was estimated that the contamination was of the order of magnitude of 0.01 grams per liter for each phbee. Presumably the greasè constituents tere surface active in their nature. Attempts to assess the contamination through its effect on interfacial tension were not successful as no change could be detected beyond the normal scatter of about 3\%. This same flooding behavior was noticed in similar work on a relatively pure benzene-water system, where the redistillation of benzene containing a trace of grease sharply reduced the flooding capacity. This phenomenon has major implications. It prompts the uneasy suspicion that the total exclusion of traces of grease might have led to difforent rosults for thc trichloroethylene-riater system. If the phenomenon is general, it indicates that any measured flooding behavior on a pulse column is not fully characterized unless some measure is provided for the amount of surface active agents present. Flooding studies on different batches of solvents, with various histories and ages, could readily give significantly different results. Pilot plant and laboratory studies might not be transferable to plant conditions, even when proper consideration has been given to the scale-up problem. This increase in capacity upon addition of contaminants might not be predictable, but it at least could be utilized. Here, then, is a clue that a study of the effects of additives on flooding capacity might be profitable, particularly for systems tending otherwise to exhibit a low capacity. 
EQUIPMENT $\Lambda$ ND MTERIALS

The equipment consisted essentially of that shown schematically in Figure 9 and pictured in Figure 10. The feed materials were pumped from 55 gallon feed tanks by steady flow, variable speed piston pumps to and through the pulse column, then back to their respective feed tanks. The column, shown in Figure 11, was a precision bore tube of chemical pyrex, 1.92 inches i.d. and 48 inches long. To reduce entrainment in the outgoing phases, the column proper was connected with standard Corning flanges to top and bottom bell-shaped end sections. The brass plates, stainless steel collars, and pressure taps between the column and its end sections were part of an assembly included to allow pressure measurement on the pulse wave, if so desired. The top and bottom feed distributors, which were identical, consisted each of one nozzle positioned to discharge on the axis of the column. The pulse flow inlet was centered in the bottom end plate. The jetting action of the pulsing flow at times created considerable mixing action and turbulence in the bottom end section.

The 23 perforated plates of 20 gage stainless steel were held together on a center tie-rod of the same length as the column, the spacing being main-tained by 2.00 inch lengths of $3 / 8 "$ " $0 . d$. stainless steel tubing. By tightening nuts on the tie-rod ends, the plates and spacers could be readily squeezed enough to cause the plate assembly to bind against the column wall with a holding power sufficient to withstand the pulsing action. The plates were perforated with $1 / 8$ inch holes in a triangular pattern so spaced as to provide $21 \%$ free space. This is a common plate geometry. Some of the plates were commercially punched, some were drilled, the punched plates having a slight indentation on the side the punch entered, the drilled plates having sharp entries on both sides. The top three plates were drilled plates, and plates 4 through 23 alternated between punched and drilled plates. All punched plates were positioned with the sharp edge upward. 



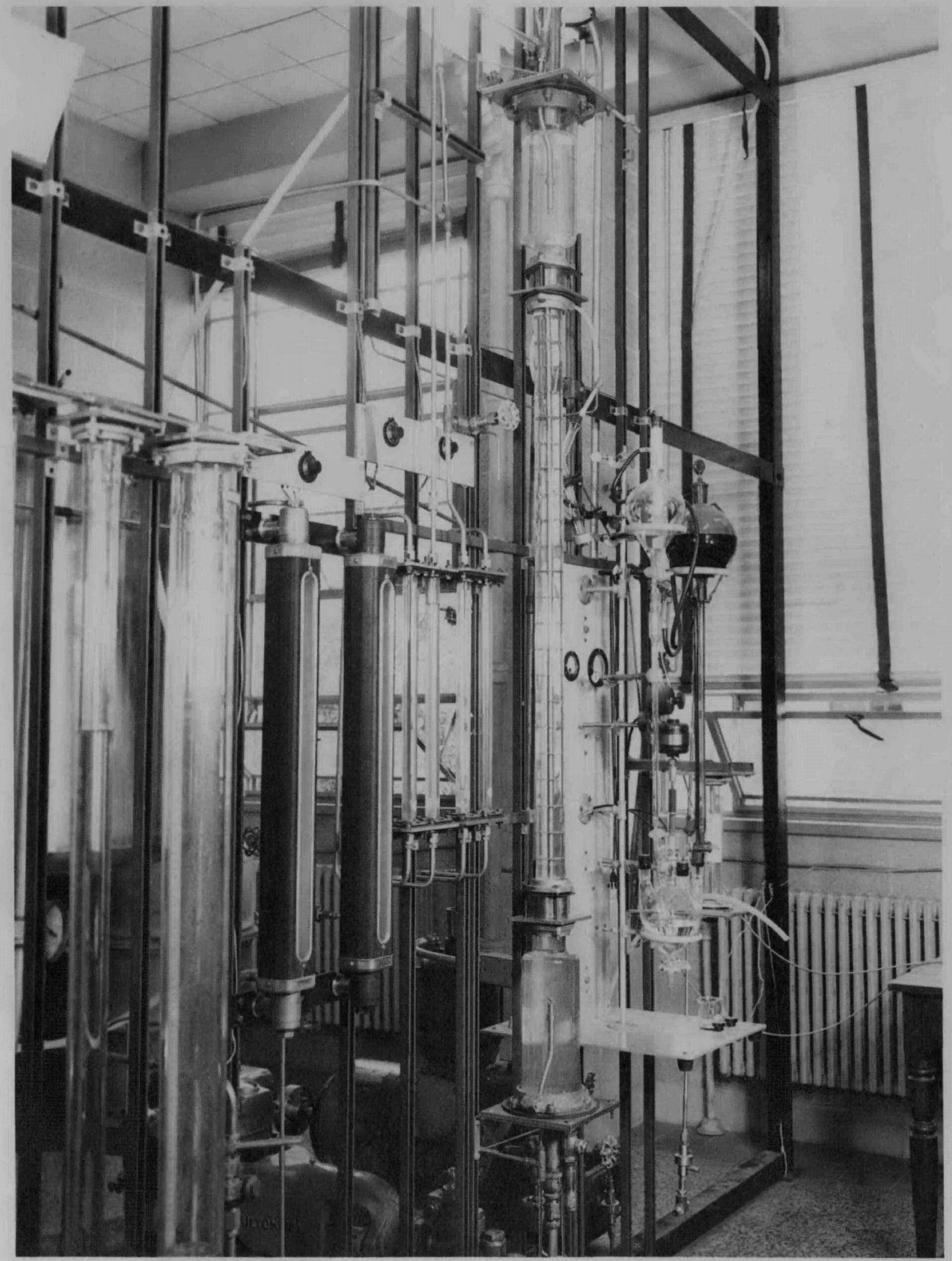

Figure 10

PULSE COLUMN UNIT

$$
2.5627
$$


26

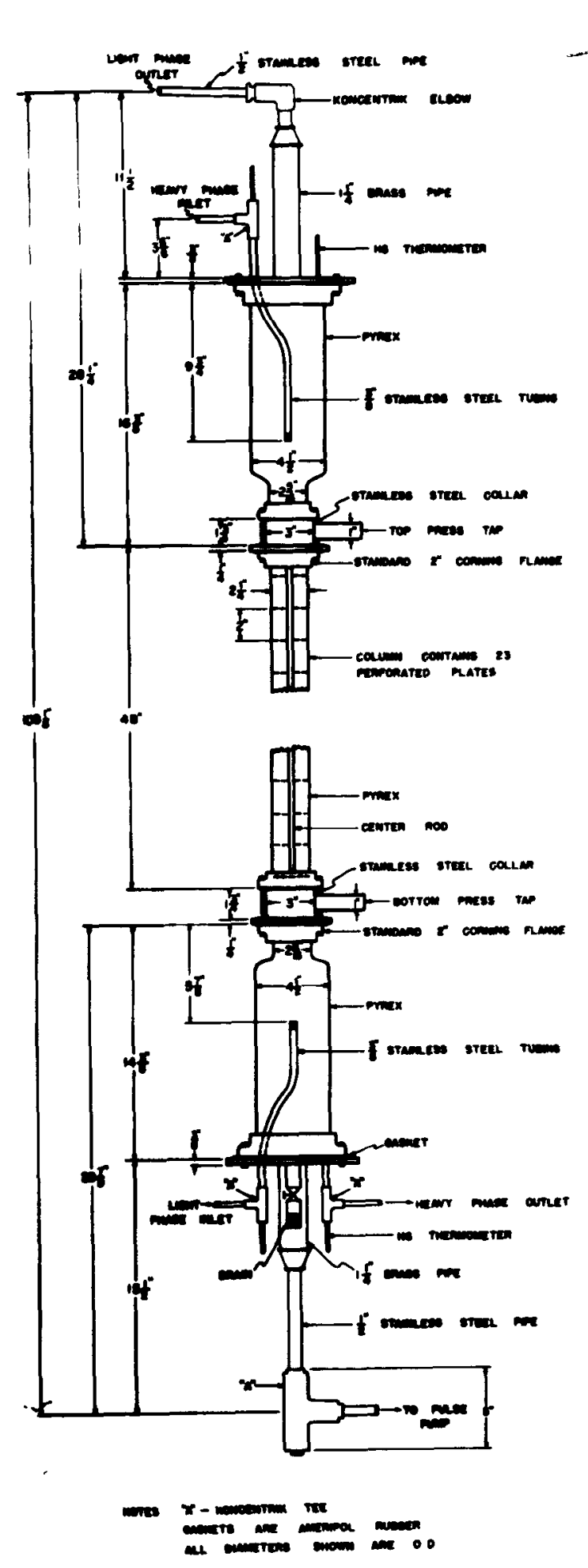

$<1$
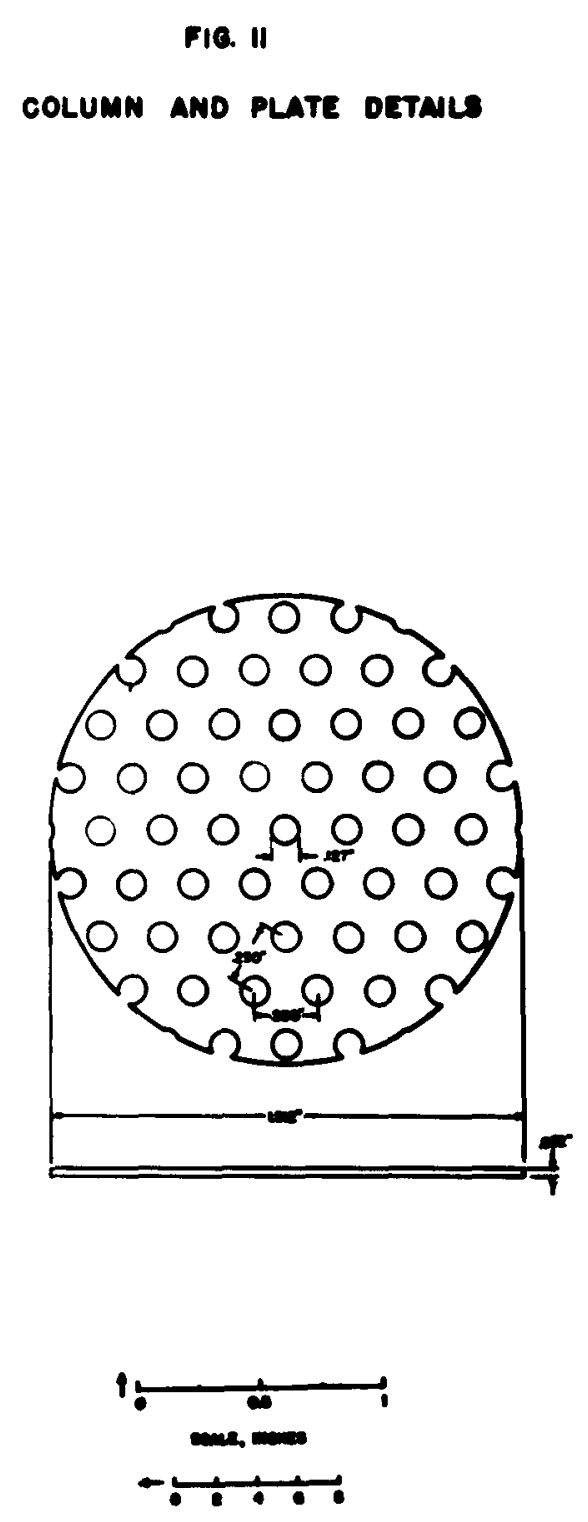

028 
The feed and discharge pumps were Milton Roy "Constametric" piston pumps controlled by DC motors and General Electric "ThymotroI" controls. These pumps possess dual pistons so geared that the resultant flow is supposed to be constant, without even a sinusoidal character, independent of the discharge pressure. This selection was made to prevent the pulse wave from travelling down the connecting flow lines, an action which would change the character of the pulse wave, In practice, it was found that the four check valves on each piston line did not function perfectly and some backflow did occur during each pulse cycle. Fortunately, the volume wastage of the pulse wave seemed to be negligible. The heavy phase feed and discharge pumps possessed $7 / 8^{\prime \prime}$ diameter stainless steel plungers, the water feed pump, I I/8" plungers, all being set for a stroke length of $1 \frac{1}{2}$ inches. By virtue of a change of gears, the speed range of these pumps could be varied 58 fold downward from a maximum of 57.0 GPH and $32.5 \mathrm{GPH}$ for the larger and the smaller pumps, respectively. The pulsing pump was a liilton-Roy "Simplex" pump equipped with a special microadjustment of the stroke length permitting the piston stroke to be changed during operation from 0 to 4 inches. The flexibility of the pulsing pump was such that the pulse frequency and pulse amplitude could be varied independently, the frequency from 7 to 148 strokes per minute, the amplitude from 0 to that equivalent to the four inch stroke of a $I \frac{1}{2}$ " diameter piston. It should be noted that all streams but one were under positive flow control, and that the one uncontrolled stream left the column at an end opposite the pulsing action input. This uncontrolled stream flowed out at a somewhat uneven rate. As a safety feature, each pump was protected by Teflon rupiure discs.

For flow indication, rotameters were used. For flow measurements, a system of calibrated gage glasses was omployed. Each tank was equipped with gage glasses of $3 "$, $1 \frac{1}{2} "$ and $3 / 4 "$ internal diameter, all about 48 " long. The 
connections included a quick-opening valve and were such that the flow could be drawn at will from either the tank or any of the three gage glasses. Temperature data were obtained from mercury-in-glass thermometers installed in the various lines.

Worthy of note wcre the construction details cmployed in an attempt to minimize the problems of contamination. The feed tanks and tubing wore of type 316 stainlcss steel, with the tubing joined with Teflon sected "Koncentrik" fittings of the same alloy. The pumps permitted mctal contact only with type 316 stainless steel and Hastalloy C. Similarly, the rotamoters were of type 316 and glass construction, with Teflon packing. In several locations it was neccssary to employ brass instead of stainless steel, such as the case of a few valves, line sections and end plates. On all threaded joints, Teflon pipe dope was employed. After a little use, this substance presumably left on the threads only a deposit of finely divided Teflon acting as a f1lm. For gasket material on the pulse column, we finally selected "Ameripol" rubber, a solvent resistant synthetic. There was no evidence that this rubber introduced into the liquids any soluble substances or affected the column behavior. In addition, the particular gaskets used had been employed for over a year on benzene service, a history which presumably minimized any leaching action during this program. However, there was one flaw in the plans to eliminate the effects of contamination. The pumps had been specified for operation without grease, and to that end had polished pistons and Teflon packing. However, in actual operation without lubricants, the pistons had a strong tendency to overheat, then to bind, then to stall. At other times, the pistons chattered and the flow rate became erratic. To counteract these faults, a number of Iubricants were examined and a selection vas made of Nordcoseal 147, a waterinsoluble lubricant, for the water pumps, and Nordcoseal 357, a trichloroethy4 
32

lene insoluble lubricant, for the trichloroethylene pumps and the pulsing pump. The fluids used in this study were water and trichloroethylene. The water was a good grade of distilled water prepared from a Barnstead still and stored in polyethylene-lined drums. The trichloroethylene was purchased as Dupont extraction grade trichloroethylene. It was given a water wash before use, to remove any water soluble contaminants.

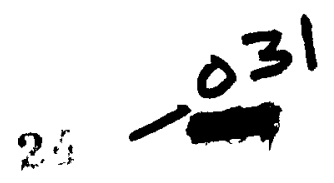




\section{3}

EXPERIMENTAL PROCEDURE

For this investigation, the pulse column was operated with water as the continuous phase and trichloroethylene as the dispersed, or discontinuous, phase. Therefore, the interface between the two phases was located in the bottom end section and the trichloroethylene was introduced at the top, passing downward. The water phase flowed upward countercurrent to the trichloroethylene. Before the runs were started, the unit was put into operation and the two fluids recycled for a number of hours in order to approach mutual saturation. This recycling action certainly reduced to almost zero any mass transfer action during the flooding runs, a precaution perhaps unnecessary. It seemed to have one bad effect in tinat the mutual saturation perhaps caused each phase to dissolve more of its assigned insoluble pump grease than it would have otherwise. At any rate, grease constituents continually were extracted at a slow rate by both phases from the pumps, and carried to the columns where, by some action, a precipitate formed and gradually collected at the interface. At intervals, this emulsified collection of grease precipitates was withdrawn and discarded.

In order to be able to set the desired amplitude for a run, the correspondence was measured between the setting of the pulse-pump stroke length and the resultant amplitude in the column containing the working plate assembly. The pulse amplitude was measured with a cathetometer. The calibration was carried out at virtually zero pulse frequency and without the complications of other flows. The results were assumed to apply equally well to actual operations when in fact pulse leakage out the flow lines would introduce errors。 However, pulse leakage was thought to be reduced to negligible proportions by maintaining a back pressure on the pumps to aid the action of the check valves. Back pressures were brought about through the use of throttling valves and small surge chambers.

$$
2: 032
$$




\section{4}

In carrying out a run, the pulse pump was first set to provide the selected pulse frequency and amplitude. Then the column was put into operation, maintaining a specified ratio of $v_{d}$ to $V_{C}$. Fine control of the heavy phase discharge pump was used to maintain the interface level at a constant position. Two methods of approaching the flooding point were used: one, approaching the flood point gradually and by small increments from flow rates below flooding, until flooding ensued, and two, first setting the flow rate above the flooding point, then gradually reducing the flow rate until the column cleared. In both cases, the flooding point was teken as that capacity below flooding which is just at the verge of flooding. The two procedures agreed closely, lending confidence in the inherent reproducibility of the phenomenon and indicating no hysteresis. It is pertinent that the flooding behavior of packed and spray columns of ten show a hysteresis effect unless the rate of approach to flooding is extremely slow. For the case at hand, observations at one setting were made for roughly thirty minutes, and rarely could more than three flooding points be determined in an 8-hour day, usually only two. For replicate runs, the prior knowledge of the flooding capacity permitted up to five determinations a day. 
II. STATISTICAI DESIGN AND ANIYSIS

George E. P. Box and J. Stuart Hunter

\section{INTRODUCTION}

In most situations an experimenter, in secking to locate an optimum point, or to delineate an unknown response function, proceeds by intuition and rule of thumb, or resorts to the tedious system of direct enumeration of many points in the experimental region. It is true that techniques for investigating unkown response functions of some complexity have been proposed by statisticians for many years. However, for several reasons, these methods have not come into wide use in the engineering sciences. Recently new patterns of experimental points, culled composite experimental designs, have been proposed and, coupled with the concepts of surface fittinc, used with considerable success in England for determining best operating conditions ind for investigating the nature of unknown response functions [2]. These experimental designs and methods of . analysis are particularly suited to the needs of the experimenter faced with many variables for they allow him to probe the malti-factor relationships with a minimum of time and effort.

This paper describes brief'iy the use of three dimensional composite designs to estimate the functional relationship between the flooding capacity, $c$, of a pulse column and the pulse amplitude, $A$, pulse frequency, $F$, and the flow ratio, $V_{d} / V_{c}, i . e .$,

$$
C=f\left(A, F, V_{d} / N_{c}\right)
$$

The statistician's role in this problem was to select the appropriate statistical design, analyze the data, and by interpreting the nature of the experimental error to assist the experimenter in forming judgements about the predicted surface. 
GENERAL BACKGROUND

In general, the purpose of these investigations was to explore an exect functional relationship of the form

$$
\eta=f\left(\xi_{1}, \xi_{2}, \xi_{3}\right)
$$

which in this particular problem relates the flooding capacity $\eta$ to the amplitude, $\xi_{1}$, frequency, $\xi_{2}$ and flow ratio, $\xi_{3}$, of a pulse column. (The Greek letter notation is conventional statistics notation for variables or functions when reference is made to their exact values. Roman letters are used to refer to approximations or estimates of these true values.) The actual choice of the independent variables $\xi_{1}, \xi_{2}$ and $\xi_{3}$, and the functional forms in which they were expressed, were determined exclusively by the chemical engineers studying the response. Furthermore, the experimental region to be investigated was chosen to be large enough to be generally descriptive of the response, subject only to the physical linitations of the system and the equipment. Finally, the scale to be used in measuring any variable was decided by the engineers, influenced by the suggestion that at the center of the experimental region approximately equal changes in response be expected for equal changes in scale.

A newly developed statistical technique $[2,3,4]$ was employed to explore the nature of the unknown function defined $b_{r}$ equation (2). This technique is briefly described as follows. In the absence of specialized knowledge concerning the form of the functional relationship, we assume that it can be represented over the ranges of interest by a Taylor's Series, which for three variables would be

$$
\begin{aligned}
\eta & =\beta_{0}+\left(\beta_{1} x_{1}+\beta_{2} x_{2}+\beta_{3} x_{3}\right)+\left(\beta_{11} x_{1}^{2}+\beta_{22} x_{2}^{2}+\beta_{33} x_{3}^{2}+\beta_{12} x_{1} x_{2}+\beta_{13} x_{1} x_{3}+\beta_{23} x_{2} x_{3}\right) \\
& +\left(\beta_{111} x_{1}{ }^{3}+\beta_{222} x_{2}{ }^{3}+\beta_{333} x_{3}{ }^{3}+\beta_{112} x_{1} x_{2}+\beta_{122} x_{1} x_{2}{ }^{2}+\beta_{113} x_{1}{ }^{2} x_{3}+\beta_{133} x_{1} x_{3}{ }^{2}+\beta_{223} x_{2}^{2} x_{3}\right. \\
& \left.+\beta_{233} x_{2} x_{3}{ }^{2}+\beta_{123} x_{1} x_{2} x_{3}\right) \text { plus terms of higher order, }
\end{aligned}
$$

The terms in the parentheses 


\section{7}

and third order, and where $x_{1}, x_{2}$ and $x_{3}$, called standardized variables, are suitable functions (to be described later) of the natural variables $\xi_{1}, \xi_{2}$ and $\xi_{3}$ i.e., the amplitude, frequency and flow ratio. This equation is of ten called the mathematical model, and can be viewed geometrically as the equation of a surface relating the response $\eta_{1}$ to the variables $x_{1}, x_{2}$ and $x_{3}$. If, as must be assumed, the function is smooth, then a closer and closer approximation to the true response function can be found by taking a higher and higher order expansion of $\eta$.

The problem of the statistician is to select a set of experimental points in the experimental region so that estimates of the coefficients in the mathematical model (2) can be obtained. If the model has $L$ coefficients $\beta_{1}, \beta_{2}$, ... and observations $\mathrm{y}_{1}, \mathrm{y}_{2}, \ldots \mathrm{y}_{\mathrm{N}}$ are available at $\mathrm{N}$ different and suitably chosen settings of the standardized variables $x_{1}, x_{2}$ and $x_{3}$ (where $N \geqslant L$ ) then estimates $b_{1}, b_{2}, \ldots$ of the unknown coefficient $\beta_{1}, \beta_{1} \ldots$ can be obtained by the method of least squares $[1,2,3 j$. The particular array of the levels of the standardized variables making up the program of $\mathrm{N}$ experiments is called the experimental design. The precision with which the coefficients are estimated depends both on the precision with which the individual observations are made and upon the choice of the experimental design. In practice it is desirable that the number of points making up the design be rather more than the minimum number $L$, for provided $N>I$ the method of least squares also provides an estimate of the total experimental error.

The actual calculations required to obtain the estimated coefficients $b_{1}$, $b_{2}, \ldots$, are routine so long as all the data called for by the experimental design are available. It is a novel fact that experimental designs that lend themselves to a quick routine analysis often possess other desirable qualities from a statistical viewpoint. Consequently, any failure to conform to the 


\section{8}

experimental design may not only require a specialized and lengthy series of calculations (particularly the inversion of a matrix of higher order) but may badly upset the precision of the estimates for some of the coefficients. In an extreme case, the loss of one point can make it impossible to estimate certain of the coefficients. The importance of satisfying the requirements of the design must therefore be made clear to the experimenter.

The total number of coefficients that must be estimated in any second degree model in $\mathrm{k}$ dimensions, and the associated number of experimental points using a second order composite design are given below in Table 1.

\section{TABLE 1}

Information on Second Order Composite Designs

$\begin{array}{lrrrrr}\text { Number of independent variables } & 2 & 3 & 4 & 5 & 6 \\ \text { Number of coefficients involved } & 6 & 10 & 15 & 21 & 28 \\ \text { Number of experimental points required } & 9 & 15 & 25 & 27 * & 45 * \\ \text { * Using the } 1 / 2 \text { replication of a cube } & & & & \end{array}$

Within the last year still another class of experimental designs, called rotatable designs, have been deve] opsd which possess some desirable properties not available in the composite designs.

A composite design is constructed by taking the $2^{k}$ points $(k=$ the number of independent variables) that occur at the vertices of a cube, i.e., the regular $2^{k}$ factorial design, and imagining the center of the cube as the origin of the co-ordinate system, placing points out a distance ' $a$ ' along each of the axes, with one additional point at the origin. An illustration of a three dimensional composite design is shown in Figure 1 , 
In the first portion of the problem, it was assumed that terms of higher order than the second in Taylor's Series could be ignored. The equation to be estimated was therefore of the form

$$
\eta=\beta_{0}+\beta_{1} x_{1}+\beta_{2} x_{2}+\beta_{3} x_{3}+\beta_{11} x_{1}{ }^{2}+\beta_{22} x_{2}{ }^{2}+\beta_{33} x_{3}{ }^{2}+\beta_{12} x_{1} x_{2}+\beta_{13} x_{1} x_{3}+\beta_{23} x_{2} x_{3}
$$

which contains ten coefficients. To obtain accurate estimates of the coefficients in this equation, the three dimensional composite design was employed. Thus the co-ordinates of the experimental points $i_{11}$ terms of the standardized variables are as :iven in Téle 2.

\begin{tabular}{|c|c|c|}
\hline \multicolumn{3}{|c|}{$\begin{array}{c}\text { Second Order } \\
\text { Experimentil Design } \\
\text { (Program of Lxperiments) }\end{array}$} \\
\hline$x_{1}$ & $x_{2}$ & $x_{3}$ \\
\hline-1 & $-I$ & -1 \\
\hline$I$ & -1 & -1 \\
\hline-1 & 1 & -1 \\
\hline 1 & 1 & -1 \\
\hline-1 & - & $I$ \\
\hline 1 & -1 & 1 \\
\hline -1 & $I$ & 1 \\
\hline 1 & $I$ & $I$ \\
\hline 0 & 0 & 0 \\
\hline-2 & 0 & 0 \\
\hline 2 & 0 & 0 \\
\hline 0 & -2 & 0 \\
\hline 0 & 2 & 0 \\
\hline 0 & 0 & -2 \\
\hline 0 & 0 & 2 \\
\hline
\end{tabular}

It will be noted that for each of the standardized variables the levels are $-2,-1,0,1$ and 2. In order to use the design for a specific purpose these standardized variables must be related to the natural variables, amplitude, frequency, and flow ratio over the ranges of interest to the experimenter described in the previous part. Drawing on the knowledge and intuition of the 


\section{0}

experimenters, the scale of the natural variables was chosen in the hope that relatively equal increments in response would result from unit changes in these scales in the mid range regions. The scales of the natural variables and the standardized variables were then matched, with the results shown in Table 3.

TABLT 3

Correspondence Between Scales of

Natural and Standardized Variables

for the Second Order Composite Design

$\begin{array}{lccccc}\text { Standardized Variables } & -2 & .1 & 0 & 1 & 2 \\ \text { Amplitude, A } & 0.248 & 0.441 & 0.784 & 1.395 & 2.480 \\ \text { Frequency, F } & 30 & 45 & 60 & 75 & 90 \\ \text { Flow Ratio, } \mathrm{V}_{\mathrm{d}} / \mathrm{V}_{\mathrm{c}} & 0.333 & 0.574 & 1.000 & 1.732 & 3.000\end{array}$

We note that the amplitude and $V_{d} / v_{c}$ are measured in a logarithmic scale. Thus $x_{1}=0.4224+4 \lg _{10} A, x_{2}=\frac{1}{15}(F-60)$ and $x_{3}=\frac{2}{I_{10} g^{3}} \lg _{10} V_{d} / N_{c}$.

In what follows we shall work throughout with the standardized variables $x_{1}, x_{2}$ and $x_{3}$, converting these to the original natural variables only at the conclusion of the calculations.

The responses recorded at each of the 15 points in the first experimental design are listed in Table 4, sets 1 through 15. Other information on these same mans is provided in Table 2 of the previous part. Note that while the runs were replicated, the responses used in the analysis are selected averages for each run, adjusted for temperature. The mathematical model, equation (3), was now fitted to these data by the method of least squares. The estimated coefficients are listed in Table 5 and the predicted responses using the estimated equation (5) are listed in Table 4. Written out, the estimated 
41

TABLE 4

Observed and Predicted Responses

\begin{tabular}{|c|c|c|c|c|c|c|c|}
\hline Set & $x_{1}$ & $\mathrm{x}_{2}$ & $\mathrm{x}_{3}$ & y obs. & Predicted & Values of & $y$ (capacity) \\
\hline Number & A & & $\mathrm{v}_{\mathrm{d}} 7 \mathrm{v}_{\mathrm{c}}$ & $\mathrm{C}$ & Eq. (5) & $\mathrm{Eq} .(6)$ & $\mathrm{Eq} \cdot(7)$ \\
\hline 1 & -1 & -1 & -1 & 179 & 191 & 190 & 208 \\
\hline 2 & 1 & -1 & -1 & 338 & 322 & 322 & 296 \\
\hline 3 & -1 & 1 & -1 & 280 & 308 & 279 & 304 \\
\hline 4 & 1 & 1 & -1 & 300 & 289 & 292 & 261 \\
\hline 5 & -1 & -1 & 1 & 185 & 197 & 177 & 208 \\
\hline 6 & 1 & -1 & 1 & 288 & 261 & 287 & 262 \\
\hline 7 & -1 & 1 & 1 & 251 & 268 & 235 & 262 \\
\hline 8 & $I$ & 1 & 1 & 193 & 182 & 204 & 186 \\
\hline 9 & 0 & 0 & 0 & 322 & 321 & 338 & 338 \\
\hline 10 & -2 & 0 & 0 & 134 & 100 & 116 & 100 \\
\hline .21 & 2 & 0 & 0 & 113 & 146 & 95 & 111 \\
\hline 12 & 0 & -2 & 0 & 211 & 221 & 219 & 239 \\
\hline 13 & 0 & 2 & 0 & 270 & 259 & 278 & 258 \\
\hline 14 & 0 & 0 & -2 & 380 & 374 & 358 & 339 \\
\hline 15 & 0 & 0 & 2 & 267 & 272 & 245 & 264 \\
\hline 16 & -1.5 & -1.5 & 0 & 107 & - & 98 & 73 \\
\hline 17 & -1.5 & 1.5 & 0 & 216 & - & 216 & 233 \\
\hline 18 & -1.5 & 0 & -1.5 & 175 & - & 190 & 192 \\
\hline 19 & -1.5 & 0 & 1.5 & 182 & - & 212 & 173 \\
\hline 20 & 1.5 & -1.5 & 0 & 244 & - & 244 & 227 \\
\hline 21 & 1.5 & 1.5 & 0 & 78 & - & 69 & 95 \\
\hline 22 & 1.5 & 0 & -1.5 & 168 & - & 198 & 238 \\
\hline 23 & 1.5 & 0 & 1.5 & 130 & - & 145 & 144 \\
\hline
\end{tabular}


42

TABLE 4

Observed and Predicted Responses

$$
\text { (Cont) }
$$

\begin{tabular}{|c|c|c|c|c|c|c|c|}
\hline $\begin{array}{c}\text { Set } \\
\text { Number }\end{array}$ & $\frac{x_{1}}{A}$ & $\begin{array}{l}x_{2} \\
\frac{2}{F}\end{array}$ & $v_{d} \stackrel{x}{3}_{c}$ & $\begin{array}{c}\text { y obs. } \\
c\end{array}$ & $\frac{\text { Predicted }}{\text { Eq. }(5)^{*}}$ & $\frac{\text { Values of } \mathrm{J}}{E q \cdot(6)^{m}}$ & $\frac{(\text { capacity })}{E q \cdot(7)^{r}}$ \\
\hline 24 & 0 & -1.5 & -1.5 & 260 & - & 259 & 265 \\
\hline 25 & 0 & -1.5 & 1.5 & 243 & - & 244 & 255 \\
\hline 26 & 0 & 1.5 & -1.5 & 337 & - & 338 & 326 \\
\hline 27 & 0 & 1.5 & 1.5 & 230 & - & 229 & 223 \\
\hline
\end{tabular}

* iquation 5 is a second order equation fitted to sets 1-15.

Equation 6 is a third order equation fitted to sets 1-27.

Equation 7 is a second order equation fitted to sets $1-27$. 
$T_{4} B L E 5$

Estimated Coefficients and Standard Errors for the Three Equations

Second Order Equation (5) based upon Runs 1-15

\begin{tabular}{lr} 
Coefficients & $\begin{array}{r}\text { Standar } \\
\text { Errors }\end{array}$ \\
\hline$b_{0}=321.4$ & 28.1 \\
$b_{1}=11.4$ & 7.9 \\
$b_{2}=9.5$ & 7.9 \\
$b_{3}=-25.4$ & 7.9 \\
$b_{11}=-49.6$ & 9.6 \\
$b_{22}=-20.3$ & 9.6 \\
$b_{33}=0.4$ & 9.6 \\
$b_{12}=-37.5$ & 11.3 \\
$b_{13}=-16.8$ & 11.3 \\
$b_{23}=-11.5$ & 11.3
\end{tabular}

Third Order Equation (6) based upon Runs 1-2?

Standard

Coefficients Errors *

$b_{0}=337.921 .2$

$b_{1}=86.232 .0$

$b_{2}=20.532 .0$

$b_{3}=-50.1 \quad 32.0$

$b_{11}=-58.1 \quad 6.2$

$b_{22}=-22.3 \quad 6.2$

$b_{33}=-9.1 \quad 6.2$

$b_{12}=-32.5 \quad 5.2$

$b_{13}=-8.3 \quad 5.2$

$b_{23}=-10.4 \quad 5.2$

$b_{117}=-22.9 \quad 7.9$

$b_{222}=-1.4 \quad 7.9$

$b_{333}=5.5 \quad 7.9$

$b_{112}=-11.9 \quad 9.3$

$b_{122}=-15.5 \quad 9.3$

$b_{113}=14.5 \quad 9.3$

$b_{133}=-19.8 \quad 9.3$

$b_{223}=7.69 .3$

$b_{233}=-2.9 \quad 9.3$

$b_{123}=-2.8 \quad 9.7$
Second Order Equation(7) based upon Runs 1-27

\begin{tabular}{|c|c|}
\hline Coefficients & $\begin{array}{l}\text { Standard } \\
\text { Errors * }\end{array}$ \\
\hline$b_{0}=337.9$ & 24.8 \\
\hline$b_{1}=2.7$ & 5.5 \\
\hline$b_{2}=4.8$ & 5.5 \\
\hline$b_{3}=-18.8$ & 5.5 \\
\hline$b_{11}=-58.1$ & 7.2 \\
\hline$b_{22}=22.3$ & 7.2 \\
\hline$b_{33}=-9.1$ & 7.2 \\
\hline$b_{12}=-32 \cdot 5$ & 6.1 \\
\hline$b_{13}=-8.3$ & 6.1 \\
\hline$b_{23}=-10.4$ & 6.1 \\
\hline
\end{tabular}

* The standard deviation of the coefficients can be used to establish a confidence interval about any estimated coefficient $b$. This confidence interval will, in the long run, include the true coefficient $\beta$ a given percent of the time. Thus. the $100(1-a) \%$ confidence interval for a true coefficient $\beta$ is $b t_{t a}\left(s_{b}\right)$ where $t_{\alpha}$ is obtained from customary $t$ tables as a function of a and the degrees of freedom used in the calculation of the standard error, $s_{b}[1,6,7]$. Thus, the $50 \%$ confidence interval for $\beta_{0}$ in equation $(5)$ is $321.4 \pm(0.727)(28.1)=$ $321.4 \pm 20.4$. 


$$
44
$$

equation is as follows (where $y$ equals $C$, the capacity),

$y=321.4+11.4 x_{1}+9.5 x_{2}-25.4 x_{3}-49.6 x_{1}^{2}-20.3 x_{2}^{2}+0.4 x_{3}^{2}-37.5 x_{1} x_{2}-16.8 x_{1} x_{3}$<smiles>[Y19][13CH2][13CH3]</smiles>

Using this estimated equation it is possible to compute the predicted values of the response at each of the experimental points. The method of least squares guarantees that the sum of squares of the differences between the predicted and the corresponding observed values is a minimum. Thus, if the mathematical model exactly represents the unknown response function, the failure of the predicted values to equal their corresponding observed values could be attributed only to experimental error, 1.e, the error caused by the inability of the experimenter to reproduce any particular observation. The error is assumed to be distributed with a mean of zero and have a variance $\sigma^{2}$. The estimate of the variance of this error, $s_{1}^{2}$ can be obtained from the analysis of variance, Table 6 .

\section{TABIE 6}

$$
\text { Analysis of Variance }
$$

Second Order Model, 15 Observations

Sum of Squares Degrees of Freedom Meen Sq.

Total Sum of Squares 999623.0 15

Reduction due to 2nd. Order Regression 994558.8 10 5064.2 5 1012.8

Deviation from Regression

The total sum of squares recorded in Table 6 is the uncorrected sum of squares of the 15 observations. This total has fifteen degrees of freedom, equal to the number of observations. The quantity 'Reduction due to Regression' equals that portion of the total sum of squares absorbed by the fitted equation. The calculation of the latter quantity is described in many statistical texts. [1, $5,6,7]$. 


\section{5}

This sum of squares posseşses ten degrees of freedom, one for each estir mated coefficient. The error sum of. squares and degrees of freedom are obtained by subtraction. This error sum of squares equals the sum of squares of deviations between the observed and predicted values. An estimate of the error variance $s^{2}$, termed the mean square in the table, is obtained by dividing the error sum of squares by its degrees of freedom, thus $s^{2}=1012.8$ and therefore the standard deviation is $s=31.8$.

In originally choosing the mathematical model it was decided that a Taylor's Series expansion including all terms through those of second order was adequate to represent the response. If this assumption was not true, but instead, third order terms were also required to represent the function, then the construction of a second order surface would only approximately represent the true response surface. Thus large deviations between observed and predicted values would occur, and hence a large deviation from regression of squares result. The calculated error variance would then be a measure of both the experimental error variance and the lack of fit of the model.

Those conducting the experiments felt that the residual error estimated by the analysis of variance was much larger than the actual experimental error. To check whether this large error was essentially due to the lack of fit of the second degree model, it was decided to carry out the Taylor's Series approximation to another order of complexity and to include the third order terms. Thus, twelve more points were added to the experimental design, making a total of 27, and all the coefficients shown in the mathematical model in equation (2), ending with the third order effects, were estimated.

The third order composite design constructed to estimate all 20 coefficients is illustrated in Figures/and ascribed as follows:

If the center of a cube is taken as the origin of a set of co-ordinates axes which pierce the mid points of the faces of a cube, then the 27 points making

$$
\because \quad 044
$$




\author{
46 \\ FIGURE I
}

THREE DIMENSIONAL COMPOSITE DESIGN

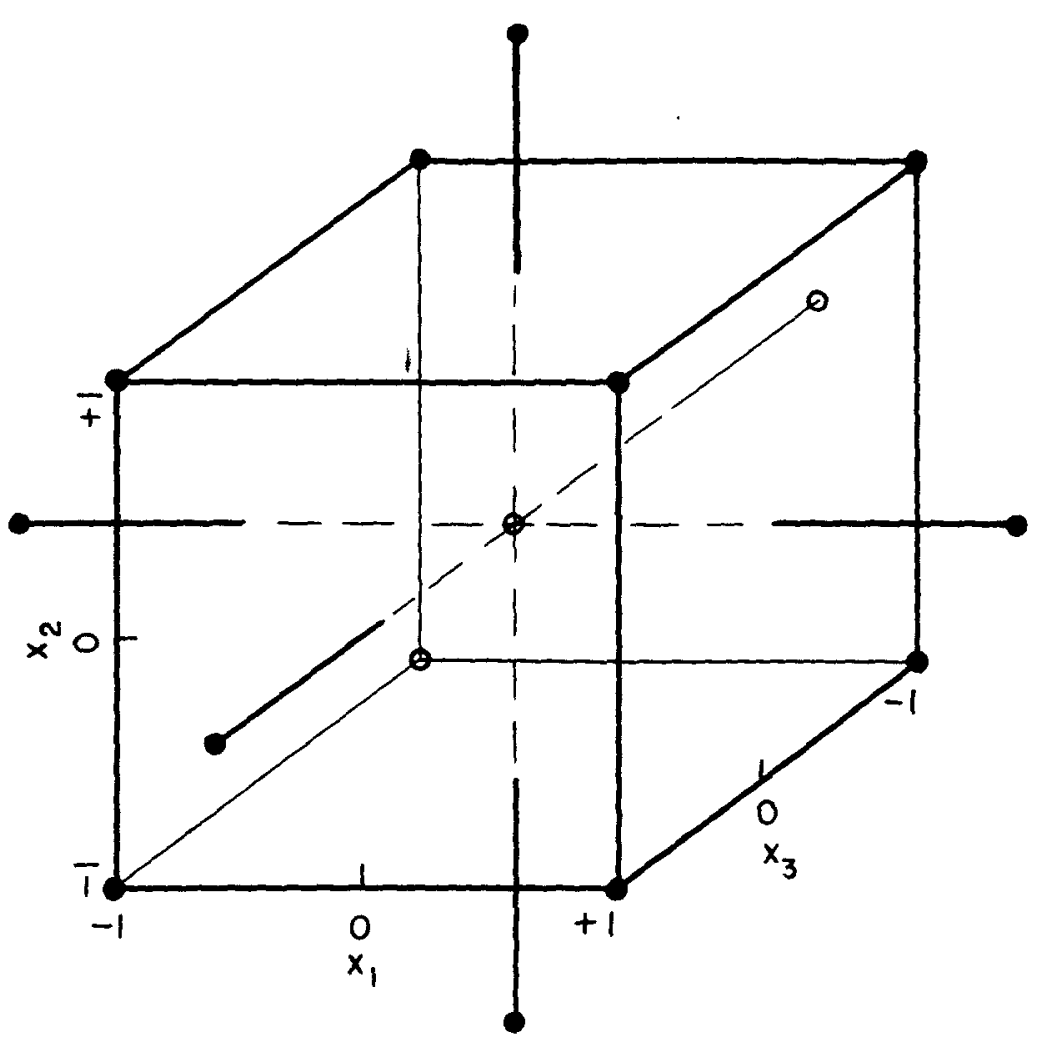

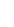




\section{7}

FIGURE 2

POINTS ADDED FOR THIRD ORDER

COMPOSITE DESIGN

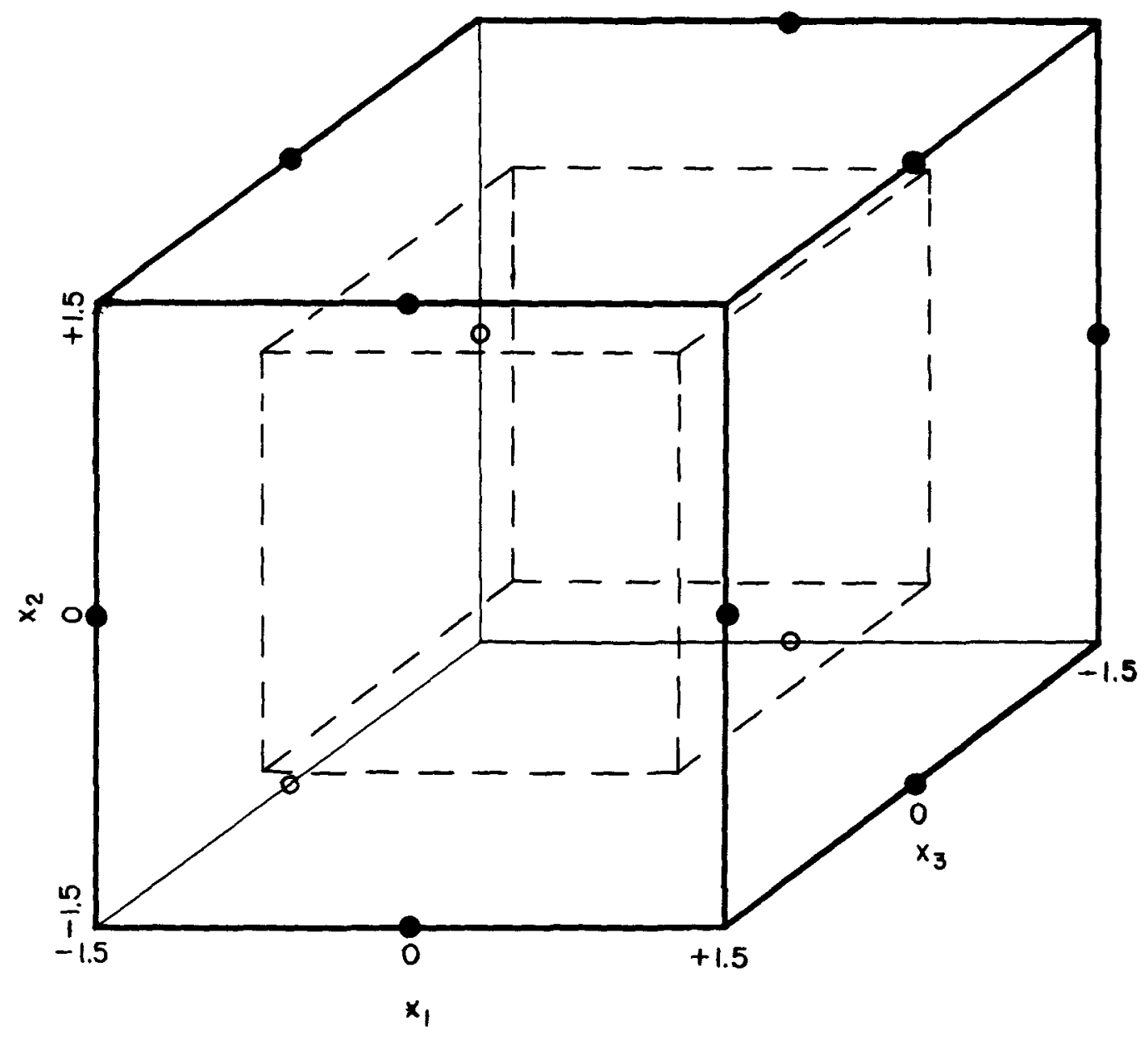

24.046 


\section{8}

up the third order composite design can be enumerated as

$I$ point at the center of the cube

8 points at the corners of a cube

6 points at the mid-points of the faces of a cube but moved out a distance $=\mathrm{a}$

12 points at the mid points of the edges of a cube, but moved out $a$ distance $=b$.
Sample coordinates

$0,0,0$

$1,1,1$

a, 0,0

$b, b, 0$

The second order composite design already used contained the center point, the eight corner points and the mid-face points with $a=2$. We note that when $a=b=1$, the design becomes the $3^{3}$ factorial. After a study of the relative magnitudes of the variances and co-variances of the estimated coefficients, the value of $b=1.5$ was chosen. The co-ordinates of this third order composite design, and the observed responses at each of the 27 points, is given in Table 4, sets 1 through 27. The predicted equation to obtinined by 1isst scuercs, is $y=337.9+86.2 x_{1}+20.5 x_{2}-50.1 x_{3}-58.1 x_{1}^{2}-22.3 x_{2}^{2}-9.1 x_{3}^{2}-32.5 x_{1} x_{2}-8.3 x_{1} x_{3}$

$$
\begin{gathered}
-10.4 x_{2} x_{3}-22.9 x_{1}{ }^{3}-1.4 x_{2}{ }^{3}+5.5 x_{3}{ }^{3}-11.9 x_{1}{ }^{2} x_{2}-15.5 x_{1} x_{2}{ }^{2}+14.5 x_{1}{ }^{2} x_{3} \\
-19.8 x_{1} x_{3}{ }^{2}+7.6 x_{2}{ }^{2} x_{3}-2.9 x_{2} x_{3}{ }^{2}-2.8 x_{1} x_{2} x_{3}
\end{gathered}
$$

The analysis of variance for this model is as indicated in Table 7.

\section{TABLE 7}

Analys is of Variance

Third Order Model, 27 Observations

Total Sum of Squaros

Reduction Due to Third Order Regression

Deviations from Regression

$\begin{array}{ccc}\text { Sums of Squares } & \text { Degrees of Freedom } & \text { Dean sq. } \\ 1,525,339 & 20 & -\end{array}$

$5,346 \quad 763.7$

We note that after taking observations at twelve more points, and fitting a higher order mathematical model, the estimated error, $(s=27.6)$, is only slightly reduced, and is still considered much larger than the expected 
49

experimental error roughly estimated to be at the most 15\%. To check whether the third order estimated equation was any better than a second order equation estimated from all 27 observations, the second order model was re-estimated yielding the regression coefficients found in Table 5. This estimated equation written out is

$$
\begin{aligned}
y= & 337.9+2.7 x_{1}+4.8 x_{2}-18.8 x_{3}-58.1 x_{1}^{2}-22.3 x_{2}^{2}-9.1 x_{3}^{2}-32.5 x_{1} x_{2}- \\
& 8.3 x_{1} x_{3}-10.4 x_{2} x_{3}
\end{aligned}
$$

Once again, forming an analysis of variance table, we get

\section{TABIE 8}

\begin{tabular}{|c|c|c|c|}
\hline & $\begin{array}{l}\text { Sums of } \\
\text { Squares }\end{array}$ & $\begin{array}{l}\text { Degrees of } \\
\text { Freedom }\end{array}$ & $\begin{array}{c}\text { Mean } \\
\text { Square } \\
\end{array}$ \\
\hline Total Sum of Squares & $1,525,339$ & 27 & \\
\hline $\begin{array}{l}\text { Reduction Due to Second Degree } \\
\text { Model }\end{array}$ & $1,507,289$ & 10 & \\
\hline $\begin{array}{l}\text { Deviations f:om Second Degree } \\
\text { Model }\end{array}$ & 18,050 & 17 & 1062 \\
\hline $\begin{array}{l}\text { Additional Reduction Due to } \\
\text { Third Order Effects }\end{array}$ & 12,704 & 10 & \\
\hline Deviation from Third Order Miodel & 5,346 & 7 & 763.7 \\
\hline
\end{tabular}

Comparison of Second and Third Order Equations, 27 Dbservations

It is apparent from the ratio of the mean squares (the F test in statistics) that the effect of the added cubic terms is negligible, and cannot actually be detected significantly different from the estimate of the residual error. The conclusion was then to accept the second order model as the best estimate of the unknown response function, and to look for other attributable causes for the large error.

The estimated second order model, equation 7 , is not, in its normal form, amenable to much interpretation. We note, however, that the equation is a 


\section{0}

general second order expression in three dimensions (for a constant $y$ ) and by taking advantage of the concepts of transiation and rotation of axes borrowed from Analytical Geometry, it is possible to reduce equation(7) to its standard or canonical form. The details of this technique are left to the text books. The equation, reduced to canonical form is

$$
y-350.673=-64.95 x_{1}^{2}-7.27 x_{2}^{2}-17.28 x_{3}^{3}
$$

where $x_{1}=.04 x_{1}-37\left(x_{2}-.40\right)+.03\left(x_{3}+1.26\right)$

$$
x_{2}=.93 x_{1}+.37\left(x_{2}-.40\right)+.10\left(x_{3}+1.26\right)
$$

and $x_{3}=.38 x_{1}-.86\left(x_{2}-.40\right)-.36\left(x_{3}+1.26\right)$

The new variates, $x_{3}, x_{2}$ and $x_{3}$ form the canonical axes, $i_{.}$, the major axes, of the fitted surface. We note now that if the response $y$ is set equal to some constant, say 300 , equation(8) is that of an ellipsoid and everywhere on the surface of this ellipsoid the response will equal 300. Another similar ellipsoid exists for $y=200$, external to the first, and similarly still another ellipsoid exists for $y=100$, external to the previous one. In fact ther, we may regard these concentric ellipsoids as contour surfaces in the space of $x_{1}$, $x_{2}$ and $x_{3}$. A drawing of these contour surfaces appears in Figure 1 , Part $I$.

Several observations can now be made concerning this figure. We notice along the $x_{3}$ axis, which is almost the canonical $x_{1}$ axis, the change in response for small changes in the flow ratio is very slight. Thus over limited ranges of $\mathrm{V}_{\mathrm{d}} / \mathrm{V}_{\mathrm{c}}$, particularly near the maximum point, one might conclude that $\nabla_{d} / v_{c}$ had little or no effect on the response. However, amplitude and frequency, although not acting independently of one another, do appear to profoundly affect the response over the ranges studied. 
On the basis of 27 sets of observations, a second order Taylor's Series approximation (equation (7) ) has been constructed representing the unknown response, throughput, as a function of pulse amplitude, pulse frequency and flow ratio. The inclusion of third order terms in the Taylor's Series approximation gave no improvement in estimating the unknown response that could not be attributed merely to error.

The predicted maximum point was found to lie well within the experimental region as did the extremes of small yield, indicating that the choice of ranges over which the variables were changed did include regions of great interest to the experimenters.

The estimate of error was much higher than expected in the first portion of the experiment and gave rise to a separate investigation to determine its cause. Randomly repeated experiments in the final stages of the experimental program indicated considerable success in reducing the experimental error. For the purposes of fitting the surface, a selected average, adjusted for temperature, was used for each point in the experimental design.

Thus, through the use of a statistically designed program of experiments it was possible to (I) estimate by means of a Taylor's Series expansion an unknown response function, (2) with this function to compare the relative importance of the independent variables studied, (3) check the estimated equation against another estimated equation of higher order, and (4) by investigating the sources of error increase the future accuracy of the experimental technique. 


\section{ADDENDUM $\quad 52$}

In this paper the concepts and methods of fitting equations by least squares, the analysis of variance, etc., are all discussed very briefly. For a fuller description of these subjects reference is made to the statistical texts listed in the bibliography. The paper, "On the Experimental Attainment of Optimum Conditions" by G. E. P. Box and K. B. Wilson [2], is the original work describing the development and use of composite designs and the concepts of surface fitting. This fundamental paper also includes several worked examples.

\section{NOMEMCLATURE}

$A=$ pulse amplitude, in inches of height in the installed plate assembly.

$C=$ column capacity calculated as $C=V_{d}+V_{c}$, cubic feet $/ \mathrm{ft} .^{2} / \mathrm{hr}$.

$F=$ pulse frequency, cycles per minute.

$V_{d}=$ input flow rate of the discontinuous phase, cubic feet $/ \mathrm{ft} .{ }^{2} / \mathrm{hr}$.

$V_{c}=$ input flow rate of the continuous phase, cubic feet $/ \mathrm{ft}^{2} / \mathrm{hr}$.

$\mathrm{V}_{\mathrm{d}} / \mathrm{V}_{\mathrm{c}}=$ dimensionless flow ratio of the input streams.

$x_{1}=$ amplitude expressed in standardized units.

$x_{2}=$ frequency expressed in standardized units.

$x_{3}=$ flow ratio expressed in standardized units.

$x_{1}, x_{2}, x_{3}=$ canonical variables for the fitted surface.

$\beta_{i}=$ true value of a coefficient in the mathematical model.

$b_{i}=$ estimates for $\beta_{i}{ }^{\circ}$

$\sigma^{2}=$ true error variance.

$s^{2}=$ estimate of the error variance.

$\mathrm{y}_{i}=$ recorded observations for the experimental variables, $A, F$, and $V_{d} / V_{c}$.

$\eta=$ true value of the capacity.

$\xi_{i}=$ true value of the experimental variables, $A, F$, and $V_{d} / N_{c}$.

$2 \therefore \quad 51$


1. Anderson, R. I, , and Bancroft, T. A., "Statistical Theory in Research," New York, Mc-Graw-Hill Book Company, 1952.

2. Box, G. E. P., and Wilson, K. E., Journal Royal Statistical Society, Series B, 13 (I), 1-45 (1951)

3. Box, G. E. P., Hader, R. J., and Hunter, J. S., Unive of N. C. Institute of Statistics, Mimeo Series No. Il.

4. Box, G. E. P., to be published, Biometrics, March 1954.

5. Cochran, W. G., and Cox, G. M., "Experimental Design," New York, John Wiley and Sons, 1950.

6. Dixon, I.. J., and Massey, F. J., Jr., "Introduction to Statistical Analysis," New York, McGraw-Hili Book Company, 1951.

7. Youden, W. J., "Statistical Methods for Chemists," New York, John Wiley and Sons, 1951. 


\section{APPENDIX 54}

This appendix contains mathematical details as follows:

A. Numerical Procedures,

Here an outline is given of the procedures whereby the coefficients of the assumed second degree fitting equation are calculated from the data. The procedures applicable to a 15 point composite design and also a 27 point composite design are covered. If there is need to fit a third order equation, consult a statistician.

B. Canonical Reduction in Two Dimensions.

Details are presented of a procedure which simplifies the calculation of the contours of a second degree fitted equation for cross-sections of the space-model represented by this equation. C. Sets of Graphs.

Here are presented $\mathbb{L}_{4}$ graphs which exhibit the capacity contours of an orderly sequence of cross-sections of the final second degree equation fitted to the trichloroethylene-water data, The graphs repeat themselves, one set being plotted in statistical units, the other set being plotted in measured units. Some of these graphs are repetitions of some of those presented in the body of the report, hence the number sequence for the graphs is irregular.

$\begin{array}{cccc}\begin{array}{c}\text { Figure } \\ \text { Number }\end{array} & \begin{array}{c}\text { Plotting } \\ \text { Units }\end{array} & & \text { Position of Cross-Section } \\ 2 & \text { Statistical } & x_{1}=0 & A=0.784 \\ 3 & \text { Statistical } & x_{2}=0 & F=60 \\ 12 & \text { Statistical } & x_{s}=-2 & V_{d} / V_{c}=0.333 \\ 4 & \text { Statistical } & x_{3}=-1 & V_{d} / V_{c}=0.574 \\ 13 & \text { Statistical } & x_{3}=0 & V_{d} / v_{c}=1.000 \\ 14 & \text { Statistical } & x_{3}=1 & V_{d} / V_{c}=1.732\end{array}$
9.53 


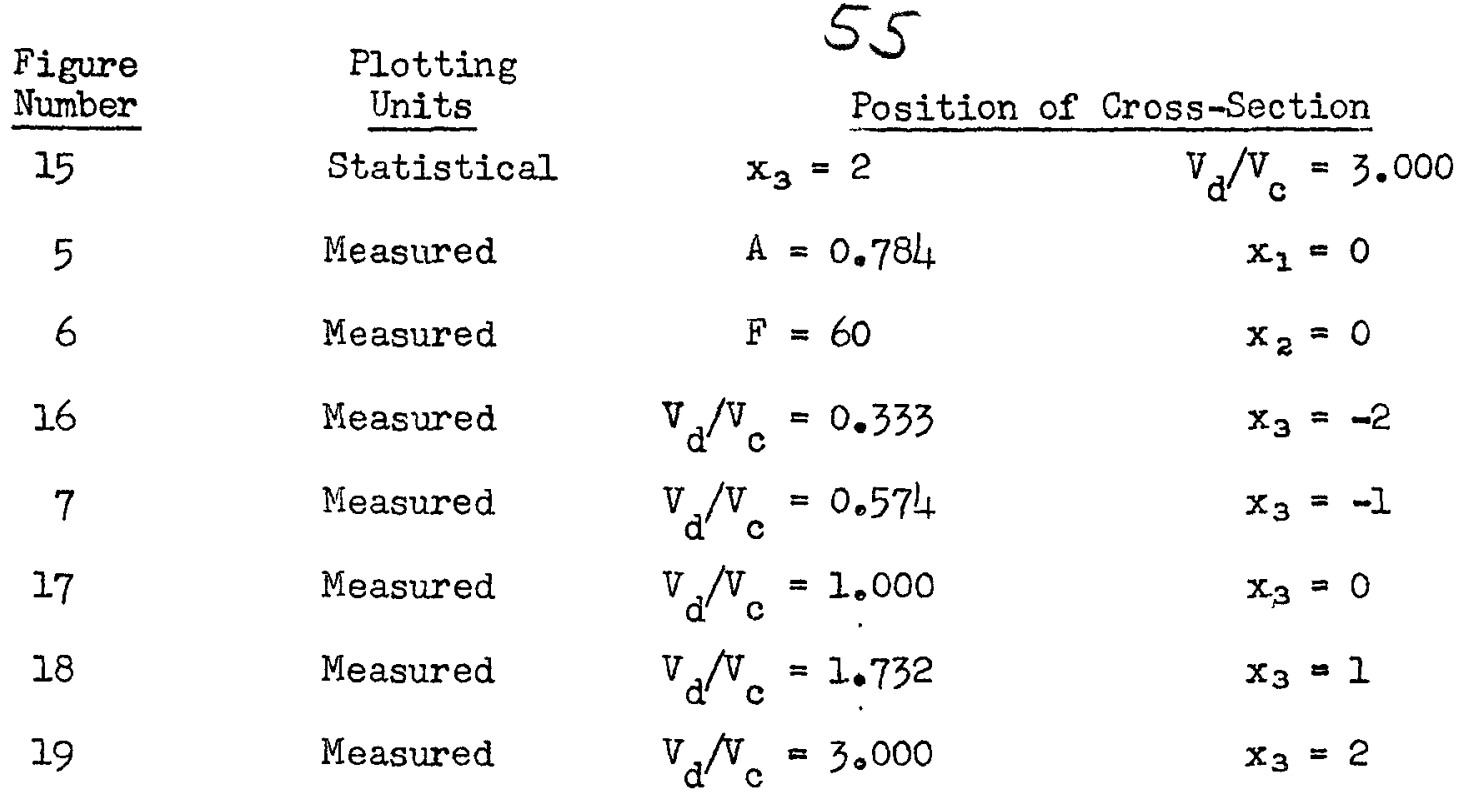

D. Tables of Carculated Capacity Contours.

Tables are provided as follows giving the calculated capacity contours derived from the finally selected equation, for certain cross-sectioning planes which can be readily identified by reference to Figure 1, Part I. The tables provide the information upon which the graphs of section $C$ are based.

Table Designation

A

B

C

D

$\mathrm{E}$

F

G

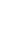

B

C

D

$E$

F

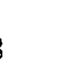

G

The units involved are as follows:

$$
\begin{aligned}
A & =\text { inches. } \\
F & =\text { cycles per minute. } \\
\mathrm{V}_{d} / \mathrm{V}_{c} & =\text { dimensionless flow ratio. }
\end{aligned}
$$

Position of Cross-Sectioning Plane

$$
\begin{array}{lrl}
\mathrm{x}_{1}=0 & A=0.784 \\
\mathrm{x}_{2}=0 & F=60 \\
\mathrm{x}_{3}=2 & V_{d} / V_{c}=3.000 \\
x_{3}=1 & V_{d} / V_{c}=1.732 \\
x_{3}=0 & V_{d} / V_{c}=1.000 \\
x_{3}=-1 & V_{d} / V_{c}=0.574 \\
x_{3}=-2 & V_{d} / V_{c}=0.333
\end{array}
$$

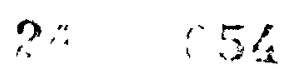


A. Numerical Procedures

\section{6}

The object of this section will be to describe the procedure required for going from the observed responses to the formation of the fitted response surface. In the second part of the paper three response surfaces were fitted:

A second degree surface based on 15 observations

A third degree surface based on 27 observations

A second degree surface based on 27 observations

The calculations required to obtain the coefficients for the above surfaces (I) and (3) will be outlined. The analysis of variance will directly follow each fitted equation. The reduction to canonical form of the fitted second order surface based on 27 observations will be described. An identical procedure would reduce equation (I) to canonical form. No effort will be made here to obtain the coefficients of the third order equation representing surface (2)。 These calculations are directiy analogous to these required for equations (1) and (3), but are so cumbersome as to reouire too much space.

The purpose of the experimentation and analysis was to explore an unknown response function

$$
\eta=f\left(\xi_{1}, \xi_{2}, \xi_{3}\right)
$$

which relates the flooding capacity $\eta_{\text {to }}$ the ampititure $\xi_{1}$, frequency $\xi_{2}$ and flow ratio $\xi_{3}$ of a pulse column. It was assumed that the unknown function was continuous and could be represented by its Taylor's Series. Furthermore, in the case of surface (1) and later for surface (3) it was decided that a valuable approximation to the unknown function would be given by all the terms in a Taylor's Series expansion of order two and less. Thus the mathematical model became

$$
i=\beta_{0}+\beta_{1} x_{1}+\beta_{2} x_{2}+\beta_{3} x_{3}+\beta_{11} x_{1}{ }^{2}+\beta_{22} x_{2}^{2}+\beta_{33} x_{3}^{2}+\beta_{12} x_{1} x_{2}+\beta_{13} x_{1} x_{3}+\beta_{23} x_{2} x_{3}
$$

where $\eta$ is the true response, the $B^{\prime}$ s are unknown coefficients, and the $x^{\prime} s$

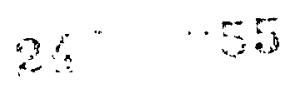


are coded values of the independent variables. This equation may be visualized as that of the best fitting second degree surface to the unknown function. However, in actual practice the recorded response $y$ at any particular combination of the factors will not equal $\eta$, but in repeated trials will vary around 7 due to some error $\varepsilon$ assumed to have a mean of zero and a variance $i^{2}$. Then the mathematical model with respect to the recorded values becomes

$$
y=\beta_{0}+\beta_{1} x_{1}+\beta_{2} x_{2}+\beta_{1} x_{3}+\beta_{11} x_{1}^{2}+\beta_{22} x_{2}^{2}+\beta_{33} x_{3}^{2}+\beta_{22} x_{1} x_{2}+\beta_{12} x_{1} x_{3}+\beta_{23} x_{1} x_{3}+\varepsilon
$$

Our object now is to secure from the data the best estimates of the unknown coefficients in equation (5), that is, the $\beta^{\prime}$. The purpose of the experimental designs suggested by the statisticians was to provide the experimenter with a pattern of experimental points so selected as to provide good estimates of these coefficients.

Using matrix notation we may rewrite equation (3) as

$$
\underline{Y}=\underline{X \beta}+\underline{\varepsilon}
$$

where $\underline{I}$ is a $N \times I$ column matrix of the recorded responses,

$X$ is an $\mathrm{N} \times \mathrm{L}$ matrix of the independent variables (the independent variables in this mathematical model are $x_{0}$, the linear effects $x_{i}$, the quarratic $x_{i}^{2}$, and the interaction effects $\left.x_{i} x_{j}\right)$,

$\underline{B}$ is a $I \times I$ matrix of the regression coefficients and

$\varepsilon$ is an $\mathrm{N} \times 1$ column matrix of errors (one error asscciated with each observation, and all essumed to be normally and independently distributed about a mean equal of zero with a variance equal to $\sigma^{2}$ ). To fit a second degree surface to the 15 observations of equation (I) this abbreviated matrix notation written out would have the appearance 


\begin{tabular}{|c|c|c|c|c|c|c|c|c|c|c|c|c|c|c|c|c|}
\hline & & $x_{0}$ & & $x_{I}$ & $x_{2}$ & $x_{3}$ & $x_{1}{ }^{2}$ & $x_{2}{ }^{2}$ & $x_{3}{ }^{2}$ & $x_{1} x_{2}$ & $x_{1} x_{3}$ & $x_{2} x_{3}$ & & & & \\
\hline $770^{-}$ & & & 1 & & & -- & & & & & & & & & & $\cdots$ \\
\hline $\begin{array}{l}179 \\
738\end{array}$ & & 1 & & -1 & -1 & -1 & 1 & 1 & 1 & 1 & 1 & 1 & & $\beta_{0}$ & & $\varepsilon_{1}$ \\
\hline 338 & & 1 & 1 & 1 & -1 & -1 & 1 & 1 & 1 & -1 & -1 & 1 & & $\beta_{1}$ & & $\varepsilon_{?}^{\perp}$ \\
\hline 280 & 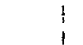 & 1 & & -1 & 1 & -1 & 1 & 1 & 1 & -1 & 1 & -1 & & $\beta_{2}$ & & $\varepsilon_{3}^{c}$ \\
\hline 300 & 1 & 1 & 1 & 1 & 1 & -1 & 1 & 1 & 1 & 1 & -1 & -1 & & $\beta_{3}$ & & $\varepsilon$ \\
\hline 185 & ' & 1 & $!$ & -1 & -1 & 1 & 1 & 1 & 1 & 1 & -1 & -1 & & $\beta_{11}$ & & \\
\hline $288+$ & & 1 & 1 & 1 & -1 & 1 & 1 & 1 & 1 & -1 & 1 & -1 & & $\beta_{22}$ & + & ${ }_{6}^{2}$ \\
\hline $\begin{array}{l}251 \\
193\end{array}$ & $=$, & $\begin{array}{l}1 \\
1\end{array}$ & $\begin{array}{l}1 \\
1\end{array}$ & $\begin{array}{r}-1 \\
1\end{array}$ & $\frac{1}{1}$ & $\begin{array}{l}1 \\
1\end{array}$ & $\frac{1}{1}$ & $\begin{array}{l}1 \\
1\end{array}$ & $\frac{1}{1}$ & $\begin{array}{r}-1 \\
1\end{array}$ & $-\frac{1}{1}$ & $\begin{array}{l}1 \\
1\end{array}$ & I & $\begin{array}{l}B_{33} \\
\beta_{12}\end{array}$ & & $\varepsilon_{0}^{\varepsilon_{0}}$ \\
\hline 322 & $!$ & $\bar{I}$ & 1 & 0 & $\overline{0}$ & 0 & 0 & $\overline{0}$ & 0 & 0 & $\overrightarrow{0}$ & 0 & & $; \beta_{22}$ & & $\varepsilon_{0}$ \\
\hline 134 & ' & $I$ & 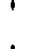 & -2 & 0 & 0 & 4 & 0 & 0 & 0 & 0 & 0 & & $B_{23}$ & & \\
\hline 113 & 1 & 1 & 1 & 2 & 0 & 0 & 4 & 0 & 0 & 0 & 0 & 0 & i & & & \\
\hline 211 & $\vdots$ & 1 & 1 & 0 & -2 & 0 & 0 & 4 & 0 & 0 & 0 & 0 & & & & \\
\hline 270 & $i$ & 1 & 1 & 0 & 2 & 0 & 0 & 4 & 0 & 0 & 0 & 0 & 1 & & & \\
\hline 380 & 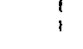 & 1 & i & 0 & 0 & -2 & 0 & 0 & 4 & 0 & 0 & 0 & & & & $\varepsilon_{7}^{\perp 3}$ \\
\hline 267 & 1 & 1 & 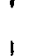 & 0 & 0 & 2 & 0 & 0 & 4 & 0 & 0 & 0 & & & & \\
\hline$I$ & & & & & & $\underline{X}$ & & & & & & & & $\underline{\beta}$ & & $\varepsilon$ \\
\hline
\end{tabular}

The coordinates of the 15 points making up the second order composite design are given by the design matrix $\underline{D}$ which is outined with dotted brackets in the matrix of independent variables $\underline{X}$ written above, Now this array of design points is so chosen as to provide unbiased estimates of the regression coefficients given by equation (6).

$$
\underline{B}=(\underline{X} \cdot \underline{X})^{-1} \underline{X} \underline{Y} \underline{Y}
$$

where $\underline{B}$ is the $I \times I$ coiumn vector of the estimates of the $\beta: s$. The matrix $(\underline{X}: \underline{X})^{-1}$ is the inverse of the product matrix $\underline{X}$, In addition, the variances and covariances of these estimates is given by $C^{-1} g^{2}$ where $C=X$ I $X$ is the sums of squares and crossproducts of the independent variables. Finally an unbiased estimate of $(N-I){ }^{2}$ is given by the residual sum of squares,

$$
(\mathrm{N}-\mathrm{L})_{\mathrm{S}}^{2}=\underline{Y} \underline{Y}-\mathrm{B}^{\prime} \mathbf{X Y}^{\prime} \text {. }
$$

We now proceed with the mechanics of getting the estimate of the g's.

Solving for $\underline{B}$ using equation (5) we must first form the product matrix $\underline{\mathrm{C}}=\underline{\mathrm{X}}: \underline{\mathrm{X}}$ composed of independent variables, For the 15 point composite design used for equation ( 1 ) this matrix is 


$$
\begin{aligned}
& 59 \\
& \begin{array}{llllllllll}
x_{0} & x_{1} & x_{2} & x_{3} & x_{1}{ }^{2} & x_{2}^{2} & x_{3}{ }^{2} & x_{1} x_{2} & x_{1} x_{3} & x_{2} x_{3}
\end{array} \\
& 15 \\
& \begin{array}{rrrrrrrrrr}
15 & 0 & 0 & 0 & 16 & 16 & 16 & 0 & 0 & 0 \\
0 & 16 & 0 & 0 & 0 & 0 & 0 & 0 & 0 & 0 \\
0 & 0 & 16 & 0 & 0 & 0 & 0 & 0 & 0 & 0
\end{array}
\end{aligned}
$$

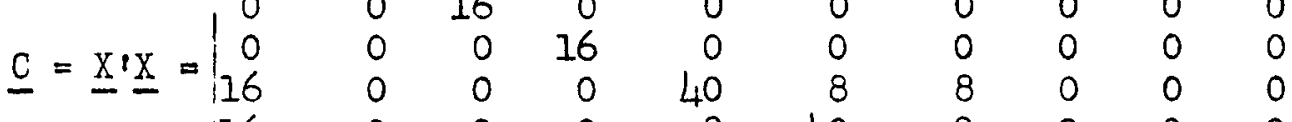

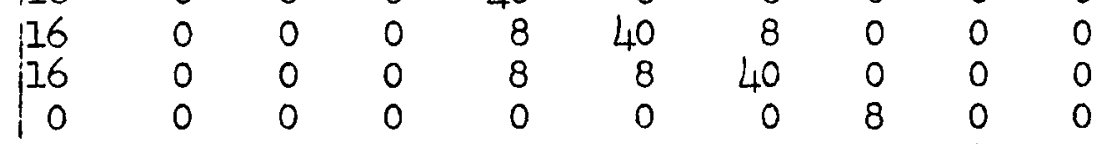

$$
\begin{aligned}
& \begin{array}{llllllllll}
0 & 0 & 0 & 0 & 0 & 0 & 0 & 8 & 0 & 0 \\
0 & 0 & 0 & 0 & 0 & 0 & 0 & 0 & 0 & 8
\end{array}
\end{aligned}
$$

The inverse of this matrix is

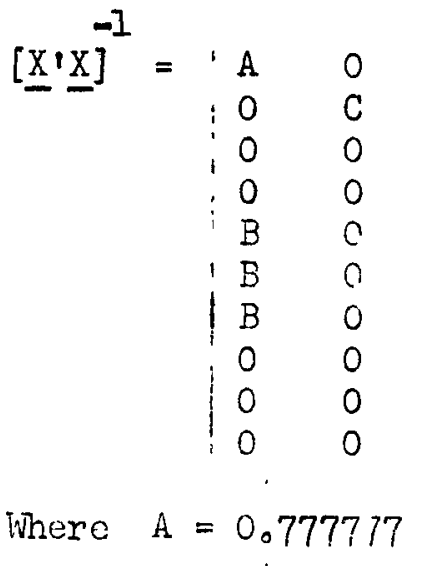

$$
\begin{aligned}
& B=0.222222 \\
& E=0.059028 \\
& C=0.062500 \\
& F=0,125000
\end{aligned}
$$

This inverse matrix can be used with all central composite designs whose coordinates are given by the design matrix $\underline{D}$ in (5).

The noxt step in sclving for the estimates of the $\beta^{\text {'s }}$ is to compute the $X^{\prime} Y$ matrix. The $X$ matr $I x$ and $Y$ matrix are given in equation (5). To form $\underline{X} \underline{Y}$ we take the elements in each of the column of $X$ and multiply them by the elements $i_{1} Y_{n}$. The ten columns in $X$ will therefore generate 10 values which form the $\underline{X} \underline{Y}$ matrix。 Trus

$$
\underline{X} \underline{I}=\begin{array}{r}
3711 \\
182 \\
152 \\
-406 \\
3002 \\
3938 \\
4602 ! \\
-300 \\
-134 \\
-92
\end{array}
$$


As indicated in equation (6) the estimates of the coefficients are given by multiplying the matrices from equations (9) and (10), i.e., forming the matrix product $[\underline{X} \cdot \underline{X}]^{-1} \underline{X} \underline{Y}$. To do this we once again multiply the elements in the first column of $[\underline{X} \cdot \underline{X}]^{-1}$ by those of $\underline{X} \underline{Y}_{0}$. The ten values obtained by these multiplications form the $\underline{B}$ matrix, the matrix of the estimated coetficient. Thus

$$
\underline{B}=\quad \begin{array}{r}
321.444 \\
11.375 \\
9.500 \\
-25.375 \\
-49.556 \\
-20.306 \\
0.444 \\
-37.500 \\
-16.750 \\
-11.750
\end{array}
$$

Therefore the estimated equation (rounded to one decinal place) is

$$
\begin{gathered}
y=321.4+11.4 x_{1}+9.5 x_{2}-25.4 x_{3}-49.6 x_{1}^{2}-20.3 x_{2}^{2}+0.4 x_{3}^{2}-37.5 x_{1} x_{2} \\
-16.8 x_{1} x_{3}-11.8 x_{2} x_{3}
\end{gathered}
$$

To perform the analysis of variance shown in Table 6 of Part II we first calculate the sum of squares of the observation, thus $\Sigma y^{2}=999623.0$. To calculate the reduction due to regression we form the matrix product EIXIY, that is, take each element of the matrix B. and multiply it by its corresponding element in $[\underline{X}, \underline{Y}]$. Thus $\underline{B} \times \underline{X} \cdot \underline{Y}=994558.8$. The remainder of the analysis is shown in Table 6.

The coefficients of the third order model indicated in equation (2) are

$$
\begin{array}{r}
y=\beta_{0}+\beta_{1} x_{1}+\beta_{2} x_{2}+\beta_{3} x_{3}+\beta_{11} x_{1}^{2}+\beta_{22} x_{2}^{2}+\beta_{33} x_{3}^{2}+\beta_{12} x_{1} x_{2}+\beta_{13} x_{1} x_{3}+\beta_{23} x_{2} x_{3}+\beta_{13} x_{1}^{3} \\
+\beta_{222} x_{2}^{3}+\beta_{333} x_{3}^{3}+\beta_{112} x_{1}^{2} x_{2}+\beta_{122} x_{1} x_{2}^{2}+\beta_{123} x_{1}^{2} x_{3}+\beta_{133} x_{1} x_{3}^{2}+\beta_{223} x_{2}^{2} x_{3}+\beta_{233} x_{2} x_{3}^{2}+\beta_{123} x_{1} x_{2} x_{3}+\varepsilon
\end{array}
$$
The calculations required to estimate the coefficients in this model, although directly analogous to those of equations ( 1 ) and (3) are omitted here. The matrices associated with the calculations are quite large and space limitations prohibit listing them. 


\section{1}

To fit a second degree equation to the 27 obsorvations we start with the same mathematical model in equation (5). The $X$ matrix, and matrix of observation $\underline{Y}$ are

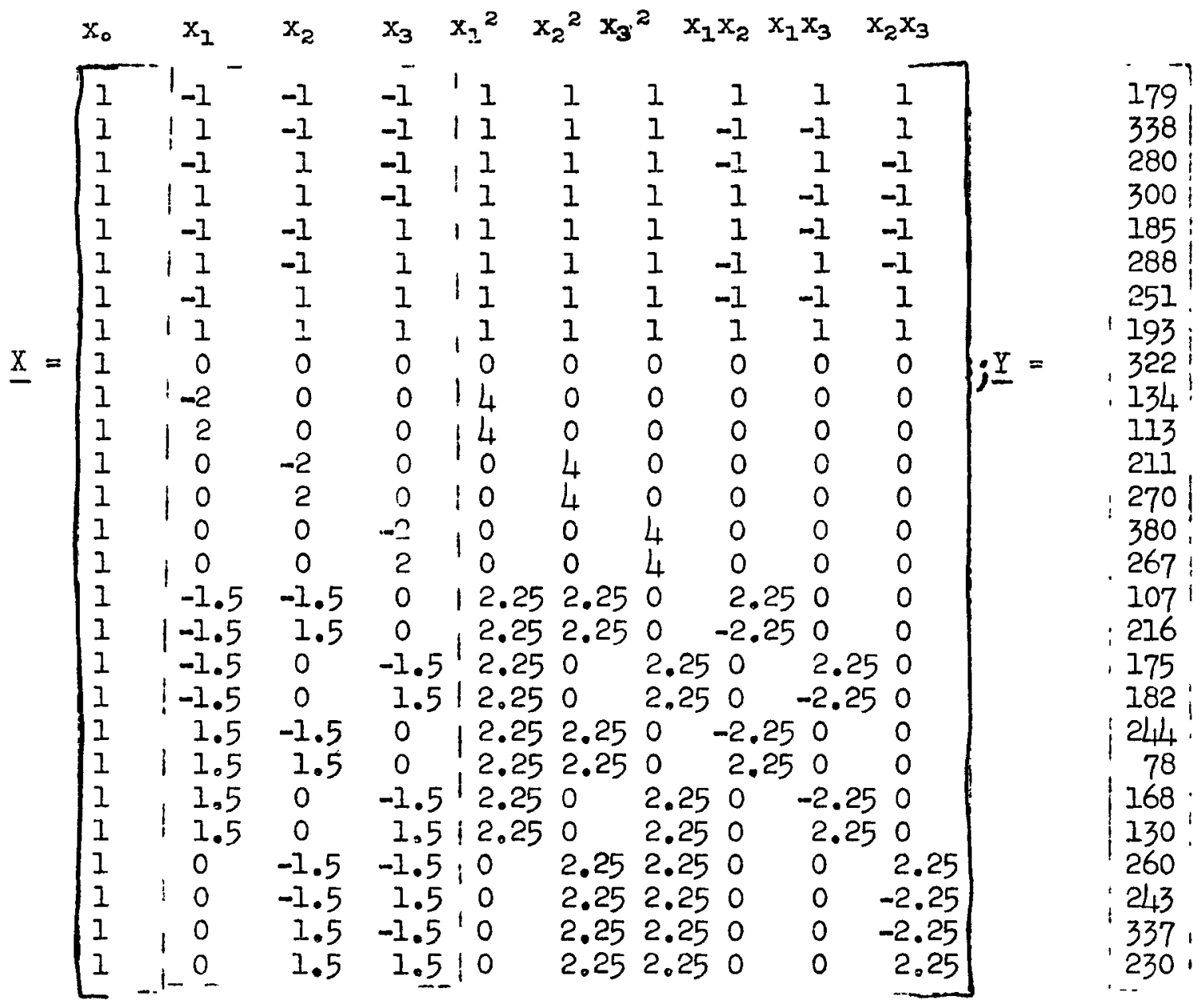

The design matrix, giving the coordinates of the 27 points making up the experimental design is indicated once again by the dotted brackets in the matrix. The inverse matrix $\left[\underline{X}^{\prime} \underline{X}\right]^{-1}$ is of the same form as that shown in equation (9) with the values

$$
\begin{array}{ll}
A=0.593069 & D=0.051720 \\
B=-0.247185 & E=0.032581 \\
C=0.029412 & F=0.035398
\end{array}
$$


The matrix $\underline{X} \underline{Y}$, and the calculated matrix of coefficients $\underline{B}$ are

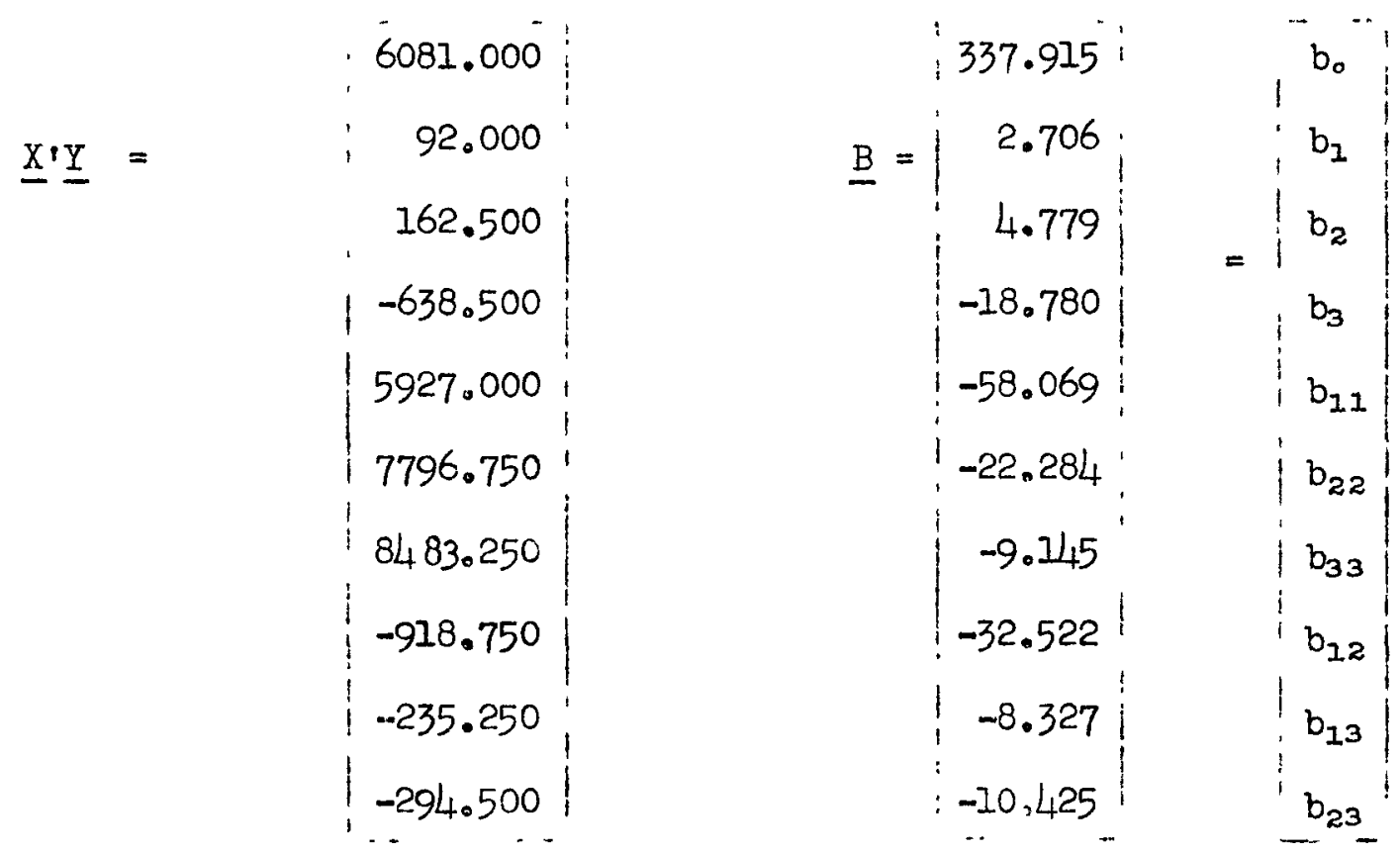

Therefore the fitted second degree equation, now based upor 27 observations is (rounded off to one figure after the decimal):

$$
y=337.9+2.7 x_{1}+4.8 x_{2}-18.8 x_{3}-58.1 x_{1}^{2}-22.3 x_{2}^{2}-9.1 x_{3}^{2}-32.5 x_{1} x_{2}-8.3 x_{1} x_{3}-10.4 x_{3}
$$

For the analysis of variance for this second order equation we calculate the total sum of squares $\Sigma y^{2}=1,525,339$. The reduction due to regression $\underline{B} \cdot \underline{X}: \underline{Y}=1,507.289$. 


$$
63
$$

\section{B. Canonical Reduction in Two Dimensions}

The purpose here is to demonstrate a procedure which simplifies the calculation of the contours for any given plane section, obtainable from a second order equation fitted to the experimental data. Incidentally, when the fitted equation is of the third order, no simplification in calculation procedure is practicable. Ordinarily the calculation task is long and tedious because the general second order equation contains cross-products between the variables which, towards the end of a chain of steps, makes it necessary to solve a complete quadratic equation, such as $0=a+b x+c x^{2}$, for each point needed at a given capacity. This last solution is the tedious step. However, by rotation and translation of the axes of the contour figures, it is possible to reduce the pertinent equations to their canonical form, in which there are no cross-product terms. This canonical reduction leads eventually to equations of the form $O=a+c x^{2}$, which are much more rapidly solved for specific values.

The entire procedure is demonstrated by this example of the calculation of the contours when $x_{3}=-1,\left(v_{d} / v_{c}=0.574\right)$, assuming the second degree equation on page 12, which is as follows:

$$
\begin{gathered}
C=337.9+2.706 x_{1}+4.779 x_{2}-18.780 x_{3}-58.069 x_{1}^{2}-22.284 x_{2}^{2}-9.145 x_{3}^{2} \\
-32.522 x_{1} x_{2}-8.327 x_{1} x_{3}-10.425 x_{2} x_{3}
\end{gathered}
$$

Note the presence of the cross-product terms, such as $x_{1} x_{2}$. Let $x_{3}=-I_{f}\left(V_{d} / V_{c}=\right.$ $0.574)$. Then,

$$
C=58.069 x_{1}^{2}-22.284 x_{2}^{2}-32.522 x_{1} x_{2}+11.033 x_{1}+15.204 x_{2}+347.55
$$

Which is in the form,

$$
0=A x_{1}^{2}+B x_{1} x_{2}+C x_{2}^{2}+D x_{1}+E x_{2}+F-C
$$

First, we rotate the axes to eliminate the cross-products terms. The rotation procedure and the subsequent translation procedure are conventional tasks in analytical geometry. The background for these operations can be 
64

found in Chapter VIII, Analytical Geometry, by W. A. WiIson and J. I. Tracey, Heath and Company, 1937. The following transformation is used:

$$
\begin{aligned}
& \mathrm{x}_{1}=\cos \theta \mathrm{y}_{1}-\sin 6 \mathrm{y}_{2} \\
& \mathrm{x}_{2}=\sin \theta \mathrm{y}_{1}+\cos \theta \mathrm{y}_{2}
\end{aligned}
$$

where $\Theta=$ the angle through which the original axes must be rotated to match the canonical axes of the original conic section. The angle $\Theta$ must always be positive.

This transformation assumes that $x_{1}$ is along the abscissa, and $x_{2}$ is along the ordinate. The geometry of the situation required that

$$
\tan 2 \theta=\frac{B}{A-C}
$$

from which $\tan 2 \theta=\frac{-32.522}{-58.069+22.284}=0.9088$

and $\epsilon=21^{\circ} 8^{\prime}, \sin \theta=0.3605, \cos \theta=0.9327$

Making the changes indicated, the equation reduces as follows

$$
C=347.55-64.345 \mathrm{y}_{1}^{2}-16.000 \mathrm{y}_{2}^{2}+15.772 \mathrm{y}_{1}+10.203 \mathrm{y}_{2}
$$

Note that all cross products between variables have disappeared.

The second step is to translate the axes, a procedure which requires the completing of the squares.

$$
c-347.55=-64.345\left(y_{1}^{2}-0.245 y_{1}+0.015\right)-16.000\left(y_{z}^{2}-0.638 y_{2}+0.101\right)+2.58
$$

Or, $c-350.13=-64.345\left(y_{1}-0.1225\right)^{2}-16.000\left(y_{2}-0.319\right)^{2}$

We translate the axes by these substitutions.

$$
\begin{aligned}
& Y_{1}=y_{2}-0.1225 \\
& Y_{2}=y_{2}-0.318
\end{aligned}
$$

Substituting, $350.13-\mathrm{C}=+64.345 \mathrm{Y}_{1}^{2}+16.000 \mathrm{Y}_{2}^{2}$

The equation is now in its canonical form,

We will calculate a point on the $C=300$ contour.

Substituting $\mathrm{C}=300$,

$$
50.13=64.345 \mathrm{Y}_{1}^{2}+16.000 \mathrm{Y}_{2}^{2}
$$


Assume $Y_{1}=0,16.000 \mathrm{Y}_{2}^{2}=50.13$

$$
Y_{2}= \pm 1.769
$$

Now, referring back to our transformation equations,

$$
\begin{aligned}
& \mathrm{x}_{1}=\cos \theta \mathrm{y}_{1}-\sin \theta \mathrm{y}_{2} \text { and } \mathrm{Y}_{1}=\mathrm{y}_{1}-0.1225 \\
& \mathrm{x}_{2}=\sin t \mathrm{y}_{1}+\cos \theta \mathrm{y}_{2} \quad \mathrm{y}_{2}=\mathrm{y}_{2}-0.318
\end{aligned}
$$

Je can rearrange to get

$$
\begin{aligned}
& x_{1}=0.9327 Y_{1}-0.3605 Y_{2}-0.0004 \\
& x_{2}=0.3605 Y_{1}+0.9327 Y_{2}+0.34 I
\end{aligned}
$$

When $Y_{1}=0$ and $Y_{2}=+1.769$

then $x_{1}=0.6381, x_{2}=1.991$

When $Y_{1}=0$ and $Y_{2}=-1.769$

then $x_{1}=0.6373, x_{2}=-1.309$

From the $x_{1}$ and $x_{2}$ values, $A$ and $F$ can readily be calculated by the conversion equations shown on page 7 of the report. 


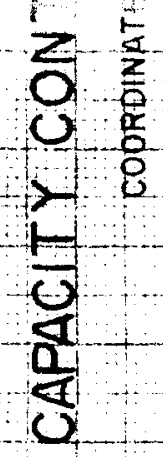

$$
+
$$

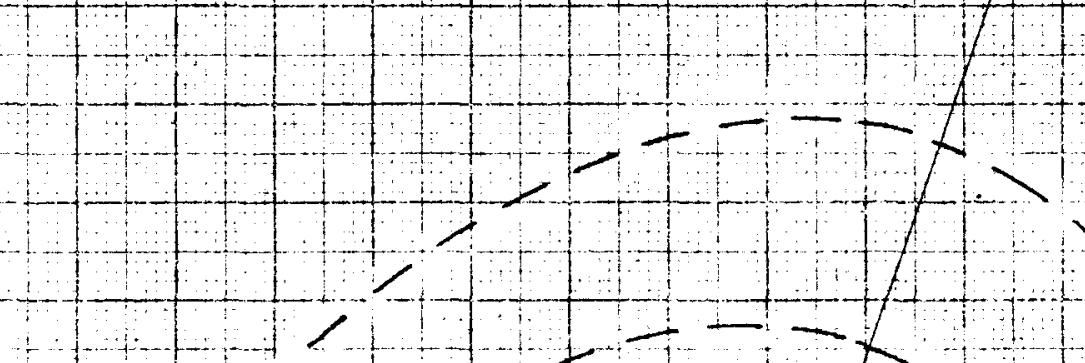

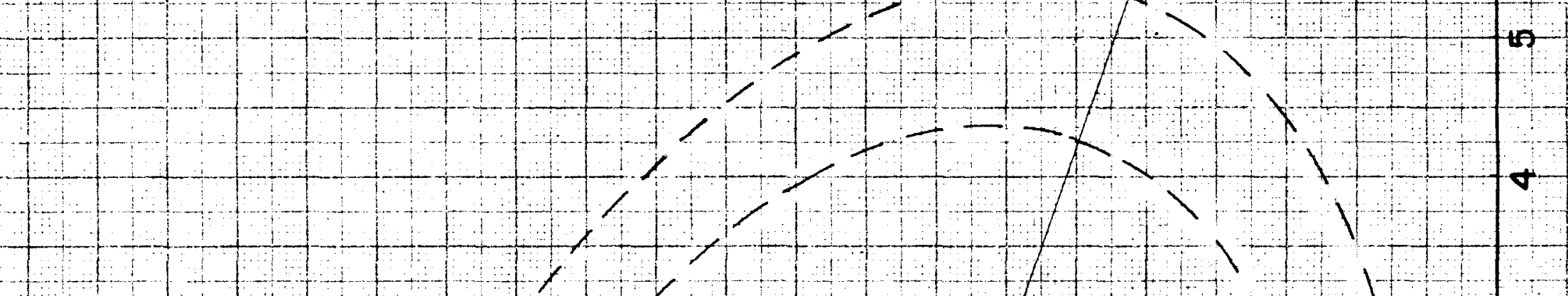
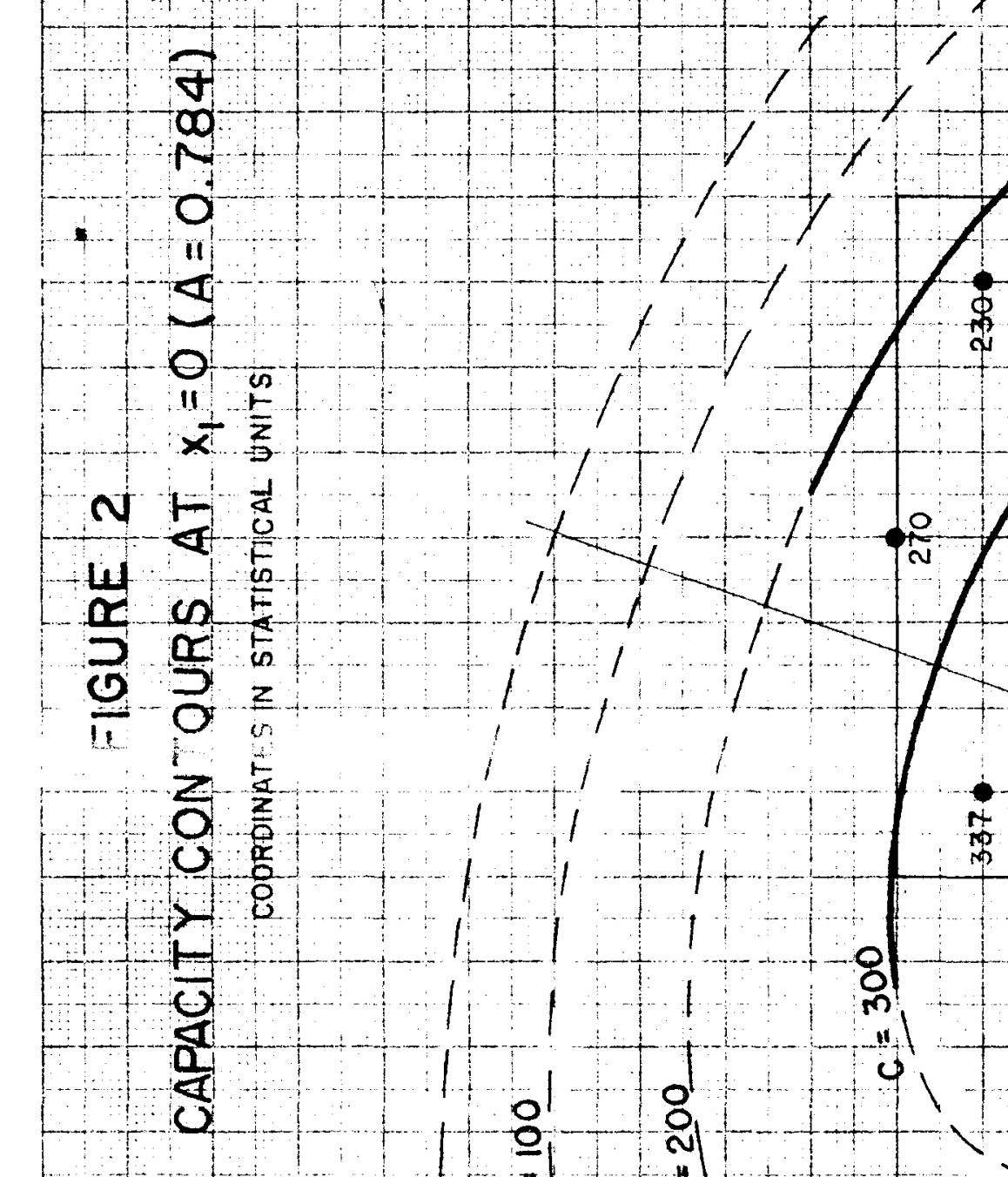

$\begin{array}{ccc}1 & 1 \\ 1 & 0 \\ 0 & 0 \\ 0 & 0 & 0 \\ 0 & 1 & 0\end{array}$

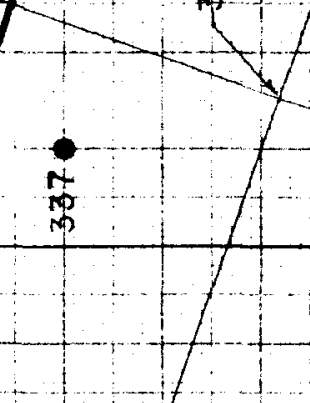

$+1+1+1$
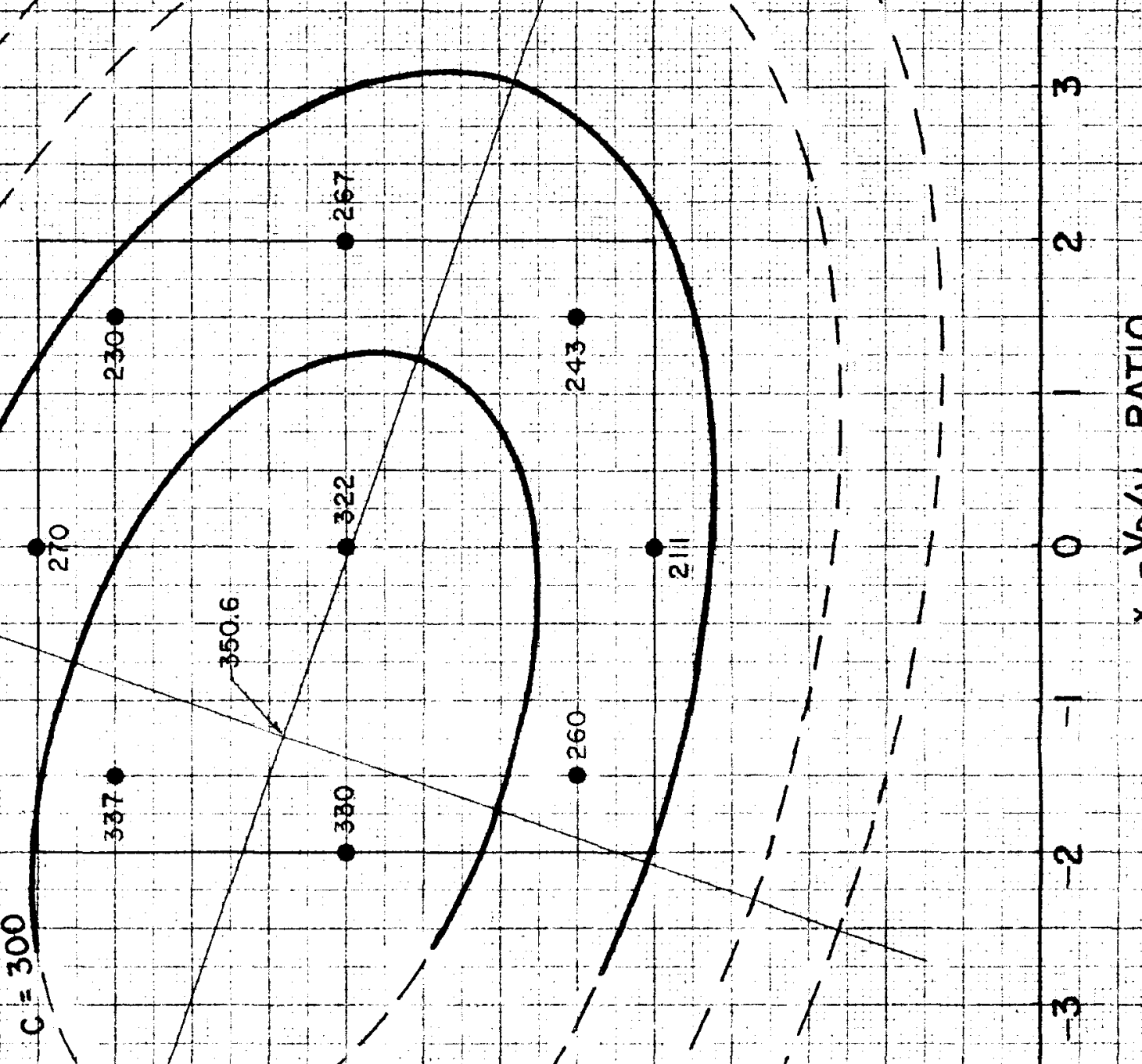

$\int \frac{1}{1}+1 / 1$ or

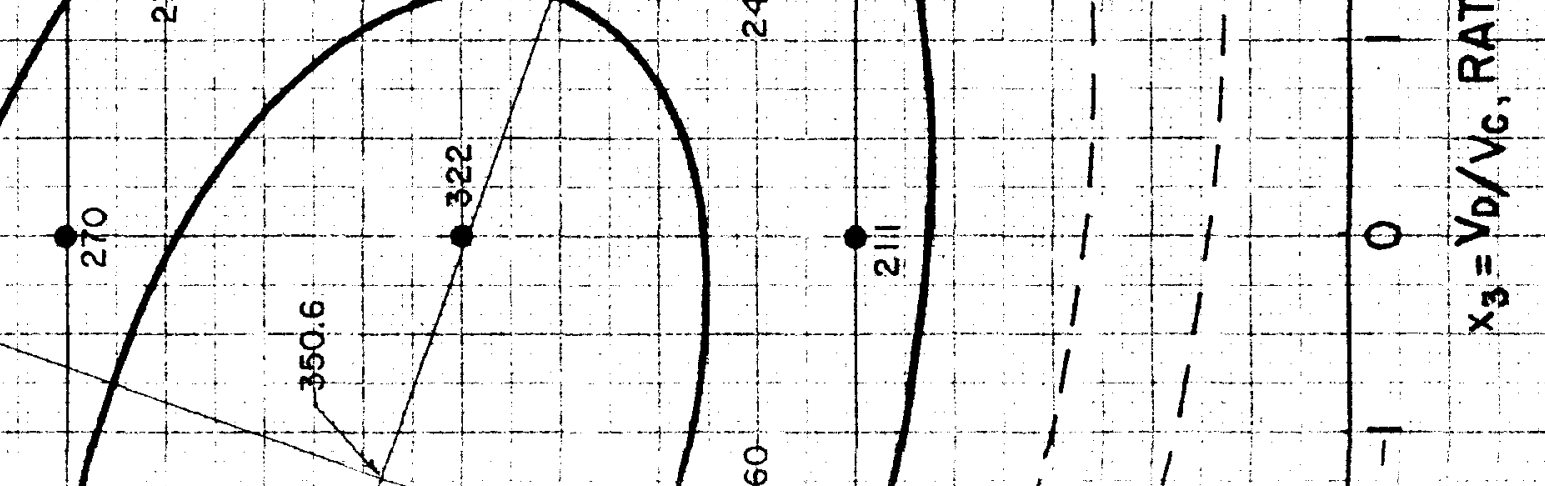

$+1-2$

의 


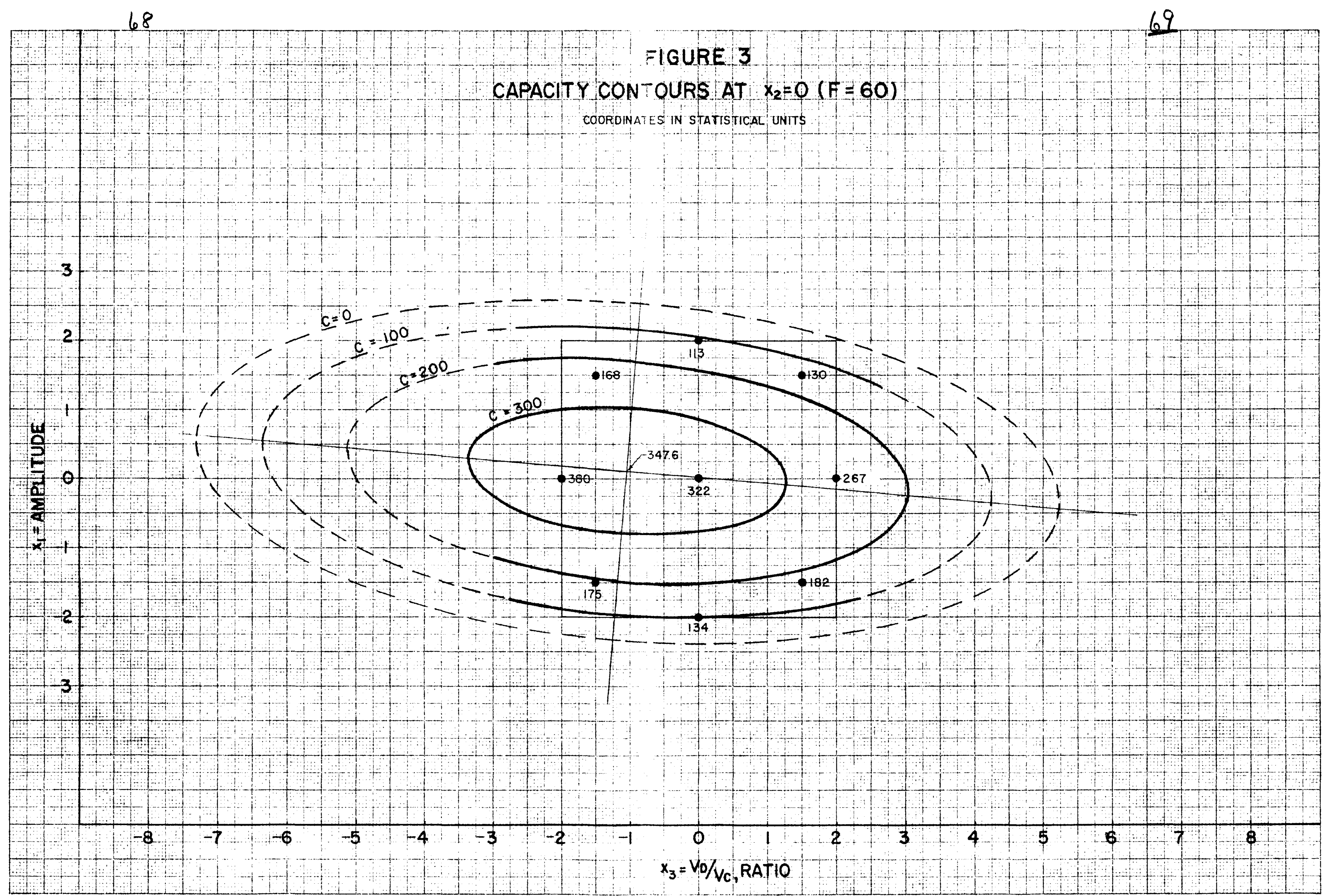


FIGURE I2
CAPACITY CONTOURS AT $x_{3}=-2\left(V_{0} / V_{C}=0.333\right)$

$5=$ coORDINATES IN S SATISTICAL UNITS

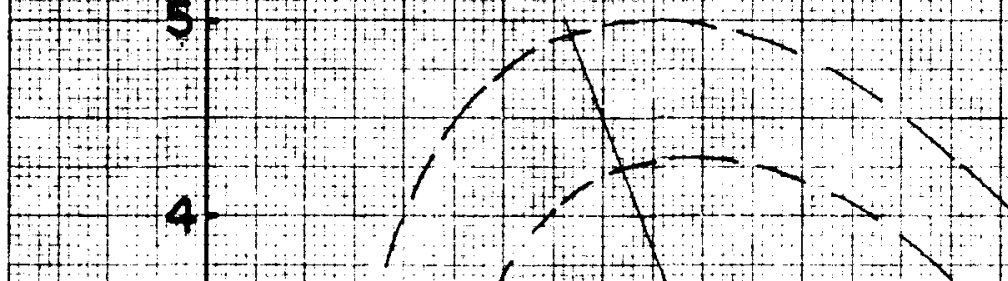

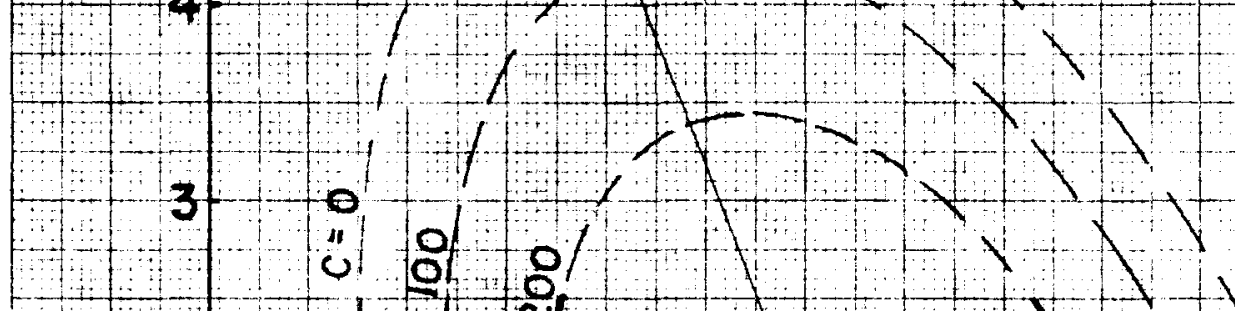

${ }^{-2}$

$-3$ 1)

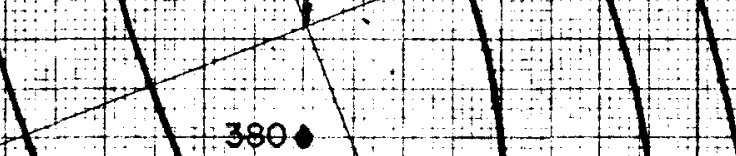

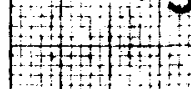

.
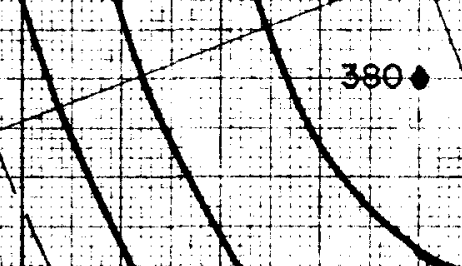

N

-
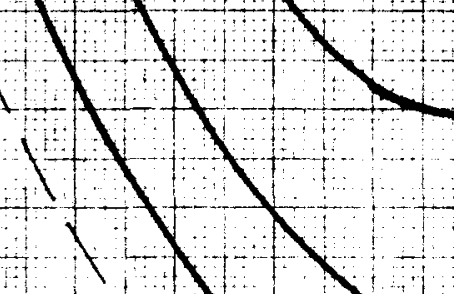


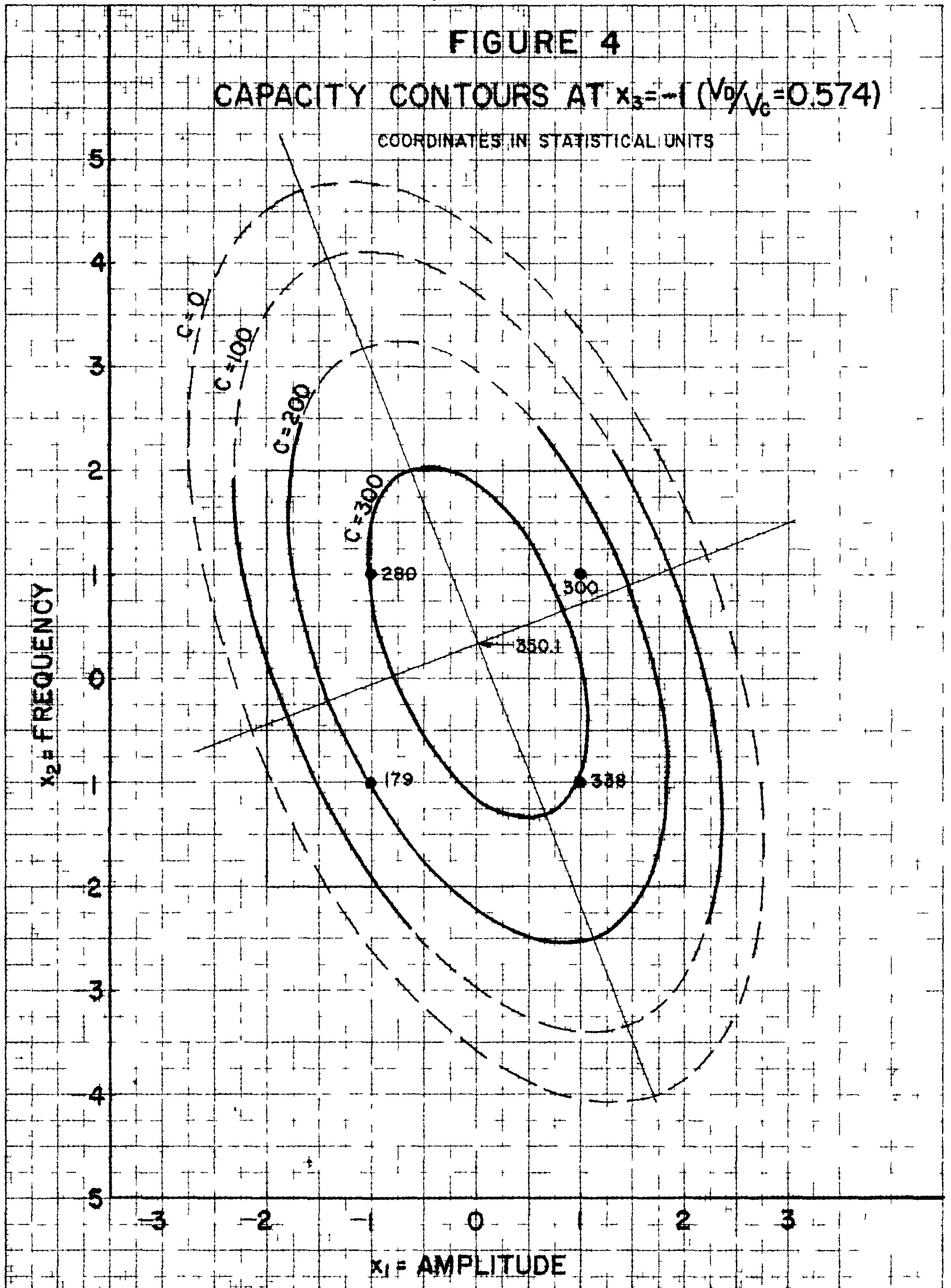




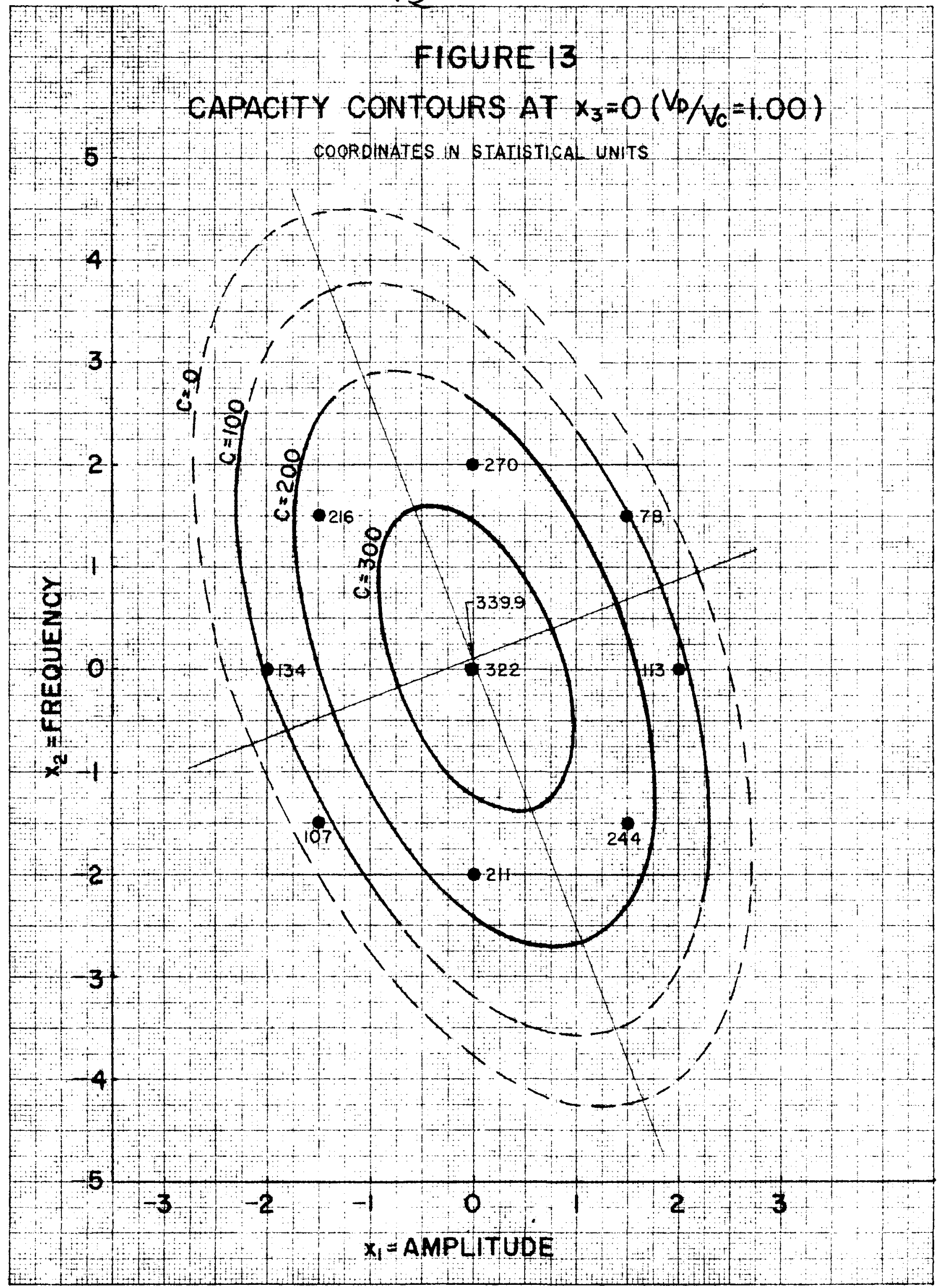




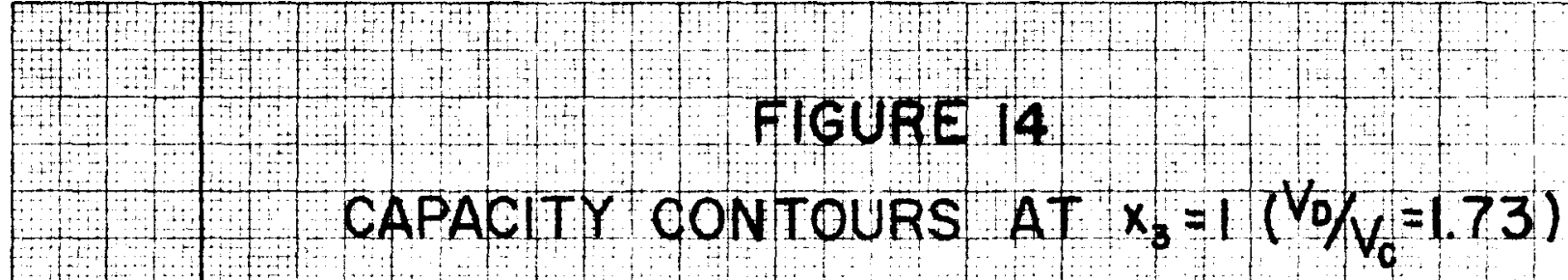

\section{COORDIMATES IN STATISTICAL UNITS}

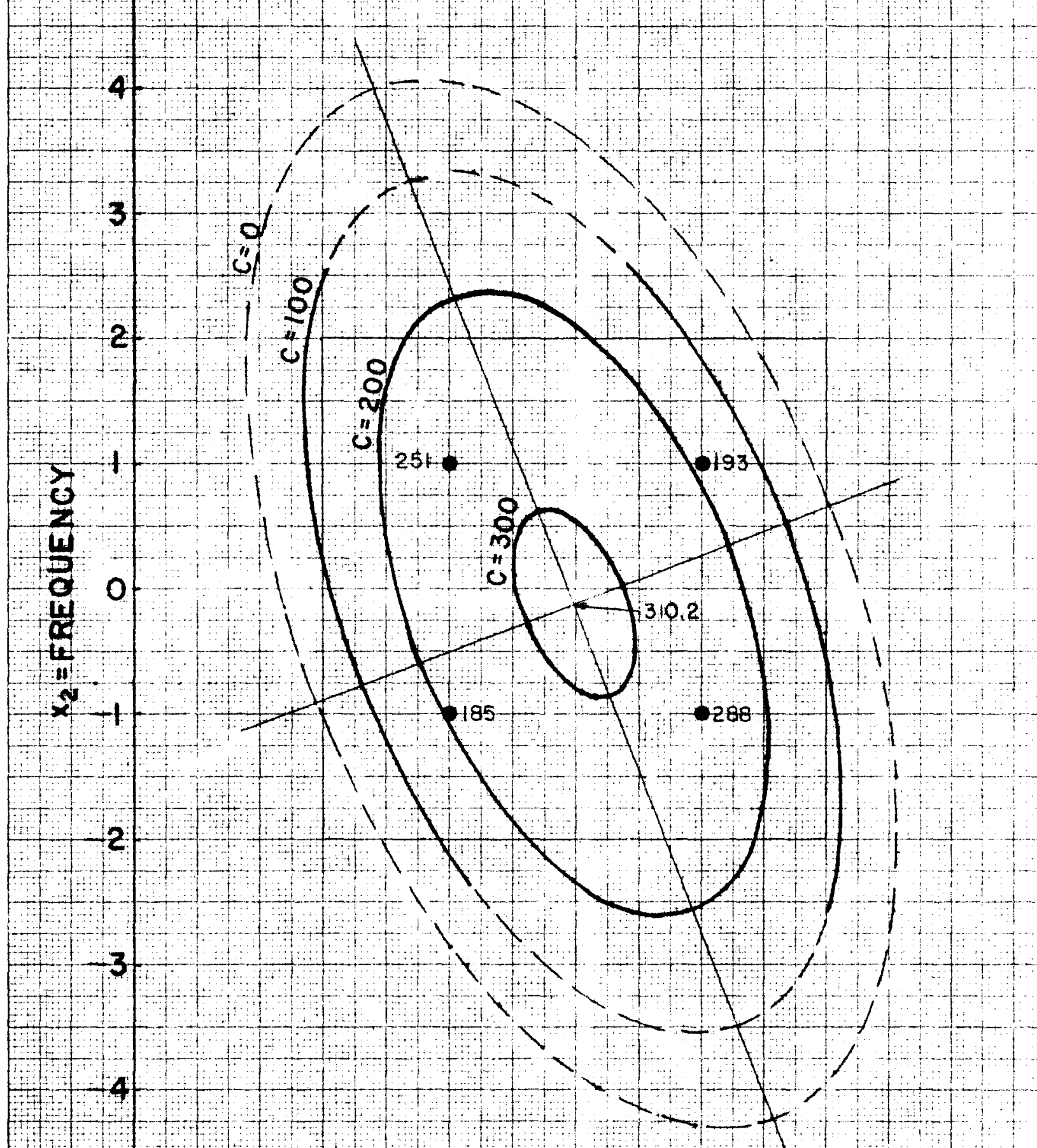

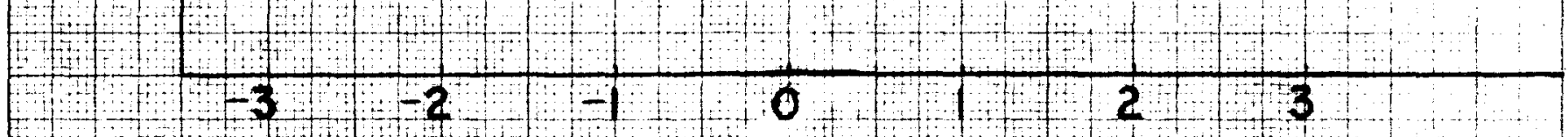

$x_{1}=$ AMPLITUDE

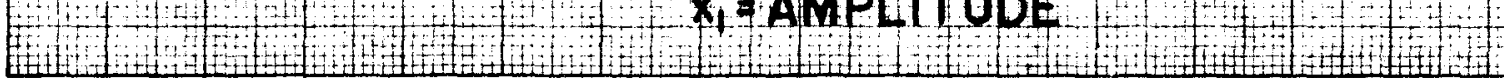




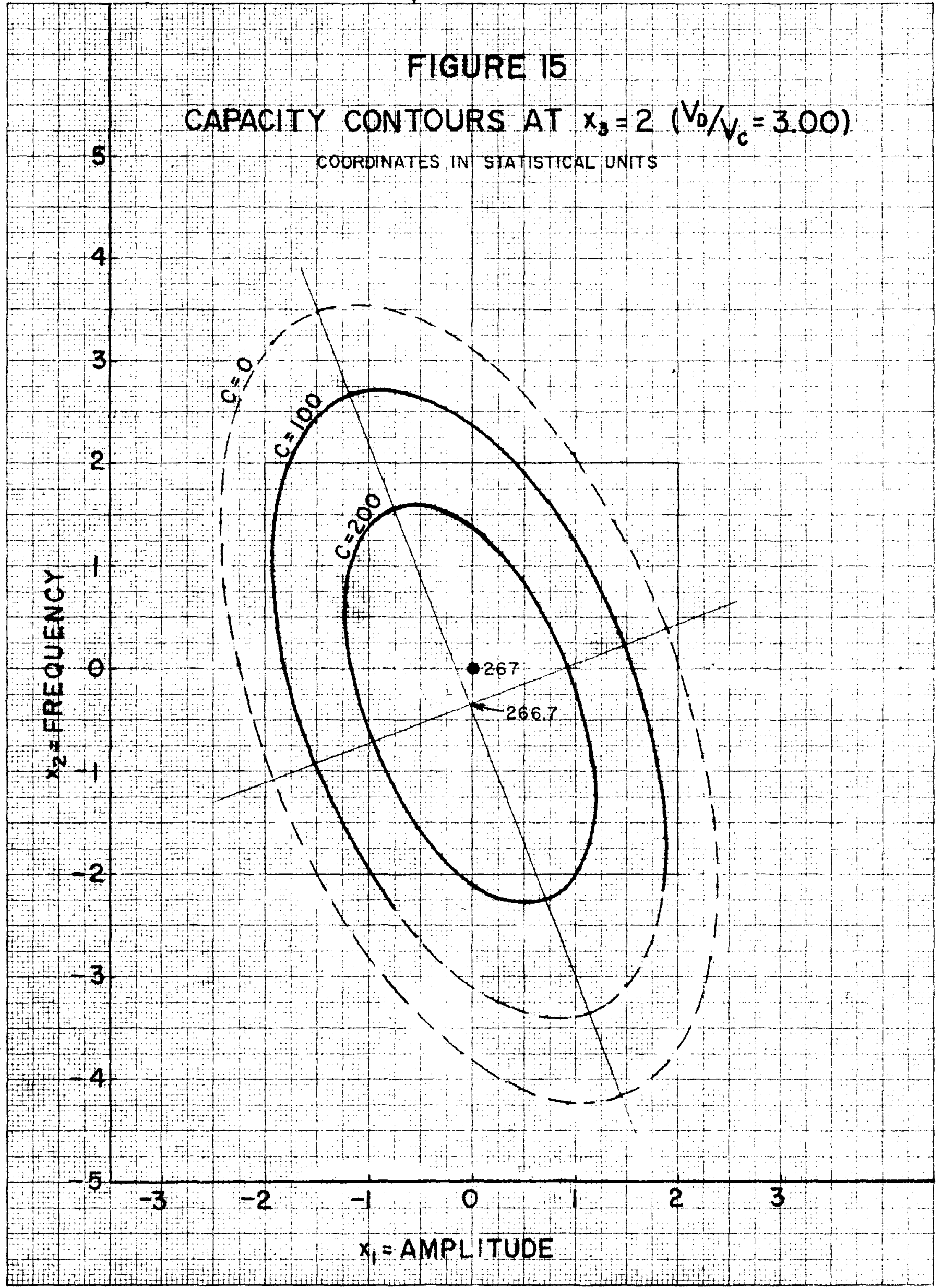




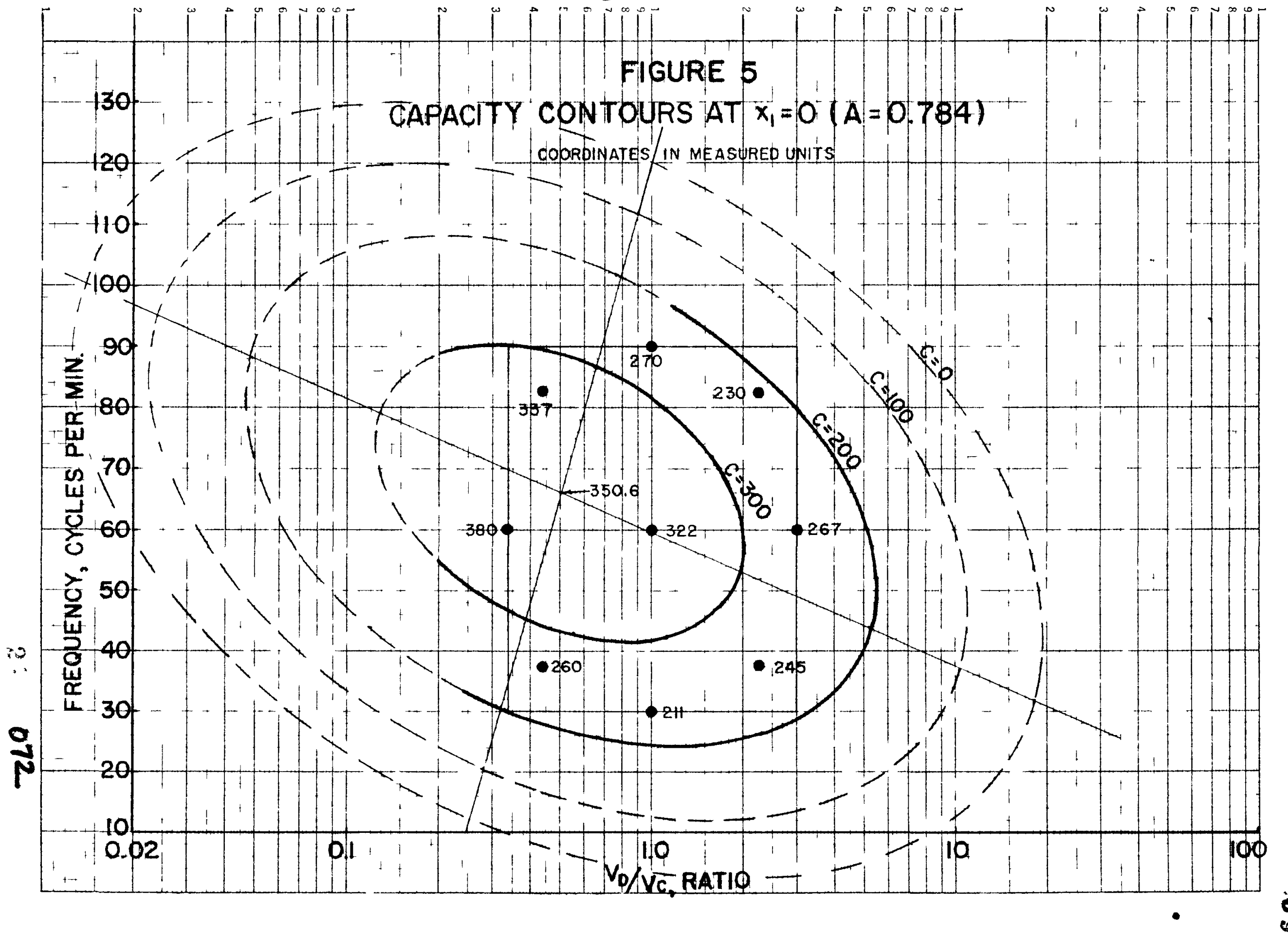




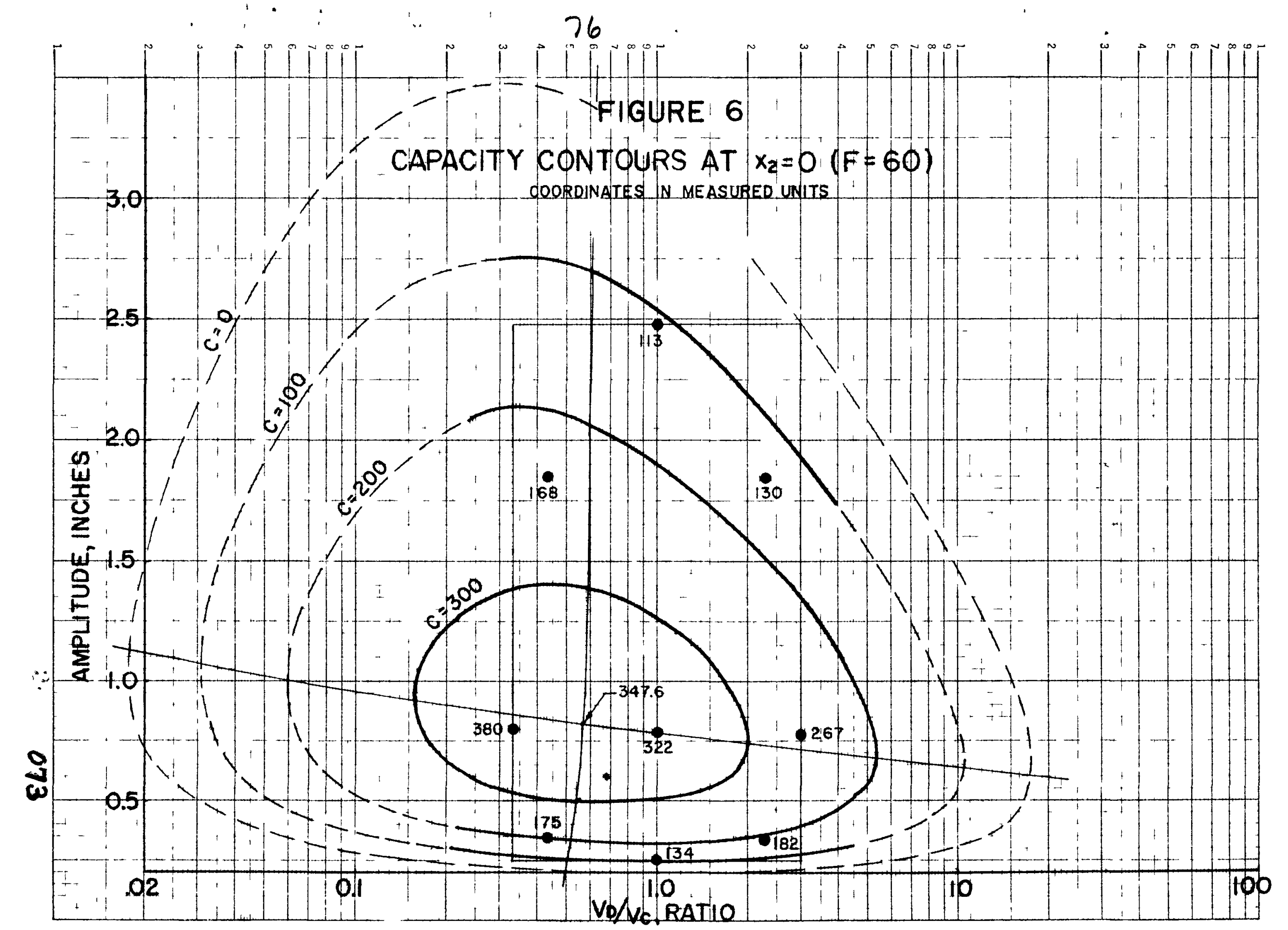




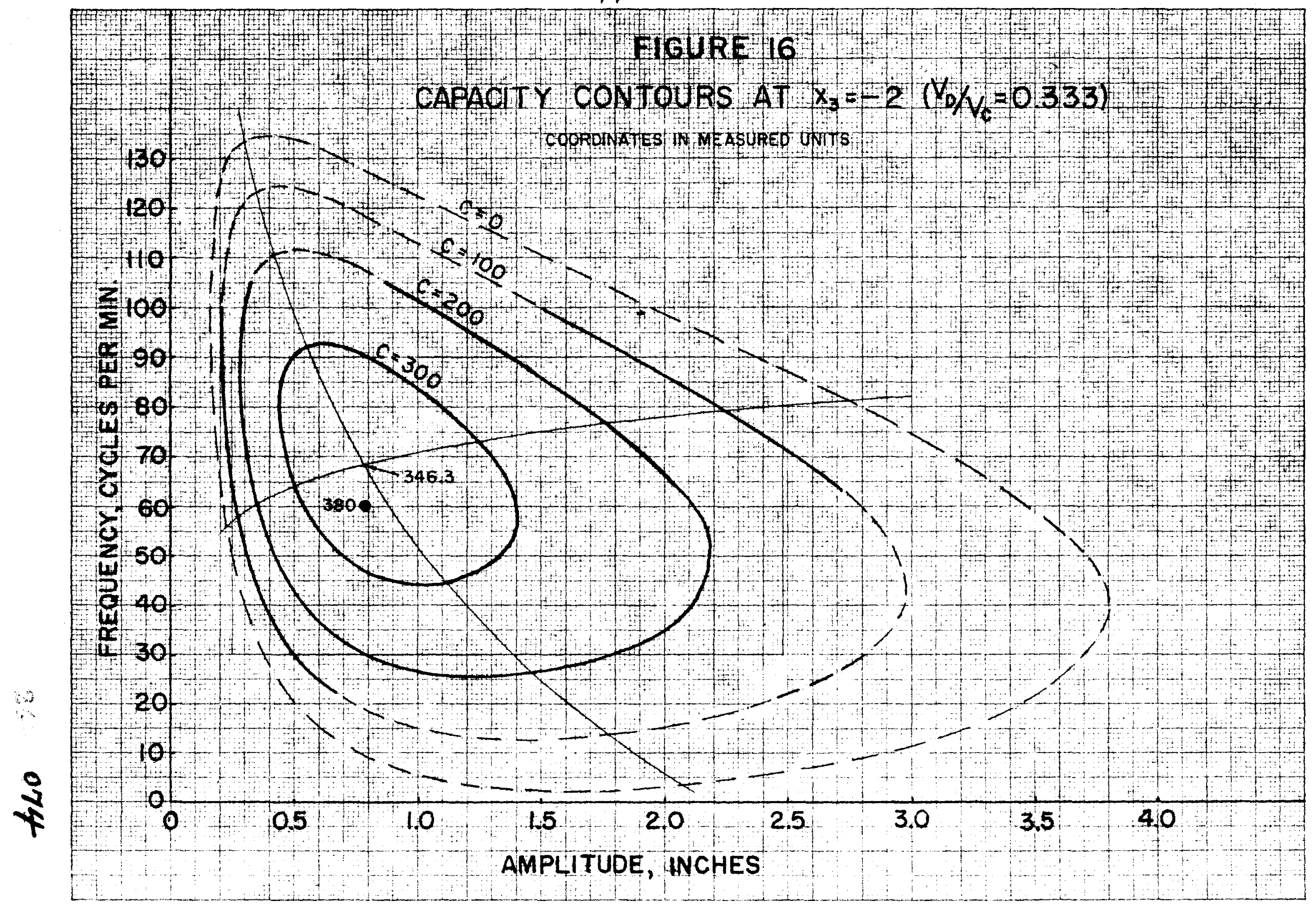




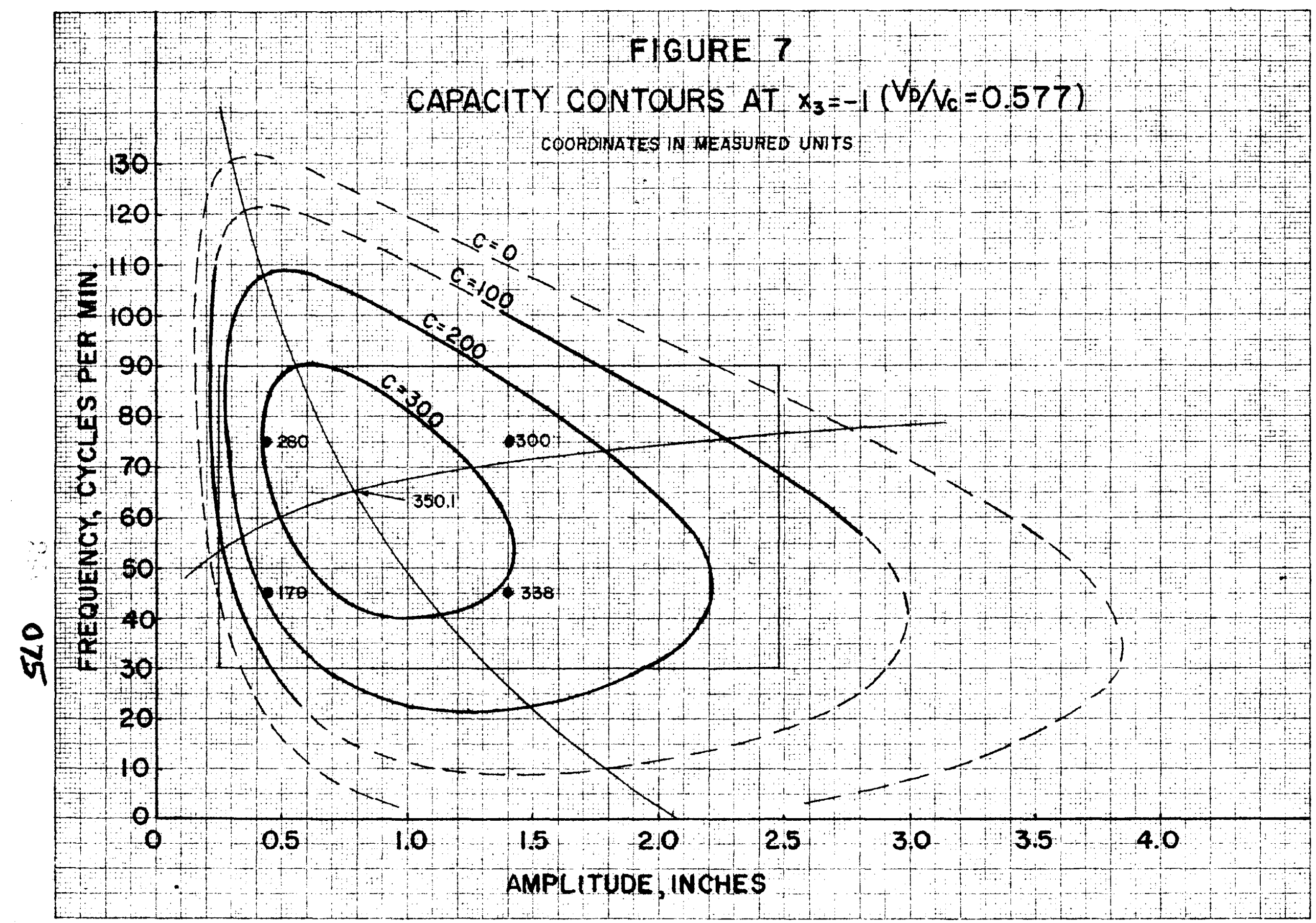


FIGURE I?

\section{CAPACITY CONTOURS AT X 0 (Vo/VC 100$)$}

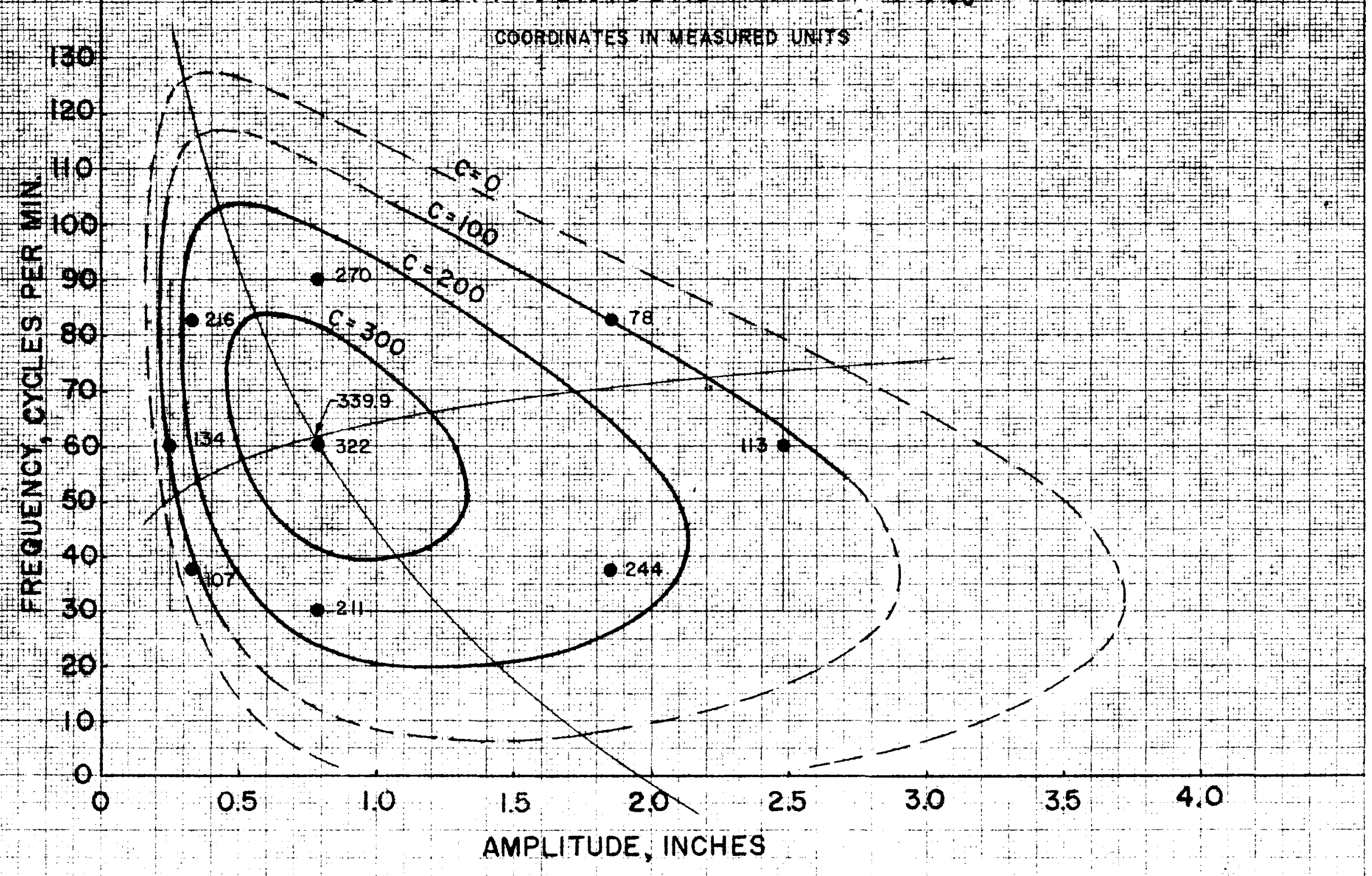




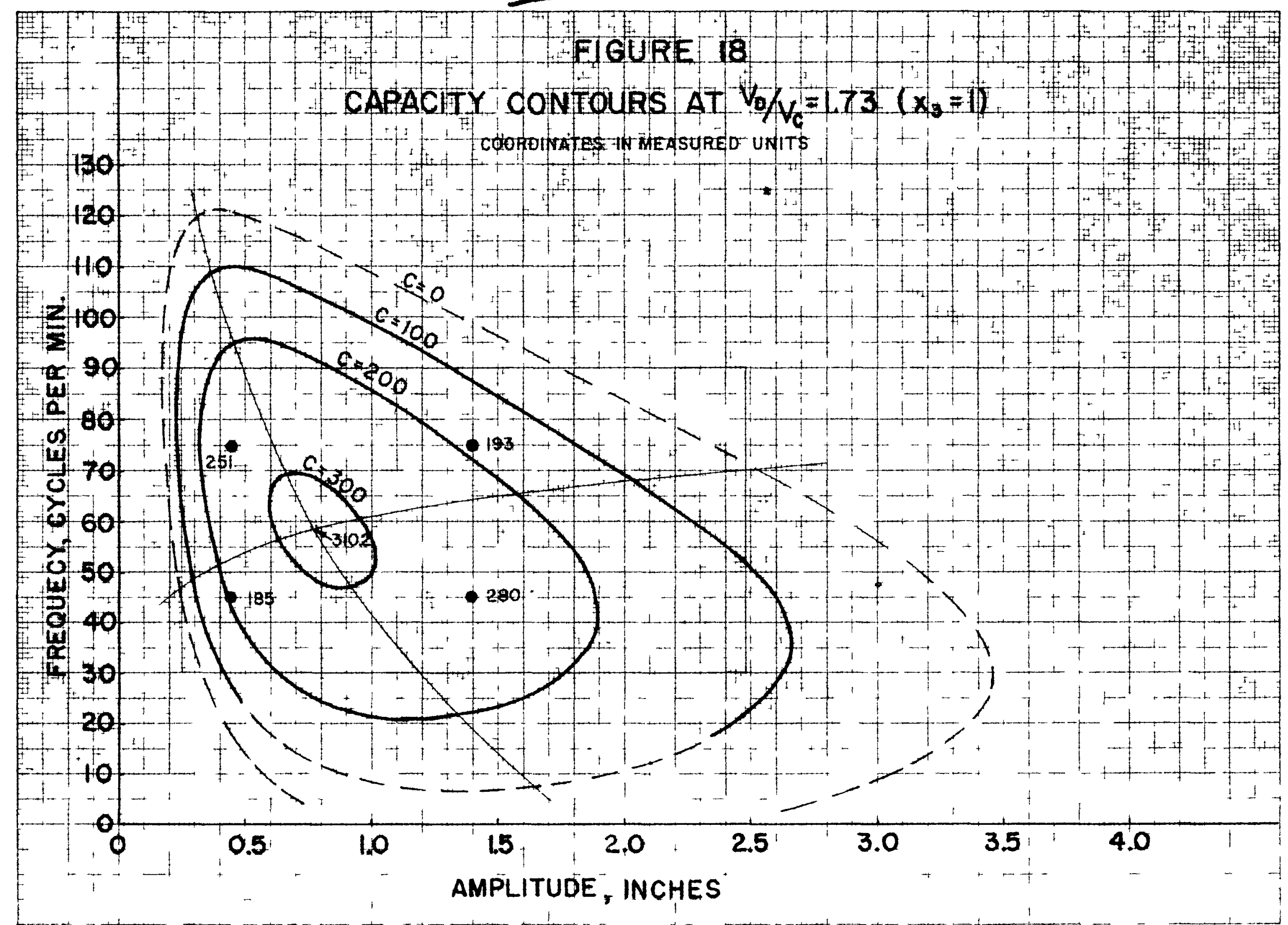


TABLE A 82

Calculated Capacity Contours for Section at $x_{1}=0, A=0.784$ $\mathrm{C}=300$ Contour $\quad \mathrm{C}=200$ Contour

\begin{tabular}{|c|c|c|c|c|c|c|c|}
\hline$\frac{\pi}{2}$ & F & $\overline{x_{3}}$ & $V_{d} / V_{c}$ & $\bar{x}_{2}$ & $F$ & $\bar{x}_{3}$ & $V_{d} N_{c}$ \\
\hline $\begin{array}{l}-0: 464 \\
-0: 883\end{array}$ & 53.1 & +1.226 & 1.961 & -1.092 & $43: 7$ & $\begin{array}{l}+3.026 \\
+2.320\end{array}$ & $\begin{array}{l}5: 271 \\
3: 576\end{array}$ \\
\hline $\begin{array}{l}883 \\
169\end{array}$ & $\begin{array}{l}46: 8 \\
42: 5\end{array}$ & $\begin{array}{l}+0.909 \\
+0.212\end{array}$ & $\begin{array}{l}1.647 \\
1.123\end{array}$ & $\begin{array}{l}-1: 905 \\
-2: 383\end{array}$ & $\begin{array}{l}31: 3 \\
24: 3\end{array}$ & $\begin{array}{l}+2.320 \\
+0.655\end{array}$ & $\begin{array}{l}3.5766 \\
1.432\end{array}$ \\
\hline$-1: 217$ & 41.7 & -0.259 & $0: 868$ & -2.374 & 24.4 & -0.129 & 0.932 \\
\hline-1.145 & 42.8 & -1.073 & 0.555 & -1.981 & $30: 3$ & -2.108 & 0.330 \\
\hline-0.967 & 45.5 & -1.732 & 0.386 & $-1: 960$ & 30.6 & -2.079 & $0: 319$ \\
\hline-0.697 & 49.5 & -2.358 & 0.274 & -1.939 & 30.9 & $-2,138$ & 0.309 \\
\hline-0.247 & $56: 3$ & -3.047 & 0.188 & $-1: 072$ & 43.9 & $-3: 863$ & 0.120 \\
\hline+0.083 & 61.2 & -3.380 & 0.156 & -0.951 & 51.1 & -4.483 & 0.085 \\
\hline+0.747 & 71.1 & -3.749 & 0.127 & $+0: 819$ & 72.3 & -5.488 & 0.049 \\
\hline$+1: 266$ & 79.1 & -3.736 & 0.128 & $+1: 894$ & 88.0 & -5.536 & 0.048 \\
\hline+1.685 & 85.4 & -3.419 & 0.513 & +2.707 & 100.7 & $-4: 830$ & 0.070 \\
\hline+1.971 & 89.6 & -2.772 & 0.218 & +3.185 & 107.8 & $-3,165$ & 0.176 \\
\hline+2.019 & 90.3 & $-2 ; 251$ & 0.291 & +3.176 & $107: 7$ & $-2,381$ & 0.271 \\
\hline+1.947 & 89.3 & -1.435 & 0.454 & $+2: 783$ & 101.7 & -0.492 & 0.763 \\
\hline & 86.6 & -0.773 & 0,652 & $+2: 762$ & 101.4 & -0.431 & 0.790 \\
\hline+1.499 & 82.5 & -0.152 & 0.920 & +2.741 & 101.1 & -0.372 & 0.815 \\
\hline+1.049 & $75 . \varepsilon$ & +0.531 & 1.338 & $+1: 874$ & 88.1 & +1.353 & $1: 989$ \\
\hline+0.719 & $70: 8$ & $+0: 870$ & 1.613 & +1.393 & 80.9 & +1.973 & $2: 887$ \\
\hline+0.061 & 60,9 & +1.239 & 1.974 & -0.017 & 59.7 & +2.978 & 5.134 \\
\hline
\end{tabular}

$C=100$ Contour $\quad C=0$ Contour

\begin{tabular}{|c|c|c|c|c|c|c|c|}
\hline 2 & $\mathrm{~F}$ & $x_{3}$ & $\mathrm{~V}_{\mathrm{d}} \mathrm{N}_{\mathrm{c}}$ & $x_{2}^{x}$ & $F$ & $x_{3}$ & $\mathrm{~V}_{\mathrm{d}} / \mathrm{N}_{\mathrm{c}}$ \\
\hline \multirow{25}{*}{$\begin{array}{l}-1: 525 \\
-2: 3774 \\
-2.998 \\
-3.177 \\
-3.139 \\
-2.860 \\
-2.6444 \\
-2.380 \\
-1.725 \\
-0.742 \\
+0.024 \\
+1.288 \\
+2.327 \\
+3.176 \\
+3.800 \\
+3.979 \\
+3.947 \\
+3.662 \\
+3.446 \\
+3.182\end{array}$} & $37: 0$ & $+4: 267$ & 10.476 & $-1: 877$ & 31.8 & $+5: 276$ & $18: 140$ \\
\hline & $24: 4$ & +3.666 & $7: 491$ & -2.747 & 18.9 & +4.719 & 13.351 \\
\hline & $15: 0$ & $+2: 418$ & 3.774 & -3.427 & 8.5 & +3.647 & $7: 409$ \\
\hline & $12: 3$ & +1.411 & 2.170 & -3.839 & 2.4 & +1.792 & 2.676 \\
\hline & 12.9 & -0.216 & $0: 888$ & -3.810 & 2.8 & +0.190 & 1.110 \\
\hline & 17.1 & -1.620 & 0.417 & -3.558 & 6.6 & -1.291 & 0.492 \\
\hline & 20.4 & -2.317 & 0.280 & -3.201 & 12.0 & $-2,517$ & 0.251 \\
\hline & 24.3 & -2.998 & 0.193 & -2.722 & 19.2 & -3.689 & 0.132 \\
\hline & $34: 0$ & -4.270 & 0.096 & -1.998 & $30: 0$ & -5.006 & 0.064 \\
\hline & 48.9 & -5.567 & 0.047 & -1.025 & 4.5 & -6.278 & 0.032 \\
\hline & 60.3 & $-6.24,6$ & 0.032 & +0.453 & 66.8 & -7.475 & 0.016 \\
\hline & $79 \therefore 4$ & -6.834 & 0.023 & $+1,655$ & 84.9 & -7.887 & 0.013 \\
\hline & 95.0 & -6.777 & 0.024 & $+2,679$ & $100: 2$ & -7.786 & 0.014 \\
\hline & 107.7 & -6.176 & 0.034 & +3.543 & $113: 1$ & -7.229 & 0.019 \\
\hline & $117: 0$ & -4.928 & 0.067 & +4.229 & 123.5 & -6.157 & 0.034 \\
\hline & 119.7 & -3.921 & 0.116 & +4.647 & $129 ; 6$ & -4.302 & 0.094 \\
\hline & $119 i 1$ & $-2: 249$ & 0.284 & $+4: 612$ & 129.2 & -2.700 & 0.227 \\
\hline & 114 :9 & $-0: 890$ & 0.613 & $+4: 360$ & 125.4 & -1.219 & 0.512 \\
\hline & $111 \div 8$ & -0.193 & 0.899 & +40003 & $120: 0$ & +0.001 & 1.000 \\
\hline & 107.7 & +0.488 & 1.307 & $+3: 524$ & 112.8 & +1.179 & 1.190 \\
\hline & & & & +2.800 & $102: 0$ & +2.496 & 3.940 \\
\hline & & & & +1.827 & 87.5 & +3.768 & $7: 923$ \\
\hline & & & & -0.349 & 65.3 & $+4: 965$ & $15: 283$ \\
\hline & & & & & & +5.377 & 19.165 \\
\hline & & & & & 079 & & \\
\hline
\end{tabular}


TABLE B

\section{3}

Calculated Capacity Contours for Section at $\boldsymbol{x}_{2}=0, F=60$

\begin{tabular}{|c|c|c|c|c|c|c|c|}
\hline \multicolumn{3}{|c|}{$C=300$ Contour } & \multicolumn{5}{|c|}{$C=200$ Contour } \\
\hline 1 & $A$ & .3 & $\mathrm{~V}_{\mathrm{d}} / \mathrm{N}_{\mathrm{c}}$ & $\bar{x}$ & $A$ & $\mathbf{x}_{3}$ & $V_{d} N_{c}$ \\
\hline $\begin{array}{l}+0.293 \\
+0.089 \\
-0.126 \\
-0.355 \\
-0.477 \\
-0.609 \\
-0.803 \\
-0.791 \\
-0.725 \\
-0.647 \\
-0.478 \\
-0.293 \\
-0.099 \\
+0.105 \\
+0.320 \\
+0.549 \\
+0.671 \\
+0.803 \\
+0.997 \\
+0.985 \\
+0.919 \\
+0.847 \\
+0.672 \\
+0.487\end{array}$ & $\begin{array}{l}0: 93 \\
0: 83 \\
0.73 \\
0: 64 \\
0: 60 \\
0: 55 \\
0: 49 \\
0: 50 \\
0: 52 \\
0: 54 \\
0: 60 \\
0: 66 \\
0: 74 \\
0: 83 \\
0: 94 \\
1.08 \\
1: 15 \\
1: 24 \\
1: 39 \\
1.38 \\
1: 33 \\
1: 27 \\
1: 16 \\
1.04\end{array}$ & $\begin{array}{l}-3.366 \\
-3.326 \\
-3.164 \\
-2.831 \\
-2.571 \\
-2.189 \\
-1.123 \\
-0.039 \\
+0.359 \\
+0.635 \\
+1.001 \\
+1.198 \\
+1.272 \\
+1.232 \\
+1.069 \\
+0.737 \\
+0.477 \\
+0.095 \\
-0.971 \\
-2.055 \\
-2.453 \\
-2.729 \\
-3.095 \\
-3.292\end{array}$ & $\begin{array}{l}0.157 \\
0.161 \\
0.176 \\
0.211 \\
0.244 \\
0.301 \\
0.540 \\
0.979 \\
1.217 \\
1.476 \\
1.732 \\
1.931 \\
2.011 \\
1.967 \\
1.798 \\
1.498 \\
1.299 \\
1.053 \\
0.587 \\
0.324 \\
0.260 \\
0.223 \\
0.183 \\
0.164\end{array}$ & $\begin{array}{l}+0.442 \\
+0.137 \\
-0.181 \\
-0.516 \\
-0.750 \\
-0.999 \\
-1.254 \\
-1.487 \\
-1.542 \\
-1.397 \\
-1.248 \\
-1.084 \\
-0.821 \\
-0.541 \\
-0.248 \\
+0.057 \\
+0.375 \\
+0.710 \\
+0.944 \\
+1.193 \\
+1.448 \\
+1.681 \\
+1.736 \\
+1: 591 \\
+1.442 \\
+1.278 \\
+1.015 \\
+0.735\end{array}$ & $\begin{array}{l}1.01 \\
0.85 \\
0.71 \\
0.58 \\
0.51 \\
0.44 \\
0.38 \\
0.33 \\
0.32 \\
0.35 \\
0.38 \\
0.42 \\
0.49 \\
0.57 \\
0.68 \\
0.81 \\
0.97 \\
1.18 \\
1.35 \\
1.56 \\
1.78 \\
2.06 \\
2.13 \\
1.96 \\
1.80 \\
1.64 \\
1.41 \\
1.20\end{array}$ & $\begin{array}{l}-5.130 \\
-5.082 \\
-4.878 \\
-4.489 \\
-4.087 \\
-3.506 \\
-2.525 \\
-1.181 \\
+0.179 \\
+1.194 \\
+1.807 \\
+2.243 \\
+2.682 \\
+2.938 \\
+3.036 \\
+2.988 \\
+2.784 \\
+2.395 \\
+1.993 \\
+1.412 \\
+0.431 \\
-0.913 \\
-2.273 \\
-3.288 \\
-3.901 \\
-4.337 \\
-4.776 \\
-5.032\end{array}$ & $\begin{array}{l}0.060 \\
0.061 \\
0.069 \\
0.085 \\
0.106 \\
0.146 \\
0.250 \\
0.523 \\
1.103 \\
1.927 \\
2.697 \\
3.426 \\
4.363 \\
5.022 \\
5.300 \\
5.162 \\
4.615 \\
3.725 \\
2.987 \\
2.172 \\
1.266 \\
0.606 \\
0.287 \\
0.164 \\
0.117 \\
0.092 \\
0.073 \\
0.063\end{array}$ \\
\hline
\end{tabular}


TABLE B 84

Calculated Capacity Contours for Section at $x_{2}=0, F=60$ (Cont)

\begin{tabular}{|c|c|c|c|c|c|c|c|}
\hline$x_{1}$ & $\bar{A}$ & $x_{3}$ & $\nabla_{d}{ }_{c}$ & $x_{1}$ & $\bar{A}$ & $x_{3}$ & ${ }_{d^{d}}{ }_{c}$ \\
\hline $\begin{array}{l}+0.544 \\
+0.033 \\
-0.508 \\
-1.092 \\
-1.345 \\
-1.480 \\
-1.628 \\
-1.955 \\
-1.964 \\
-1.914 \\
-1.849 \\
-1.704 \\
-1.290 \\
-0.835 \\
-0.350 \\
+0.161 \\
+0.702 \\
+1.286 \\
+1.539 \\
+1.674 \\
+1.822 \\
+2.149 \\
+2.158 \\
+2.108 \\
+2.043 \\
+1.898 \\
+1.484 \\
+1.029\end{array}$ & $\begin{array}{l}1.07 \\
0.80 \\
0.58 \\
0.42 \\
0.36 \\
0.33 \\
0.31 \\
0.25 \\
0.25 \\
0.26 \\
0.27 \\
0.29 \\
0.37 \\
0.49 \\
0.64 \\
0.86 \\
1.18 \\
1.64 \\
1.90 \\
2.06 \\
2.24 \\
2.70 \\
2.72 \\
2.64 \\
2.54 \\
2.34 \\
1.84 \\
1.42\end{array}$ & $\begin{array}{l}-6.335 \\
-6.219 \\
-5.753 \\
-4.795 \\
-4.173 \\
-3.766 \\
-3.197 \\
-1.220 \\
+0.783 \\
+1.368 \\
+1.793 \\
+2.449 \\
+3.491 \\
+4.041 \\
+4.2117 \\
+4.125 \\
+3.659 \\
+2.701 \\
+2.079 \\
+1.672 \\
+1.103 \\
-0.874 \\
-2.877 \\
-3.462 \\
-3.887 \\
-4.543 \\
-5.585 \\
-6.135\end{array}$ & $\begin{array}{r}0.031 \\
0.033 \\
0.042 \\
0.072 \\
0.101 \\
0.126 \\
0.173 \\
0.512 \\
1.537 \\
2.120 \\
2.676 \\
3.837 \\
6.801 \\
9.200 \\
10.267 \\
9.634 \\
7.458 \\
4.407 \\
3.131 \\
2.505 \\
1.832 \\
0.619 \\
0.260 \\
0.149 \\
0.118 \\
0.083 \\
0.047 \\
0.034\end{array}$ & $\begin{array}{l}+0.627 \\
+0.012 \\
-0.638 \\
-1.217 \\
-1.727 \\
-2.019 \\
-2.199 \\
-2.333 \\
-2.389 \\
-2.371 \\
-2.265 \\
-1.977 \\
-1.560 \\
-1.0114 \\
-0.433 \\
+0.182 \\
+0.832 \\
+1.411 \\
+1.921 \\
+2.213 \\
+2.393 \\
+2.527 \\
+2.583 \\
+2.565 \\
+2.459 \\
+2.171 \\
+1.754 \\
+1.208\end{array}$ & $\begin{array}{l}1.13 \\
0.79 \\
0.54 \\
0.39 \\
0.29 \\
0.25 \\
0.22 \\
0.20 \\
0.20 \\
0.20 \\
0.21 \\
0.25 \\
0.32 \\
0.44 \\
0.61 \\
0.87 \\
1.27 \\
1.77 \\
2.37 \\
2.80 \\
3.11 \\
3.36 \\
3.47 \\
3.43 \\
3.29 \\
2.74 \\
2.15 \\
1.57\end{array}$ & $\begin{array}{l}-7.313 \\
-7.171 \\
-6.603 \\
-5.683 \\
-4.472 \\
-3.329 \\
-2.370 \\
-1.252 \\
-0.128 \\
+0.847 \\
+1.964 \\
+3.303 \\
+4.307 \\
+4.975 \\
+5.219 \\
+5.077 \\
+4.509 \\
+3.589 \\
+2.318 \\
+1.235 \\
+0.276 \\
-0.842 \\
-1.966 \\
-2.941 \\
-4.058 \\
-5.397 \\
-6.401 \\
-7.069\end{array}$ & $\begin{array}{r}0.018 \\
0.019 \\
0.027 \\
0.044 \\
0.089 \\
0.161 \\
0.272 \\
0.503 \\
0.932 \\
1.592 \\
2.947 \\
6.134 \\
10.647 \\
15.368 \\
17.571 \\
16.254 \\
11.897 \\
7.177 \\
3.573 \\
1.970 \\
1.164 \\
0.630 \\
0.339 \\
0.199 \\
0.108 \\
0.052 \\
0.030 \\
0.021\end{array}$ \\
\hline
\end{tabular}


TABLE C 85

Calculated Capacity Contours for Section at $x_{3}=+2, V_{d} / V_{c}=3.000$ $C=300$ Contour $C=200$ Contour

\begin{tabular}{|c|c|c|c|c|}
\hline & $x_{1}$ & 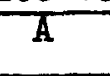 & $x_{2}$ & $F$ \\
\hline None & $\begin{array}{l}-0.760 \\
-0.933 \\
-1.076 \\
-1.181 \\
-1.215 \\
-1.229 \\
-1.212 \\
-0.974 \\
-0.524 \\
-0.319 \\
-0.145 \\
-0.009 \\
+0.278 \\
+0.511 \\
+0.712 \\
+0.885 \\
+1.028 \\
+1.133 \\
+1.167 \\
+1.181 \\
+1.164 \\
+0.926 \\
+0.476 \\
+0.271 \\
+0.097 \\
-0.057 \\
-0.326 \\
-0.559\end{array}$ & $\begin{array}{l}0.51 \\
0.46 \\
0.42 \\
0.40 \\
0.39 \\
0.39 \\
0.39 \\
0.45 \\
0.58 \\
0.65 \\
0.72 \\
0.78 \\
0.92 \\
1.05 \\
1.18 \\
1.30 \\
1.42 \\
1.51 \\
1.53 \\
1.55 \\
1.53 \\
1.34 \\
1.03 \\
0.92 \\
0.83 \\
0.76 \\
0.65 \\
0.57\end{array}$ & $\begin{array}{l}+1.562 \\
+1.452 \\
+1.265 \\
+0.980 \\
+0.788 \\
+0.547 \\
+0.223 \\
-0.710 \\
-1.557 \\
-1.809 \\
-1.978 \\
-2.098 \\
-2.239 \\
-2.282 \\
-2.248 \\
-2.138 \\
-1.951 \\
-1.666 \\
-1.474 \\
-1.233 \\
-0.909 \\
+0.024 \\
+0.871 \\
+1.123 \\
+1.292 \\
+1.412 \\
+1.553 \\
+1.596\end{array}$ & $\begin{array}{l}83: 4 \\
81: 8 \\
80: 0 \\
74: 7 \\
71: 8 \\
68: 2 \\
63: 3 \\
49: 3 \\
36: 6 \\
32: 9 \\
30: 3 \\
28: 5 \\
26: 4 \\
25: 8 \\
26: 3 \\
27: 1 \\
30: 7 \\
35: 0 \\
37: 9 \\
47: 5 \\
46.4 \\
60.4 \\
73: 1 \\
76: 8 \\
79.4 \\
81: 2 \\
83: 3 \\
83.9\end{array}$ \\
\hline
\end{tabular}



Calculated Capacity Contours for Section at $x_{3}=+2, V_{d} / V_{c}=3.000$ $C=100$ Contour

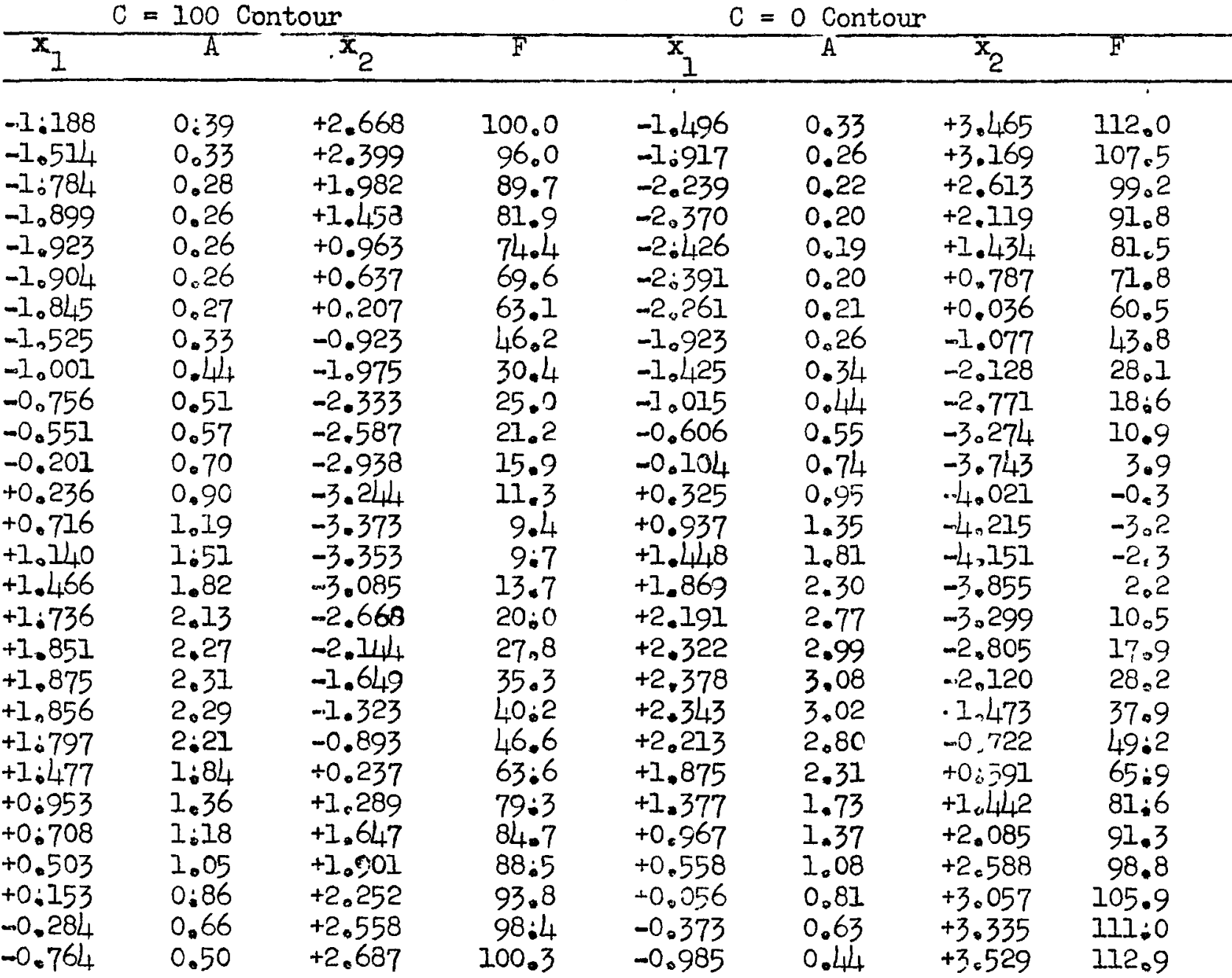


TABLE D

Calculated Capacity Contours for Section at $x_{3}=+I, V_{d} / V_{c}=1.732$

\begin{tabular}{|c|c|c|c|c|c|c|c|}
\hline \multicolumn{3}{|c|}{$C=300$ Contour } & \multicolumn{5}{|c|}{$\mathrm{C}=200$ Contour } \\
\hline$x_{1}$ & $A$ & $x_{2}$ & $F$ & $x_{1}$ & $A$ & $x_{2}$ & $F$ \\
\hline $\begin{array}{l}-0.303 \\
-0.387 \\
-0.451 \\
-0.485 \\
-0.478 \\
-0.387 \\
-0.206 \\
-0.107 \\
+0.045 \\
+0.169 \\
+0.271 \\
+0.355 \\
+0.419 \\
+0.453 \\
+0.446 \\
+0.355 \\
+0.174 \\
+0.075 \\
-0.077 \\
-0.201\end{array}$ & $\begin{array}{l}0.66 \\
0: 63 \\
0: 60 \\
0.60 \\
0: 60 \\
0: 63 \\
0: 70 \\
0: 74 \\
0: 80 \\
0: 86 \\
0: 92 \\
0: 96 \\
1: 00 \\
1: 02 \\
1: 01 \\
0.96 \\
0: 87 \\
0: 82 \\
0: 75 \\
0.70\end{array}$ & $\begin{array}{l}+0.628 \\
+0.569 \\
+0.456 \\
+0.265 \\
+0.112 \\
-0.258 \\
-0.594 \\
-0.711 \\
-0.830 \\
-0.871 \\
-0.858 \\
-0.799 \\
-0.686 \\
-0.495 \\
-0.342 \\
+0.038 \\
+0.364 \\
+0.481 \\
+0.600 \\
+0.641\end{array}$ & $\begin{array}{l}69: 4 \\
68: 5 \\
66: 8 \\
64: 0 \\
61: 7 \\
56: 1 \\
51: 1 \\
49: 3 \\
47: 5 \\
46: 9 \\
47: 1 \\
48: 0 \\
49: 7 \\
52: 6 \\
54: 9 \\
60: 4 \\
65: 5 \\
67: 2 \\
69: 0 \\
69: 6\end{array}$ & $\begin{array}{l}-0.962 \\
-1.217 \\
-1.417 \\
-1.504 \\
-1.559 \\
-1.512 \\
-1.236 \\
-0.758 \\
-0.339 \\
-0.020 \\
+0.265 \\
+0.625 \\
+0: 930 \\
+1.185 \\
+1.385 \\
+1.472 \\
+1.527 \\
+1.480 \\
+1.204 \\
+0.726 \\
+0: 307 \\
-0.012 \\
-0.297 \\
-0.657\end{array}$ & $\begin{array}{l}0.45 \\
0.39 \\
0.35 \\
0.33 \\
0.32 \\
0.33 \\
0.39 \\
0.51 \\
0.64 \\
0.78 \\
0.91 \\
1.12 \\
1.34 \\
1.55 \\
1.74 \\
1.83 \\
1.89 \\
1.84 \\
1.57 \\
1.19 \\
0.94 \\
0.78 \\
0.66 \\
0.58\end{array}$ & $\begin{array}{l}+2.333 \\
+2.159 \\
+1.844 \\
+1.518 \\
+1.102 \\
+0.428 \\
-0.587 \\
-1.524 \\
-2.054 \\
-2.324 \\
-2.506 \\
-2.605 \\
-2.563 \\
-2.389 \\
-2.074 \\
-1.748 \\
-1.332 \\
-0.658 \\
+0.357 \\
+1.234 \\
+1.824 \\
+2.094 \\
+2.276 \\
+2.375\end{array}$ & $\begin{array}{l}95: 0 \\
92: 4 \\
87: 7 \\
82: 8 \\
76: 5 \\
66: 4 \\
51: 2 \\
37: 1 \\
29: 2 \\
25: 1 \\
22: 4 \\
20: 9 \\
21: 6 \\
24: 1 \\
28: 9 \\
33: 8 \\
40: 0 \\
50: 1 \\
65: 4 \\
79: 4 \\
87: 4 \\
91: 4 \\
94: 1 \\
95: 6\end{array}$ \\
\hline
\end{tabular}



Calculated Capacity Contours for Section at $x_{3}=+I, V_{d} / N_{c}=1.732$

\begin{tabular}{|c|c|c|c|c|c|c|c|}
\hline \multicolumn{3}{|c|}{$C=100$ Contour } & \multicolumn{5}{|c|}{$c=0$ Contour } \\
\hline$\overline{x_{1}}$ & $A$ & $x_{2}$ & $\bar{F}$ & $x_{1}$ & $A$ & $x_{2}$ & $F$ \\
\hline $\begin{array}{l}-1.323 \\
-1.741 \\
-2.037 \\
-2.137 \\
-2.144 \\
-2.045 \\
-1.701 \\
-1.159 \\
-0.686 \\
-0.321 \\
+0.139 \\
+0.777 \\
+1.291 \\
+1.709 \\
+2.005 \\
+2.105 \\
+2.112 \\
+2.013 \\
+1.669 \\
+1.127 \\
+0.654 \\
+0.289 \\
-0.171 \\
-0.809\end{array}$ & $\begin{array}{l}0.37 \\
0.29 \\
0.24 \\
0.23 \\
0.23 \\
0.24 \\
0.29 \\
0.40 \\
0.53 \\
0.65 \\
0.85 \\
1.23 \\
1.65 \\
2.10 \\
2.47 \\
2.63 \\
2.65 \\
2.50 \\
2.05 \\
1.50 \\
1.14 \\
0.93 \\
0.71 \\
0.40\end{array}$ & $\begin{array}{l}+3.265 \\
+2.961 \\
+2.340 \\
+1.765 \\
+1.230 \\
+0.419 \\
-0.766 \\
-1.875 \\
-2.542 \\
-2.933 \\
-3.292 \\
-3.551 \\
-3.495 \\
-3.191 \\
-2.570 \\
-1.995 \\
-1.460 \\
-0.649 \\
+0.536 \\
+1.645 \\
+2.312 \\
+2.703 \\
+3.062 \\
+3.321\end{array}$ & $\begin{array}{r}109.0 \\
104.4 \\
95.1 \\
86.5 \\
78.5 \\
66.3 \\
48.5 \\
31.9 \\
21.9 \\
16.0 \\
10.6 \\
6.7 \\
7.6 \\
12.1 \\
21.4 \\
30.1 \\
38.1 \\
50.3 \\
68.0 \\
84.7 \\
94.7 \\
100.5 \\
105.9 \\
109.8\end{array}$ & $\begin{array}{r}-1.603 \\
-2.103 \\
-2.464 \\
-2.574 \\
-2.606 \\
-2.583 \\
-2.438 \\
-2.063 \\
-1.512 \\
-0.993 \\
-0.598 \\
-0.256 \\
+0.194 \\
+0.951 \\
+1.571 \\
+2.071 \\
+2.432 \\
+2.542 \\
+2.574 \\
2.551 \\
2.406 \\
+2.031 \\
+1.480 \\
+0.961 \\
+0.566 \\
+0.224 \\
-0.226 \\
-0.983\end{array}$ & $\begin{array}{l}0.31 \\
0.23 \\
0.19 \\
0.18 \\
0.17 \\
0.18 \\
0.19 \\
0.24 \\
0.33 \\
0.44 \\
0.56 \\
0.68 \\
0.88 \\
1.36 \\
1.94 \\
2.58 \\
3.18 \\
3.39 \\
3.45 \\
3.40 \\
3.13 \\
2.52 \\
1.84 \\
1.36 \\
1.09 \\
0.89 \\
0.69 \\
0.45\end{array}$ & $\begin{array}{l}+3.992 \\
+3.620 \\
+2.891 \\
+2.343 \\
+1.871 \\
+1.258 \\
+0.326 \\
-0.906 \\
-2.070 \\
-2.858 \\
-3.327 \\
-3.655 \\
-3.987 \\
-4.282 \\
-4.222 \\
-3.850 \\
-3.121 \\
-2.573 \\
-2.301 \\
-1.488 \\
-0.556 \\
+0.676 \\
+1.840 \\
+2.628 \\
+3.097 \\
+3.425 \\
+3.757 \\
+4.052\end{array}$ & $\begin{array}{r}119.9 \\
114.3 \\
103.4 \\
95.1 \\
88.1 \\
78.9 \\
64.9 \\
46.4 \\
28.9 \\
17.1 \\
10.1 \\
5.2 \\
0.2 \\
-4.2 \\
-3.3 \\
2.2 \\
13.2 \\
21.4 \\
28.5 \\
37.7 \\
51.7 \\
70.1 \\
87.6 \\
99.4 \\
106.5 \\
111.4 \\
116.4 \\
120.8\end{array}$ \\
\hline
\end{tabular}




\section{TABLE E}

Calculated Capacity Contours for Section at $x_{3}=0, v_{d} / N_{c}=1.000$

\begin{tabular}{|c|c|c|c|c|c|c|c|}
\hline \multicolumn{3}{|c|}{$C=300$ Contour } & \multicolumn{5}{|c|}{$C=200$ Contour } \\
\hline$x_{1}$ & A & $x_{2}$ & $F$ & $x_{1}$ & A & $x_{2}$ & $F$ \\
\hline $\begin{array}{l}-0.577 \\
-0.746 \\
-0.871 \\
+0.913 \\
-0.937 \\
-0.921 \\
-0.881 \\
-0.742 \\
-0.535 \\
-0.401 \\
-0.199 \\
-0.035 \\
+0.109 \\
+0.356 \\
+0.561 \\
+0.730 \\
+0.855 \\
+0: 897 \\
+0.921 \\
+0.905 \\
+0: 865 \\
+0.726 \\
+0.519 \\
+0.385 \\
+0.183 \\
+0.019 \\
-0.125 \\
-0.372\end{array}$ & $\begin{array}{l}0.56 \\
0.51 \\
0.47 \\
0.46 \\
0.46 \\
0.46 \\
0.47 \\
0.51 \\
0.58 \\
0.62 \\
0.70 \\
0.77 \\
0.84 \\
0.96 \\
1.08 \\
1.19 \\
1.28 \\
1.31 \\
1.33 \\
1.32 \\
1.29 \\
1.19 \\
1.06 \\
0.98 \\
0.87 \\
0.79 \\
0.73 \\
0.63\end{array}$ & $\begin{array}{l}+1.586 \\
+1.465 \\
+1.238 \\
+1.070 \\
+0.851 \\
+0.535 \\
+0.290 \\
-0.171 \\
-0.604 \\
-0.813 \\
-1.057 \\
-1.204 \\
-1.300 \\
-1.383 \\
-1.360 \\
-1.239 \\
-1.012 \\
-0.844 \\
-0.625 \\
-0.309 \\
-0.064 \\
+0.397 \\
+0.830 \\
+1.039 \\
+1.283 \\
+1.430 \\
+1.526 \\
+1.609\end{array}$ & $\begin{array}{l}83: 8 \\
82.0 \\
78.6 \\
76: 1 \\
72: 8 \\
68: 0 \\
64: 4 \\
57: 4 \\
50.9 \\
47: 8 \\
44.1 \\
47: 9 \\
40: 5 \\
39: 3 \\
39: 6 \\
47: 4 \\
44: 8 \\
47: 3 \\
50: 6 \\
55: 4 \\
59: 0 \\
65: 3 \\
72: 5 \\
75: 6 \\
79: 2 \\
81.5 \\
82: 9 \\
84.0\end{array}$ & $\begin{array}{l}-1.074 \\
-1.251 \\
-1.407 \\
-1.542 \\
-1.599 \\
-1.724 \\
-1.754 \\
-1.648 \\
-1.382 \\
-0.980 \\
-0.502 \\
-0.158 \\
+0.277 \\
+0.406 \\
+0.645 \\
+0.861 \\
+1.058 \\
+1.235 \\
+1.391 \\
+1.526 \\
+1.583 \\
+1.708 \\
+1.738 \\
+1.3632 \\
+1.568 \\
+0.964 \\
+0.484 \\
+0.742 \\
-0.293 \\
-0.422 \\
-0.661 \\
-0.877\end{array}$ & $\begin{array}{l}0.42 \\
0.38 \\
0.35 \\
0.32 \\
0.31 \\
0.29 \\
0.29 \\
0.30 \\
0.35 \\
0.45 \\
0.59 \\
0.72 \\
0.92 \\
0.99 \\
1.14 \\
1.29 \\
1.44 \\
1.60 \\
1.74 \\
1.89 \\
1.95 \\
2.10 \\
2.13 \\
2.01 \\
1.72 \\
1.37 \\
1.04 \\
0.85 \\
0.66 \\
0.61 \\
0.54 \\
0.47\end{array}$ & $\begin{array}{l}+2.871 \\
+2.773 \\
+2.624 \\
+2.416 \\
+2.288 \\
\because-.780 \\
+1.301 \\
+0.473 \\
-0.418 \\
-1.257 \\
-1.941 \\
-2.274 \\
-2.566 \\
-2.622 \\
-2.686 \\
-2.691 \\
-2.645 \\
-2.547 \\
-2.398 \\
-2.190 \\
-2.062 \\
-1.554 \\
-1.075 \\
-0.247 \\
+0.644 \\
+1.483 \\
+2.167 \\
+2.500 \\
+2.792 \\
+2.848 \\
+2.912 \\
+2.917\end{array}$ & $\begin{array}{r}103: 1 \\
101.6 \\
99.4 \\
96.2 \\
94: 3 \\
86.7 \\
79.5 \\
67: 1 \\
53: 7 \\
41.1 \\
30: 9 \\
25: 9 \\
21: 5 \\
20: 7 \\
19: 7 \\
19: 6 \\
20: 3 \\
21: 8 \\
24: 0 \\
27: 1 \\
29: 1 \\
36: 7 \\
43: 9 \\
56: 3 \\
69: 7 \\
82: 2 \\
92: 5 \\
97: 5 \\
101: 9 \\
102: 7 \\
103: 7 \\
103.8\end{array}$ \\
\hline
\end{tabular}


TABLE E $\quad \underline{90}$

Calculated Capacity Contours for Section at $x_{3}=0, \mathrm{~V}_{\mathrm{d}} / \mathrm{v}_{\mathrm{c}}=1.000$ (Cont)

\begin{tabular}{|c|c|c|c|c|c|c|c|}
\hline$x_{1}$ & A & $x_{2}$ & $F$ & $\mathrm{x}_{1}$ & A & $x_{2}$ & $F$ \\
\hline $\begin{array}{l}-1.404 \\
-1.662 \\
-1.895 \\
-2: 082 \\
-2: 220 \\
-2.236 \\
-2: 256 \\
-2.028 \\
-1.809 \\
-1.532 \\
-0.932 \\
-0.528 \\
-0.034 \\
+0: 388 \\
+0: 759 \\
+1.086 \\
+1: 388 \\
+1: 61.6 \\
+1: 879 \\
+2: 066 \\
+2: 204 \\
+2: 270 \\
+2.240 \\
+2.012 \\
+1.793 \\
+1: 516 \\
+0.916 \\
+0.512 \\
-0: 018 \\
-0.404 \\
-0.775 \\
-1.102\end{array}$ & $\begin{array}{l}0.35 \\
0.30 \\
0.26 \\
0.24 \\
0.22 \\
0.21 \\
0.21 \\
0.24 \\
0.28 \\
0.32 \\
0.46 \\
0.58 \\
0.77 \\
0.98 \\
1.21 \\
1.47 \\
1.74 \\
2.02 \\
2.31 \\
2.58 \\
2.79 \\
2.90 \\
2.85 \\
2.50 \\
2: 20 \\
1.88 \\
1.33 \\
1.07 \\
0.78 \\
0.62 \\
0.50 \\
0.42\end{array}$ & $\begin{array}{l}+3.725 \\
+3.561 \\
+3.329 \\
+2.0 .95 \\
+2.51 .9 \\
+1.0116 \\
+1.210 \\
+0.059 \\
-0.583 \\
-1.213 \\
-2.212 \\
-2.702 \\
-3.149 \\
-3.407 \\
-3.535 \\
-3.551 \\
-3.499 \\
-3.335 \\
-3.103 \\
-2.759 \\
-2.283 \\
-1.620 \\
-0.986 \\
+0.157 \\
+0.809 \\
+1.439 \\
+2.438 \\
+2.928 \\
+3.375 \\
+3.633 \\
+3.761 \\
+3.777\end{array}$ & $\begin{array}{r}115: 9 \\
113: 4 \\
109: 9 \\
104: 8 \\
97.6 \\
87.7 \\
78: 2 \\
61: 0 \\
51: 3 \\
41.8 \\
26: 8 \\
19.5 \\
12: 8 \\
8: 9 \\
7: 0 \\
6: 7 \\
7: 5 \\
10: 0 \\
13: 5 \\
18.6 \\
25: 8 \\
35.7 \\
4.5: 2 \\
62: 4 \\
72: 1 \\
81.6 \\
96.6 \\
103.9 \\
110.6 \\
114: 5 \\
116: 4 \\
116.7\end{array}$ & $\begin{array}{l}-1.670 \\
-2.017 \\
-2.312 \\
-2.544 \\
-2.693 \\
-2.720 \\
-2.691 \\
-2.540 \\
-2.445 \\
-2.151 \\
-1.769 \\
-1.580 \\
-1.055 \\
-0.654 \\
-0.307 \\
+0.290 \\
+0.804 \\
+1.255 \\
+1.654 \\
+2.001 \\
+2.296 \\
+2.528 \\
+2.677 \\
+1 . .704 \\
+2.075 \\
+2.524 \\
+2.1 .29 \\
+2.135 \\
+1.753 \\
+1.564 \\
+1.039 \\
+0.638 \\
+0.291 \\
-0.306 \\
-0.820 \\
-1.271\end{array}$ & $\begin{array}{l}0.30 \\
0.25 \\
0.21 \\
0.18 \\
0.17 \\
0.16 \\
0.17 \\
0.18 \\
0.19 \\
0.23 \\
0.28 \\
0.32 \\
0.43 \\
0.54 \\
0.66 \\
0.93 \\
1.25 \\
1.61 \\
2.03 \\
2.48 \\
2.94 \\
3.36 \\
3.66 \\
3.72 \\
3.66 \\
3.36 \\
3.18 \\
2.68 \\
2.15 \\
1.93 \\
1.43 \\
1.13 \\
0.93 \\
0.66 \\
0.49 \\
0.38\end{array}$ & $\begin{array}{l}+4.412 \\
+4.203 \\
+3.855 \\
+3.347 \\
+. .622 \\
+. .137 \\
+1.509 \\
+.0 .562 \\
+0.177 \\
. .0 .715 \\
-1.573 \\
-1.922 \\
-2.0725 \\
-3.209 \\
-3.550 \\
-3.987 \\
-4.205 \\
-4.265 \\
-.4 .186 \\
-3.977 \\
-3.629 \\
-3.121 \\
-2.396 \\
-1.911 \\
-1.283 \\
-0.336 \\
+0.049 \\
+0.941 \\
+1.799 \\
+2.148 \\
+2.951 \\
+3.435 \\
+3.776 \\
+4.213 \\
+4.431 \\
+4.491\end{array}$ & $\begin{array}{r}126: 2 \\
123: 0 \\
117: 8 \\
110: 2 \\
99: 3 \\
92: 1 \\
82: 6 \\
68: 4 \\
62: 7 \\
49: 3 \\
36: 4 \\
31: 2 \\
19: 1 \\
11: 9 \\
6.7 \\
0: 2 \\
-3: 1 \\
-4: 0 \\
-2.3 \\
0: 3 \\
5: 6 \\
13: 2 \\
24: 1 \\
31: 3 \\
40: 8 \\
55: 0 \\
60.7 \\
74: 1 \\
87: 0 \\
92: 2 \\
104: 3 \\
111: 5 \\
116: 6 \\
123: 2 \\
126: 5 \\
127.4\end{array}$ \\
\hline
\end{tabular}




\section{TABLE F 91}

Calculated Capacity Contours for Section at $x_{3}=-1, V_{d} / N_{c}=0.574$ $C=300$ Contour

$C=200$ Contour

\begin{tabular}{|c|c|c|c|c|c|c|c|}
\hline$x_{1}$ & A & $x_{2}$ & $F$ & $x_{1}$ & $\mathbf{A}$ & $x_{2}$ & $F$ \\
\hline $\begin{array}{l}-0.638 \\
-0.929 \\
-0.978 \\
-1.009 \\
-1.038 \\
-1: 040 \\
-0.824 \\
-0.318 \\
-0.172 \\
+0.001 \\
+0.104 \\
+0.225 \\
+0.638 \\
+0.929 \\
+0.978 \\
+1.009 \\
+1.038 \\
+1.040 \\
+0.824 \\
+0.318 \\
+0.172 \\
-0.001 \\
-0.1044 \\
-0.225\end{array}$ & $\begin{array}{l}0.54 \\
0.46 \\
0.45 \\
0.44 \\
0.43 \\
0.43 \\
0.49 \\
0.65 \\
0.71 \\
0.78 \\
0.83 \\
0.89 \\
1.13 \\
1.34 \\
1.38 \\
1.39 \\
1.43 \\
1.43 \\
1.26 \\
0.94 \\
0.87 \\
0.78 \\
0.74 \\
0.69\end{array}$ & $\begin{array}{l}+1.992 \\
+1.697 \\
+1.571 \\
+1.452 \\
+1.226 \\
+1.012 \\
+0.023 \\
-0.054 \\
-1.012 \\
-1.160 \\
-1.227 \\
-1.287 \\
-1.310 \\
-1.015 \\
-0.889 \\
-0.770 \\
-0.544 \\
-0.330 \\
+0.659 \\
+1.536 \\
+1.694 \\
+1.842 \\
+1.909 \\
+1.969\end{array}$ & $\begin{array}{l}89: 9 \\
85: 5 \\
83: 6 \\
81: 8 \\
78.5 \\
76: 8 \\
60.3 \\
47: 2 \\
44: 8 \\
42.6 \\
41.5 \\
40.6 \\
40: 3 \\
44.7 \\
46.6 \\
48: 4 \\
51: 9 \\
55: 0 \\
69: 9 \\
83.1 \\
85: 4 \\
87: 6 \\
88: 7 \\
89.6\end{array}$ & $\begin{array}{l}-1.101 \\
-1.509 \\
-1.767 \\
-1.800 \\
-1.708 \\
-1.424 \\
-0.986 \\
-0.358 \\
-0.099 \\
+0.577 \\
+1.101 \\
+1.509 \\
+1.767 \\
+1.800 \\
+1.708 \\
+1.424 \\
+0.986 \\
+0.358 \\
+0.099 \\
-0.577\end{array}$ & $\begin{array}{l}0.42 \\
0.33 \\
0.29 \\
0.28 \\
0.29 \\
0.35 \\
0.44 \\
0.64 \\
0.74 \\
1.09 \\
1.48 \\
1.87 \\
2.17 \\
2.21 \\
2.10 \\
1.78 \\
1.38 \\
0.96 \\
0.83 \\
0.56\end{array}$ & $\begin{array}{l}+3.189 \\
+2.860 \\
+2.136 \\
+1.789 \\
+0.753 \\
-0.210 \\
-1.113 \\
-1.941 \\
-2.176 \\
-2.538 \\
-2.507 \\
-2.178 \\
-1.454 \\
-1.107 \\
-0.071 \\
+0.892 \\
+1.795 \\
+2.623 \\
+2.858 \\
+3.220\end{array}$ & $\begin{array}{r}107: 9 \\
102: 9 \\
92: 1 \\
86: 9 \\
71: 3 \\
56: 8 \\
43.0 \\
30: 9 \\
27: 3 \\
21: 9 \\
22: 3 \\
27: 3 \\
38.2 \\
43: 3 \\
58: 9 \\
73: 4 \\
87: 0 \\
99: 3 \\
102: 9 \\
108.3\end{array}$ \\
\hline
\end{tabular}


TABLE F 92 Calculated Capacity Contours for Section at $x_{3}=-1, V_{d} / V_{c}=0.574$ $C=100$ Contour

$C=0$ Contour

\begin{tabular}{|c|c|c|c|c|c|c|c|}
\hline$x_{1}$ & A & $x_{2}$ & $F$ & $x_{1}$ & $A$ & $x_{2}$ & $F$ \\
\hline $\begin{array}{l}-1.425 \\
-1.846 \\
-2: 117 \\
-2.280 \\
-2.308 \\
-2.140 \\
-1.838 \\
-1.418 \\
-0.866 \\
-0.116 \\
+0.407 \\
+0.914 \\
+1: 425 \\
+1: 846 \\
+2.1177 \\
+2.280 \\
+2.308 \\
+2.140 \\
+1: 838 \\
+1: 4118 \\
+0: 866 \\
+0: 116 \\
-0.407 \\
-0.914\end{array}$ & $\begin{array}{l}0.35 \\
0.27 \\
0.23 \\
0.21 \\
0.21 \\
0.23 \\
0.27 \\
0.35 \\
0.48 \\
0: 73 \\
0.99 \\
1.33 \\
1.78 \\
2: 27 \\
2: 65 \\
2.91 \\
2: 96 \\
2: 69 \\
2: 26 \\
1.77 \\
1: 29 \\
0: 84 \\
0: 62 \\
0.46\end{array}$ & $\begin{array}{l}+4.028 \\
+3.732 \\
+3.275 \\
+2.676 \\
+1.593 \\
+0.5 .6 \\
-0.570 \\
-1.90 \\
-2.137 \\
-2.920 \\
-3.255 \\
-3.470 \\
-3.347 \\
-3.053 \\
-2.593 \\
-1.994 \\
-0.911 \\
+0.096 \\
+1.052 \\
+1.962 \\
+2.89 .9 \\
+3.602 \\
+3.937 \\
+4.092\end{array}$ & $\begin{array}{r}120.5 \\
116.0 \\
109.2 \\
100.2 \\
83: 9 \\
68.9 \\
54: 4 \\
40.8 \\
27: 9 \\
16.2 \\
11.1 \\
8.9 \\
9.7 \\
14.3 \\
21.1 \\
30.1 \\
46: 3 \\
61.5 \\
75.8 \\
89.4 \\
102: 3 \\
114.0 \\
117: 1 \\
121.4\end{array}$ & $\begin{array}{l}-1.687 \\
-2.190 \\
-2.457 \\
-2.690 \\
-2.733 \\
-2.613 \\
-2.176 \\
-1.491 \\
-0.997 \\
-0.108 \\
+0.591 \\
+1.070 \\
+1.687 \\
+2.190 \\
+2.457 \\
+2.690 \\
+2.733 \\
+2.613 \\
+2.1 .76 \\
+1.491 \\
+0.997 \\
+0.108 \\
+0.591 \\
-1.070\end{array}$ & $\begin{array}{l}0.30 \\
0.22 \\
0.19 \\
0.16 \\
0.16 \\
0.17 \\
0.22 \\
0.33 \\
0.444 \\
0.74 \\
1.10 \\
1.45 \\
2.07 \\
2.77 \\
3.23 \\
3.69 \\
3.78 \\
3.53 \\
2.74 \\
1.85 \\
1.39 \\
0.83 \\
0.56 \\
0.42\end{array}$ & $\begin{array}{l}+4.704 \\
+4.341 \\
+3.922 \\
+3.141 \\
+1.865 \\
+0.998 \\
-0.500 \\
-1.902 \\
-2.625 \\
-3.547 \\
-3.962 \\
-4.091 \\
-1.022 \\
-3.659 \\
-. .240 \\
-.2 .450 \\
-1.183 \\
-0.316 \\
+1.182 \\
+2.584 \\
+3.307 \\
+4.223 \\
+4.644 \\
+4.773\end{array}$ & $\begin{array}{r}130.5 \\
125: 1 \\
118: 8 \\
107.1 \\
88: 1 \\
75.0 \\
52.5 \\
31.5 \\
20: 5 \\
6: 9 \\
0.6 \\
-1: 4 \\
-0.3 \\
5: 1 \\
11.4 \\
23: 1 \\
42: 3 \\
55.2 \\
77.7 \\
98: 7 \\
109: 7 \\
123: 3 \\
129: 6 \\
131.6\end{array}$ \\
\hline
\end{tabular}


TABLE G

Calculated Capacity Contours for Section at $x_{3}=-2, V_{d} / V_{c}=0.333$ $C=300$ Contour

$C=200$ Contour

\begin{tabular}{|c|c|c|c|c|c|c|c|}
\hline$x_{1}$ & A & $x_{2}$ & $F$ & $x_{1}$ & A & $x_{2}$ & $F$ \\
\hline $\begin{array}{l}-0: 606 \\
-0: 776 \\
-0: 906 \\
-0: 954 \\
-0: 986 \\
-0: 992 \\
-0: 942 \\
-0: 780 \\
-0: 536 \\
-0: 300 \\
-0: 120 \\
+0: 036 \\
+0: 174 \\
+0: 416 \\
+0: 620 \\
+0: 790 \\
+0: 920 \\
+0: 968 \\
+1: 000 \\
+1: 006 \\
+0: 956 \\
+0: 798 \\
+0: 550 \\
+0: 314 \\
+0: 134 \\
-0: 022 \\
-0: 160 \\
-0.402\end{array}$ & $\begin{array}{l}0: 55 \\
0: 50 \\
0: 47 \\
0: 45 \\
0: 44 \\
0: 44 \\
0.46 \\
0.50 \\
0: 58 \\
0: 66 \\
0: 73 \\
0: 80 \\
0.87 \\
1: 00 \\
1: 12 \\
1: 24 \\
1: 33 \\
1: 37 \\
1: 39 \\
1: 40 \\
1: 36 \\
1: 24 \\
1: 08 \\
0: 94 \\
0: 85 \\
0: 77 \\
0: 71 \\
0.62\end{array}$ & $\begin{array}{l}+2.157 \\
+2.040 \\
+1.824 \\
+1.671 \\
+1.475 \\
+1.113 \\
+0.808 \\
+0.214 \\
-0.244 \\
-0.577 \\
-0.767 \\
-0.871 \\
-0.972 \\
-1: 244 \\
-1.317 \\
-0.900 \\
-0.684 \\
-0.531 \\
-0.335 \\
-0.073 \\
+0.322 \\
+0: 675 \\
+1.3814 \\
+1.717 \\
+1.907 \\
+2.031 \\
+2.112 \\
+2.184\end{array}$ & $\begin{array}{l}92: 3 \\
90: 6 \\
87: 4 \\
85: 1 \\
82: 1 \\
76: 7 \\
72: 1 \\
64: 0 \\
56: 3 \\
51: 3 \\
49: 5 \\
46: 6 \\
45: 4 \\
44: 3 \\
44: 7 \\
46.5 \\
49: 7 \\
52: 0 \\
55: 0 \\
53: 9 \\
65: 0 \\
75: 1 \\
80: 8 \\
85: 8 \\
88.6 \\
90: 5 \\
91: 7 \\
92.8\end{array}$ & $\begin{array}{l}-1: 083 \\
-1: 341 \\
-1.553 \\
-1: 707 \\
-1: 756 \\
-1.758 \\
-1: 704 \\
-1: 643 \\
-1: 400 \\
-1: 047 \\
-0: 894 \\
-0.654 \\
-0: 282 \\
+0.043 \\
+0.4447 \\
+0.795 \\
+1: 097 \\
+1: 355 \\
+1: 567 \\
+1: 721 \\
+1: 770 \\
+1: 772 \\
+1: 718 \\
+1: 657 \\
+1: 414 \\
+1: 061 \\
+0: 908 \\
+0: 668 \\
+0: 296 \\
-0: 029 \\
-0: 433 \\
-0.781\end{array}$ & $\begin{array}{l}0.42 \\
0.36 \\
0.32 \\
0.29 \\
0.28 \\
0.28 \\
0.29 \\
0.30 \\
0.35 \\
0.43 \\
0.47 \\
0.54 \\
0.67 \\
0.80 \\
1.01 \\
1.24 \\
1.47 \\
1.71 \\
1.93 \\
2.11 \\
2.17 \\
2.18 \\
2.11 \\
2.03 \\
1.77 \\
1.44 \\
1.32 \\
1.15 \\
0.93 \\
0.80 \\
0.61 \\
0.50\end{array}$ & $\begin{array}{l}+3.391 \\
+3.226 \\
+2.941 \\
+2.509 \\
+2.080 \\
+1.529 \\
+1.112 \\
+0.819 \\
+0.026 \\
-0.725 \\
-0.982 \\
-.1327 \\
-1.734 \\
-2.017 \\
-2: 243 \\
-2: 302 \\
-2.251 \\
-2.086 \\
-1: 801 \\
-1: 369 \\
-0.940 \\
-0.389 \\
+0: 028 \\
+0.321 \\
+1: 114 \\
+1.865 \\
+2.122 \\
+2.467 \\
+2.874 \\
+3: 157 \\
+3.373 \\
+3.442\end{array}$ & $\begin{array}{r}110: 9 \\
108: 4 \\
104: 1 \\
97: 6 \\
91: 2 \\
89: 9 \\
75: 7 \\
72: 3 \\
60: 4 \\
49: 1 \\
45: 3 \\
40: 1 \\
34: 0 \\
29: 7 \\
26: 4 \\
25: 5 \\
26: 2 \\
28: 7 \\
33: 0 \\
39: 5 \\
45: 9 \\
54: 2 \\
60: 4 \\
64: 8 \\
76: 7 \\
88: 0 \\
91: 8 \\
97: 0 \\
103: 1 \\
107: 4 \\
110: 6 \\
111.6\end{array}$ \\
\hline
\end{tabular}


TABLE G

Calculated Capacity Contours $\underset{\text { (Cont) }}{\text { for Section }}$ at $x_{3}=-2, V_{d} / V_{c}=0.333$ C - 100 Contour $C=0$ Contour

\begin{tabular}{|c|c|c|c|c|c|c|c|}
\hline$x_{1}$ & A & $x_{2}$ & $F$ & $x_{1}$ & A & $x_{2}$ & $F$ \\
\hline $\begin{array}{l}-1.407 \\
-1.750 \\
-2: 030 \\
-2.188 \\
-2.287 \\
-2: 299 \\
-2.279 \\
-2.226 \\
-2.098 \\
-1.817 \\
-1.432 \\
-1.118 \\
-0.879 \\
-0.671 \\
-0.311 \\
+0.150 \\
+0.552 \\
+1.018 \\
+1.421 \\
+1.764 \\
+2.044 \\
+2.202 \\
+2.301 \\
+2.313 \\
+2.293 \\
+2.240 \\
+2.112 \\
+1.831 \\
+1.446 \\
+1.142 \\
+0.893 \\
+0: 695 \\
+0.325 \\
-0.136 \\
-0.538 \\
-1.004\end{array}$ & $\begin{array}{l}0.35 \\
0.29 \\
0: 24 \\
0: 22 \\
0: 21 \\
0.21 \\
0: 21 \\
0.22 \\
0.23 \\
0: 28 \\
0: 34 \\
0: 41 \\
0: 47 \\
0: 53 \\
0: 66 \\
0: 86 \\
1: 08 \\
1: 41 \\
1.78 \\
2: 16 \\
2: 54 \\
2: 79 \\
2: 95 \\
2.97 \\
2: 94 \\
2: 85 \\
2: 65 \\
2: 25 \\
1: 80 \\
1: 51 \\
1: 31 \\
1: 17 \\
0: 94 \\
0: 73 \\
0: 58 \\
0.44\end{array}$ & $\begin{array}{l}+4.229 \\
+4.008 \\
+3.621 \\
+3.199 \\
+2.621 \\
+2.098 \\
+1.767 \\
+1.354 \\
+0.746 \\
-0.135 \\
-0.976 \\
-1.512 \\
-1.853 \\
-2.112 \\
-2.491 \\
-2.853 \\
-3.057 \\
-3.156 \\
-3.089 \\
-2.868 \\
-2.481 \\
-2.059 \\
-1.4411 \\
-0.9148 \\
-0.627 \\
-0.2114 \\
+0.394 \\
+1.275 \\
+2.116 \\
+2.652 \\
+2.993 \\
+3.252 \\
+3.631 \\
+3.993 \\
+4.197 \\
+4.296\end{array}$ & $\begin{array}{l}123: 4 \\
120: 1 \\
114.3 \\
108: 0 \\
99: 3 \\
91: 5 \\
86.5 \\
80: 3 \\
71.2 \\
58.0 \\
45.4 \\
37.3 \\
32: 2 \\
28.3 \\
22.6 \\
17.2 \\
14.1 \\
12.7 \\
13.7 \\
17.0 \\
22.8 \\
29.1 \\
37.8 \\
45.8 \\
50.5 \\
56.8 \\
65.9 \\
79: 1 \\
91.7 \\
99.8 \\
104.9 \\
108: 8 \\
114: 5 \\
119: 9 \\
123.0 \\
124.4\end{array}$ & $\begin{array}{l}-1.670 \\
-2: 173 \\
-2: 547 \\
-2: 686 \\
-2: 727 \\
-2.664 \\
-2: 577 \\
-2.356 \\
-2.157 \\
-1: 920 \\
-1.513 \\
-1: 240 \\
-0.803 \\
-0.284 \\
+0.323 \\
+1.067 \\
+1.684 \\
+2.187 \\
+2.561 \\
+2.700 \\
+2.747 \\
+2.678 \\
+2.591 \\
+2.6370 \\
+2.171 \\
+1.934 \\
+1.527 \\
+1.254 \\
+0.817 \\
+0.298 \\
-0.309 \\
-1.053\end{array}$ & $\begin{array}{l}0.30 \\
0.22 \\
0.18 \\
0.17 \\
0.16 \\
0.17 \\
0.17 \\
0.20 \\
0.23 \\
0.26 \\
0.33 \\
0.38 \\
0.49 \\
0.67 \\
0.94 \\
1.45 \\
2.07 \\
2.76 \\
3.43 \\
3.71 \\
3.80 \\
3.66 \\
3.48 \\
3.07 \\
2.74 \\
2.39 \\
1.89 \\
1.61 \\
1.25 \\
0.93 \\
0.66 \\
0.43\end{array}$ & $\begin{array}{l}+4.909 \\
+4.546 \\
+3.850 \\
+3.099 \\
+2.374 \\
+1.656 \\
+1.153 \\
+0.304 \\
-0.266 \\
-0.822 \\
-1.599 \\
-2.030 \\
-2.604 \\
+3.113 \\
-3.576 \\
-3.838 \\
-3.769 \\
-3.406 \\
-2.710 \\
-1.958 \\
-1.234 \\
-0.516 \\
-0.013 \\
+0.836 \\
+1.406 \\
+1.962 \\
+2.739 \\
+3.170 \\
+3.744 \\
+4.253 \\
+4.716 \\
+4.978\end{array}$ & $\begin{array}{r}133.6 \\
128: 2 \\
117.8 \\
106: 5 \\
95: 6 \\
84: 8 \\
77: 3 \\
64: 6 \\
56: 0 \\
47: 7 \\
36: 0 \\
29: 5 \\
20: 1 \\
13: 3 \\
6: 4 \\
2: 4 \\
3.5 \\
8: 9 \\
19: 3 \\
30.6 \\
41: 5 \\
52.3 \\
59: 8 \\
72.5 \\
81.1 \\
89.4 \\
101: 1 \\
107: 6 \\
116: 2 \\
123: 8 \\
130: 7 \\
134.7\end{array}$ \\
\hline
\end{tabular}

